\title{
Fundamental processes in thin film growth The origin of compressive stress and the dynamics of the early growth stages
}

Daniel Magnfält

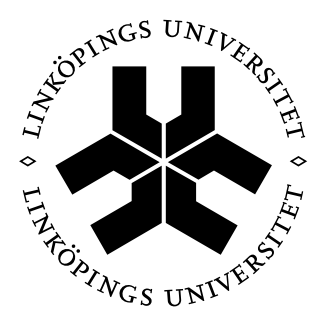

\section{Linköping University} INSTITUTE OF TECHNOLOGY

\author{
Plasma \& Coatings Physics Division \\ Department of Physics, Chemistry and Biology \\ Linköping University, Sweden
}

Linköping 2014 


\section{Cover image}

The cover image is a cross sectional TEM image looking down a grain boundary in a Mo film. The image is approximately $37 \mathrm{~nm}$ across and $20 \mathrm{~nm}$ high. Courtesy of Robert Boyd.

(C) Daniel Magnfält, 2014

ISBN: 978-91-7519-352-6

ISSN: 0345-7524

Printed by LiU-tryck, Linköping 2014 
Sometimes, the best answer is a more interesting question. -Terry Pratchett, The Science of Discworld 



\section{Abstract}

The fundamental mechanisms behind the generation of compressive stresses in polycrystalline thin films, the effects of pulsed deposition fluxes on the dynamics of the early growth stages as well as the generation of energetic $\mathrm{Ar}^{+}$ions in high power impulse magnetron sputtering (HiPIMS) discharges has been studied in this thesis.

It was found that compressive film stresses in Mo films deposited using energetic vapor fluxes are correlated with high film densities while only a slight lattice expansion compared to relaxed Mo was found. This implies that the stress is caused by grain boundary densification and not defect creation in the grain bulk. The compressive stress magnitude should scale with the grain boundary length per unit area, or the inverse grain size, if the stress originates in the grain boundaries. This was found to be the case for dense Mo films confirming that the observed compressive stresses originate in the grain boundaries. Similarly to what has been suggested for conditions where adatoms are highly mobile we suggest that atom insertion into grain boundaries is the cause of the compressive stresses observed in the Mo films.

Island nucleation, growth and coalescence are the dynamic processes that decide the initial microstructure of thin films growing in a three dimensional fashion. Using $\mathrm{Ag}$ on $\mathrm{SiO}_{2}$ as a model system and estimations of adatom life times and coalescence time it was shown that the time scales of island nucleation and coalescence are in the same range as the time scale of the vapor flux modulation in HiPIMS and other pulsed deposition methods. In situ real time measurements were used to demonstrate that it is possible to decrease the thickness at which a continuous film is formed from 21 to $15 \mathrm{~nm}$ by increasing the flux modulation frequency. A more in depth study where in situ real time monitoring was coupled with ex situ imaging and kinetic Monte Carlo simulations showed that this behavior is due to the interplay of the pulsed deposition flux 
and island coalescence where island coalescence is hindered at high pulsing frequencies.

The generation of energetic $\mathrm{Ar}^{+}$ions was investigated by ion mass spectrometry and Monte Carlo simulations of gas transport. It was shown that the energetic $\mathrm{Ar}^{+}$ions originate from $\mathrm{Ar}$ atoms backscattered from the target that are ionized in the plasma by correlating the length of the high energy tail in the ion energy distribution functions with the atomic mass of the $\mathrm{Cr}$, Mo and $\mathrm{W}$ sputtering targets. 


\section{Populärvetenskaplig sammanfattning}

\section{Fundamentala processer under tunnfilmstillväxt:}

Tryckspänningars ursprung och dynamiska processer i de tidiga tillväxtstegen

Tunnfilmer, med tjocklekar från något atomlager (någon tiomiljarddels meter) till några mikrometer (miljondels meter), kan hittas nästan överallt idag. De används i allt från fönsterglas, solceller, mikroprocessorer till hårda skyddande beläggningar på borrar och andra skärande komponenter. Vilket material filmerna tillverkas av avgörs av vilka egenskaper man vill att filmen ska ha. Det är dock inte det enda som avgör filmernas egenskaper. I de flesta fall är tunnfilmer polykristallina, det vill säga de är uppbyggda av ett otal små kristalliter, eller korn. Kornstorleken och korngränsernas täthet och struktur har också ett stort inflytande på filmegenskaperna. Dessa och andra strukturer samlas i begreppen mikro- och nanostruktur, alltså filmens struktur på mikro- och nanometernivå som till stor del bestäms av förhållandena som råder under beläggningen.

Det finns ett stort antal olika sätt att tillverka tunnfilmer. Beläggningsprocessen jag använt till mina filmer kallas högeffektspulsad sputtring (en. high power impulse magnetron sputtering eller kort och gott HiPIMS) och är en variant av den mycket vanliga beläggningsprocessen sputtring. Här accelereras ädelgasjoner från ett plasma in mot en materialkälla, kallad target, med hjälp av högspänning. När en jon träffar target händer vad som enklast kan beskrivas som biljard med atomer och någon atom i target slås då ut, sputtras, och far iväg. Eftersom beläggningen sker i ett vakuum krockar de sputtrade atomerna några enstaka gånger med gasatomer och förlorar därmed inte mycket av den energi de får när de sputtras. När atomerna landar på substratet leder deras energi ofta till att bil- 
jardeffekter uppkommer även i den växande filmen, men inte lika våldsamma som de i target, och tätare filmer. I HiPIMS läggs spänningen på materialkällan i mycket korta pulser $(\approx 100 \mu \mathrm{s})$. Det gör att det går att ha en väldigt hög effekt i pulserna vilket leder till att mycket av materialet som sputtras joniseras och ett pulsat beläggningsflöde. Jonerna har generellt sett också mer energi än atomerna i vanlig sputtring vilket bland annat leder till än tätare filmer.

När polykristallina filmer beläggs på ett substrat går de igenom ett antal tillväxtsteg med olika karaktäristiska strukturer. Materialet beläggs atom för atom på substratet där de diffunderar, hoppar omkring, slumpmässigt på ytan tills de träffar på en annan atom och bildar en kärna. Kärnbildningen (en. nucleation) fortgår till dess att det är större sannolikhet att en diffunderande atom träffar på en kärna än en annan diffunderande atom. Efter det går i stort sett alla atomer som beläggs till att växa kärnorna, som vi det här laget är så stora (med andra ord några nanometer) att de istället kallas öar. Ö-tillväxten (en. island growth) fortsätter till öarna kommer i kontakt med varandra då mycket starka drivkrafter för öarna att växa samman (en. coalesce) till en större ö uppstår. Tiden det tar för två öar att växa samman ökar mycket snabbt med öradien. Tillförs material tillräckligt snabbt stoppas därför sammanväxningen vilket leder till att avlånga grupper av öar bildas. Dessa kommer sedan växa och komma i kontakt med andra avlånga grupper vilket till slut leder till att filmen blir elektriskt ledande trots att den inte täcker hela substratet. Ytterligare beläggning fyller ut de tomma ytorna mellan kedjorna bildar en heltäckande film.

Vi har undersökt hur kärnbildning, ö-tillväxt och ö-sammanväxning påverkas när ett beläggningsprocessen har ett pulsat beläggningsflöde istället för ett kontinuerligt. Genom kontinuerliga optiska mätningar under beläggningens gång har vi följt hur mycket av substratet som täcks av film och när filmen blir ledande respektive täcker substratet helt för olika pulsfrekvenser. Filmtjockleken där filmerna blir ledande och helt täcker substratet minskar med ökande pulsfrekvens vilket är helt i linje med vad som händer när beläggningshastigheten ökas för kontinuerliga beläggningsflöden. Vid höga frekvenser är dock filmtjockleken där filmerna blir ledande och heltäckande konstant. Vi fann också att en större del av substratet är täckt av öar vid höga pulsfrekvenser än vid låga pulsfrekvenser. Eftersom vi inte kan följa beläggningen från början experimentellt användes datorsimuleringar för att undersöka de allra tidigaste tillväxtstegen. 
Därifrån ser vi att kärnbildningen inte påverkas av när pulsfrekvensen ändras vilket betyder att den högre ö-densiteten vid höga frekvenser måste uppstå på grund av att sammanväxningen av öar stoppas vid höga pulsfrekvenser.

Under tillväxten uppstår spänningar i filmen. Under de första tillväxtstegen går de från tryckspänning (en. compressive stress), alltså att filmen vill expandera men hålls på plats av substratet, under ö-tillväxten till dragspänning (en. tensile stress), där filmen istället vill dra ihop sig, när öarna växer samman. När filmen är kontinuerlig utvecklas spänningarna olika beroende på mikrostrukturen och hur mobila atomerna i filmen är. Är filmen tät och atommobiliteten hög, när atomerna kan diffundera snabbt, uppstår tryckspänning igen. Har filmen inte helt täta korngränser, vilket är fallet vid låg atommobilititet, uppstår istället dragspänningar. Situationen kompliceras ytterligare när partiklar med hög energi används för att påverka filmtillväxten. De kan ge upphov till tryckspänningar genom att skapa defekter (skador på atomnivå) som leder till expansion av kornen.

Vi har funnit att tryckspänningar även uppstår i täta tunnfilmer belagda vid låga temperaturer utan att vi har någon expansion av kornen. Istället visade det sig att storleken på tryckspänningarna beror på filmdensiteten, ju högre filmdensitet desto högre spänningar. Tryckspänningarna i täta filmer visade sig också vara beroende på kornstorleken för annars identiska beläggningsförhållanden. Eftersom korngränslängden är direkt beroende på kornstorleken pekar det på att tryckspänningarna som observerats har sitt ursprung filmens korngränser. Även om detta inte tidigare setts i filmer med låg atommobilitet är det i linje med en föreslagen förklaring till att tryckspänningar uppstår i filmer med hög atommobilitet. Den säger att atomer från ytan diffunderar in i korngränserna och ger upphov till tryckspänningar. Vi föreslår att de beläggningsförhållanden som använts leder till diffusion av atomer in i toppen av korngränserna, förtätning av korngränserna och tryckspänningar.

Vi passade också på att mäta hur mycket energi olika joner i vårt plasma har eftersom det påverkar hur filmens mikrostruktur utvecklas. Vi fann att gasjoner på väg bort från target har olika mycket energy beroende på vilken metall som sputtras. Det är välkänt att gasatomer med hög energi kan studsa tillbaka från materialkällan om det är en stor skillnad i massa mellan materialet och gasen. En del av dessa atomer joniseras sedan i plasmat. Energin på de här jonerna är så höga att de kan orsaka defekter i den växande filmen. 


\section{Preface}

This thesis comprises research that I carried out during my doctoral studies in the Plasma and Coatings Physics Division of the Department of Physics Chemistry and Biology (IFM) at Linköping University from June 2009 to May 2014. The research was supported by the Swedish Research Council (VR) through grant no. 621-2011-4280. Part of the was performed during a visit to Insitut Pprime at Université de Poitiers financed by COST Action MP0804 "Highly Ionized Pulsed Plasmas".

The results of the work is presented in the appended papers. A background to the work and introduction to the field is given in introductory part of the thesis. The introductory part of the thesis is largely based on my licentiate thesis titled "Nucleation and stress generation in thin films deposited with a pulsed energetic deposition flux" Linköping studies in Science and Technology Licentiate Thesis No. 1570, 2013.

April 2013

Daniel Magnfält 


\section{Included papers}

PAPER 1

Atom insertion into grain boundaries and stress generation in physically vapor deposited films

D. Magnfält, G. Abadias and K. Sarakinos

Applied Physics Letters, 103, 051910 (2013)

\section{PAPER 2}

Atom insertion into grain boundaries generates compressive intrinsic stresses in polycrystalline thin films

D. Magnfält, A. Fillon, R. D. Boyd, U. Helmersson, K. Sarakinos and G. Abadias

submitted

\section{PAPER 3}

Time-domain and energetic bombardment effects in the nucleation and coalescence of thin metal films on amorphous substrates

D. Magnfält, V. Elofsson, G. Abadias, U. Helmersson and K. Sarakinos Journal of Physics D: Applied Physics 46, 215303 (2013)

\section{PAPER 4}

Unravelling the physical mechanisms that determine microstructural evolution in ultra thin Volmer-Weber films

V. Elofsson, B. Lü, D. Magnfält, E. P. Münger and K. Sarakinos submitted

\section{PAPER 5}

The origin of energetic $\mathrm{Ar}^{+}$ions in high power impulse magnetron sputtering discharges

D. Magnfält, D. Lundin, U. Helmersson, T. Minea and K. Sarakinos in manuscript 


\section{Authors contributions}

Paper 1: I planned the study, performed all deposition and took part in the characterization and in writing the paper.

Paper 2: I planned the study, performed all depositions, took part in the characterization and wrote the paper.

Paper 3: I took part in planning the study, performed all experiments except for the ellipsometry and took part in writing the paper.

Paper 4: I took part in planning the study, performed the imaging and took part in writing the paper.

Paper 5: I planned the study, performed the experiments and wrote the paper. 


\title{
Related papers
}

\author{
PAPER 6 \\ Tilt of the columnar microstructure in off-normally deposited thin films using highly \\ ionized vapor fluxes \\ V. Elofsson, D. Magnfält, M. Samuelsson and K. Sarakinos \\ Journal of Applied Physics 113, 17906 (2013) \\ PAPER 7
}

Epitaxial growth of $\gamma-\mathrm{Al}_{2} \mathrm{O}_{3}$ on $\mathrm{Ti}_{2} \mathrm{AlC}(0001)$ by reactive high-power impulse magnetron sputtering

P. Eklund, J. Frodelius, L. Hultman, J. Lu and D. Magnfält

AIP Advances 4, 017138 (2014)

\section{PAPER 8}

Atomistic view on thin film nucleation and growth by using highly ionized and pulsed vapour fluxes

K. Sarakinos, D. Magnfält, V. Elofsson and B. Lü

Surface and Coatings Technology, accepted for publication 


\section{Acknowledgements}

Working on a thesis is not a lonely task and I have gotten a lot of inspiration from people around me. I would like to thank everyone (listed or not) who have contributed with seeds of ideas and knowledge. I could not have done this without you.

- Ulf Helmersson for taking me on as a student and giving me freedom to define my own work.

- Kostas Sarakinos for all long discussions about experiments, confusing results and non-work related science.

- Gregory Abadias for a good cooperation and a nice and productive albeit rainy visit in Poitiers.

- Viktor Elofsson and Bo Lü for all diffusion and coalescence discussions it all seems a lot more clear now.

- Former and present members of the Plasma and Coatings Physics group for all lunches, coffee breaks and trips. Life is more fun when it is slightly absurd...

- Colleagues and friends in the Thin Film Physics and Nanostructured Materials groups for Friday cake discussions about work and everything else and for creating a great working environment.

- Min familj och vänner för allt stöd och uppmuntran.

- $\mathrm{Z}$ for everything. 


\section{Contents}

1 Introduction 1

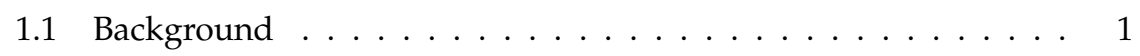

1.2 Aim of the thesis $\ldots \ldots \ldots \ldots \ldots \ldots$

1.3 Outline ................... 3

2 Thin film growth 5

2.1 Adatoms and surface diffusion $\ldots \ldots \ldots \ldots \ldots$

2.2 The initial stages of film growth $\ldots \ldots \ldots \ldots \ldots$

2.2 .1 Nucleation . . . . . . . . . . . . . . . . . 8

2.2.2 Island growth and coarsening . . . . . . . . . . 11

2.2.3 Coalescence and percolation $\ldots \ldots \ldots$. . . . . 13

2.3 Microstructure evolution during film growth . . . . . . . . 14

2.3.1 Kinetically limited epitaxial growth $\ldots \ldots \ldots \ldots$

2.3.2 Growth modes from a thermodynamic perspective . . . 18

2.3.3 Polycrystalline thin films . . . . . . . . . . . . . 19

3 Stresses in thin films 23

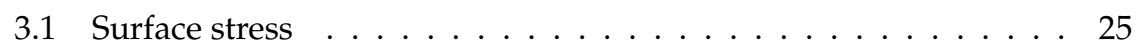

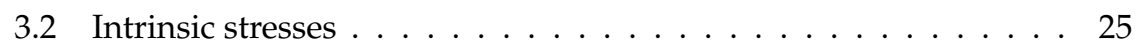

3.2.1 Pre-coalescence stress . . . . . . . . . . . . . . 27

3.2.2 Stress generation during island coalescence . . . . . . . . 29

3.2.3 Stresses in continuous films . . . . . . . . . . . . . 32 
4 Deposition processes $\quad 43$

4.1 Basic plasma physics ... . . . . . . . . . . . . 44

4.2 Magnetron sputtering . . . . . . . . . . . . 47

4.3 High Power Impulse Magnetron Sputtering . . . . . . . . . . . . . 50

5 Thin film characterization $\quad 53$

5.1 X-ray diffractometry . . . . . . . . . . . . 53

$5.1 .1 \quad$ X-ray reflectometry . . . . . . . . . . 55

5.1 .2 The $\sin ^{2} \psi$-method . . . . . . . . . . . 57

5.2 Stress measurements by substrate curvature . . . . . . . . . . . . 59

5.3 Transmission electron microscopy . . . . . . . . . . . . 62

5.3.1 Scanning transmission electron microscopy . . . . . . . . 63

5.4 Atomic force microscopy . . . . . . . . . . . . . . . . 63

5.5 Spectroscopic ellipsometry . . . . . . . . . . . . . 65

6 Plasma characterization $\quad 67$

6.1 Ion mass spectrometry . . . . . . . . . . . . . 67

7 Computational methods $\quad 69$

7.1 Gas transport simulations ................... 69

7.2 Film growth simulations . . . . . . . . . . . . . . 70

8 Summary of results $\quad 73$

8.1 Intrinsic stresses in polycrystalline thin films . . . . . . . . . 73

8.2 Nucleation and growth of polycrystalline thin films . . . . . . . 75

8.3 Energetic bombarding species in HiPIMS discharges . . . . . . . 76

9 Contributions to the field $\quad 79$

$\begin{array}{ll}10 \text { Future outlook } & 81\end{array}$

$\begin{array}{lr}\text { Paper 1 } & 95\end{array}$ 
CONTENTS

$\begin{array}{ll}\text { Paper } 2 & 107\end{array}$

Paper 3

135

Paper 4

Paper 5 


\section{CONTENTS}




\section{Introduction}

\subsection{Background}

Thin films, material layers with thicknesses between fractions of a monolayer and several micrometers, are ubiquitous today and can be found more or less everywhere. Thin films are applied to modify or enhance the surface of a material or to build functional devices such as light emitting diodes. A small selection of applications where thin films are used are; eyeglasses, microelectronics, drill bits and cutting tools, solar cells, mirrors, flat screens and windows. The properties of a film and thereby its area of application is, of course, mainly determined by the choice of material. But the structure of the film on a nanometer scale or micrometer scale, known as the microstructure, can also affect the film properties substantially [1]. With most thin film systems being polycrystalline ${ }^{1}$, that is that the film made up by a large number of small crystallites, the microstructure is to a large extent determined by the grain size and morphology and the grain boundary morphology. The microstructure of the film has a large influence on a number of functional properties of thin films such as mechanical properties [2-6], optical properties [7-9], electrical properties [10,11] as well as heat transport in films [12]. Understanding the processes behind the film microstructure evolution is therefore imperative for synthesis of functional thin films.

The evolution of the microstructure of the film is highly dependent on the conditions under which film deposition takes place. Even though films can be deposited by a large number of deposition techniques that seem, and in many

\footnotetext{
${ }^{1}$ With notable exceptions like semiconductor devices such as microprocessors and light emitting diodes.
} 
ways are, vastly different the mechanisms behind morphological evolution of the growing films are similar. Atoms that deposited on the substrate diffuse around until they meet other atoms, nucleate and form islands. The islands grow with further deposition and will eventually grow to come in contact with other islands. When islands touch they will begin coalescing to minimize their surface area. Island coalescence will drastically slow down or stop when a continuous films has formed. The film structure will continue to evolve as the film thickness increases but the length scales setting the initial conditions for the microstructural evolution of film growth are to a large extent set by the island nucleation, growth and coalescence processes. Although these processes have been the subjects extensive studies separately their individual and combined effects on the microstructural evolution during growth is not well understood. Thin films are often in a stressed state during and after deposition. Film stress can lead to failure of the films through cracking or decohesion [13-18] and can also affect the magnetic [19-21] and electrical properties [22] as well as mechanical properties [13]. The generation of film stresses have been observed to be connected to the microstructural evolution during film growth as well as bombardment by energetic species during deposition [13-18]. Even though a number of stress sources are known there is still some debate concerning the origin of some compressive stresses [23-26].

Films can be deposited by as different methods as (electro-)chemical reaction between precursor liquids on immersed substrates, condensation of atomic vapor or decomposition of precursor molecules in the vapor phase. The latter techniques are known as physical vapor deposition (PVD) or chemical vapor deposition (CVD). The deposition method used in this thesis is a variation of the PVD method sputter deposition known as high power impulse magnetron sputtering (or HiPIMS). In sputter deposition energetic ions from a plasma are bombarding a material source that ejects atoms due to collision processes between the incoming ions and atoms in the material source. The ejected atoms travel through the vacuum of the deposition chamber before they condense on the substrate [1]. In HiPIMS the power is applied in very short high power pulses repeated at a low frequency leading to ionization of the sputtered material and a more energetic deposition flux than in conventional sputter deposition. 


\subsection{Aim of the thesis}

The aim of the thesis is to contribute to the understanding of:

- How the island nucleation, growth and coalescence processes during the initial stages of film growth are affected by/can be controlled using a pulsed deposition flux.

- How compressive stresses are generated in thin films.

In order to simplify the experiments we have chosen to use metallic films as model systems. Ag has been used when island nucleation, growth and coalescence processes have been investigated as it has a high mobility at room temperatures resulting in very pronounced differences between the various formation stages. Mo has a low mobility resulting in the film structure begin frozen in making it possible to connect post deposition characterization of the film microstructure to the processes leading to stress generation during film deposition. Mo also have the additional advantage of having a thermal expansion coefficient $\left(\alpha_{M o}=4.8 \times 10^{-6} \mathrm{~K}^{-1}\right.$ [27]) that is fairly close to that of $\mathrm{Si}$, $\alpha_{S i}=2.6 \times 10^{-6} \mathrm{~K}^{-1}$ [28]. The pulsed deposition flux and energetic ionized depositing species from the HiPIMS discharge were used to drive surface diffusion under conditions that otherwise would resulted in a very limited atomic mobility as well as to control the time between flux pulses to affect the nucleation and coalescence processes in a controlled manner. For all investigations in situ real time characterization have been combined with ex situ post deposition characterization of the films as well as investigations of the time domain and energetics of the deposition flux to provide an as complete understanding as possible of the growth processes.

\subsection{Outline}

The goal of the introductory part of the thesis is to provide a background putting the appended papers into a wider context. Chapter 2 give an introduction to film nucleation and growth and how they are affected by process conditions while chapter 3 is treats stresses in thin films and how the development of stresses in thin films is connected to the microstructural evolution and surface processes during growth. The following chapters (4 to 6) provide a background 
on the deposition, film and plasma characterization techniques used in the papers. Chapter 7 is a very brief description of the simulation methods used in the papers. The last chapters ( 8 and 9 ) summarizes the papers and details how the papers have contributed to advance the research field. 


\section{Thin film growth}

Thin films go through several distinct stages during growth, each affecting the resulting film microstructure and hence it's physical properties in some, sometimes not reversible, ways. This chapter deals with the different growth stages and the process of surface diffusion in chronological order from the perspective of a growing film.

\subsection{Adatoms and surface diffusion}

When an atom or ion impinges on a surface it starts interacting with the surface at a distance of several $\AA^{1}$. It collides with the surface and looses most of its momentum and kinetic energy and lowers it's potential energy by adsorbing on the surface. Adsorbed atoms, referred to as adatoms, see a potential energy landscape defined by the atomic structure and chemistry of the surface where adsorption sites of different depth, or stability, are present. The adatoms diffuse between these adsorption sites in a random walk process with the jump rate, $\Gamma$ (2.1.1), determined by the thermal jitters of the adatoms called the attempt frequency, $v$, the diffusion barrier, $E_{d}$, and the substrate temperature, $T$, while $k_{B}$ denotes Boltzmann's constant.

$$
\Gamma=v e^{-\frac{E_{d}}{k_{B} T}}
$$

Assuming that the diffusion barrier is the same in all directions and that the adsorption sites are separated by a distance, $a$, one can calculate the surface

\footnotetext{
${ }^{1}$ The Ångström $(\AA)$ is a practical unit of length when dealing with atoms and is $10^{-10} \mathrm{~m}$ or $0.1 \mathrm{~nm}$
} 
diffusion coefficient or diffusivity to

$$
D=\frac{1}{4} a^{2} \Gamma=\frac{1}{4} a^{2} v e^{-\frac{E_{d}}{k_{B} T}}=D_{0} e^{-\frac{E_{d}}{k_{B} T}}
$$

where the factor $1 / 4$ in the expression is due to the two-dimensional nature of surface diffusion [29]. $D_{0}$ and $E_{d}$ are parameters usually found by experimental investigations of surface diffusion. Since $D$ has the unit $\mathrm{m}^{2} / \mathrm{s}$ it is evident that the lifetime of an adatom, $\tau_{D}$, can be calculated (2.1.3) by taking the average distance between sites with high binding energies, e.g. step edges and islands $\left(L_{0}\right)$, into account while assuming that adatoms do not desorb from the substrate ${ }^{2}$.

$$
\tau_{D}=\frac{L_{0}^{2}}{D}
$$

The diffusion barrier is a result of the atomic structure of the surface and varies between different materials and between different surface orientations in the same material. Depending on the surface structure there might also be different diffusion barriers in different directions on the surface resulting in preferred diffusion directions [30]. The diffusion barrier is also affected by the presence of other adatoms, nuclei, impurities and steps on the surface. The barrier most important to the morphology of growing films is the, at first sight counterintuitive, step edge or Erlich-Schwoebel barrier $\left(E_{E S}\right)[31,32]$, which is an additional diffusion barrier for diffusion down surface steps. The cause of the step edge barrier can be viewed, in a much simplified way, in the light of bond coordination. Figure 2.1 shows a side-view of adatoms on a surface with a step. Moving from one adsorption site to another requires stretching and rotating bonds, both actions requiring energy (the diffusion barrier $E_{d}$ ). Moving down the step edge requires stretching and breaking the bonds on the top surface and reforming them at the lower surface. This results in a large barrier for diffusion $\left(E_{E S}\right)$ over the step edge as breaking bonds is energetically expensive action. From this reasoning it is also evident that atoms at the bottom of the step edge are strongly bound to the step making it a preferred adsorption site. It should be noted that small changes in the diffusion barriers result in large changes in the diffusion rates as it is situated in the exponential term of Eq. (2.1.2). Step edge barriers exists for many surfaces resulting in lower rates of interlayer diffusion when the temperature is low and trapping of adatoms on the top of islands. The trap-

\footnotetext{
${ }^{2}$ This assumption is valid if the surface binding energy of an adatom is much larger than that of the diffusion barrier
} 


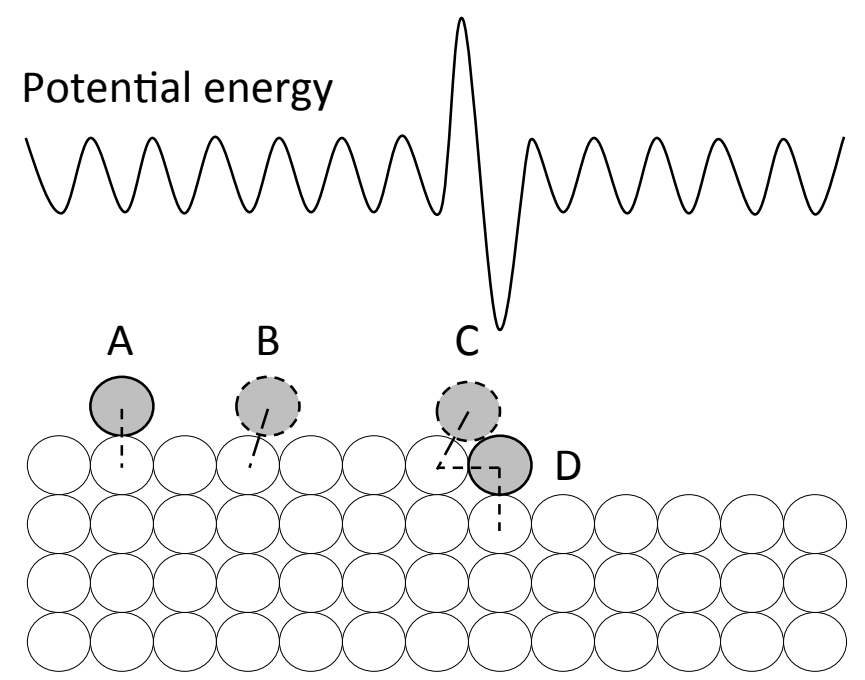

Figure 2.1: Cartoon of bond for; A an adatom in rest, B a diffusing adatom, C an adatom diffusing over a step edge and $\mathrm{D}$ an atom bonded to the step edge. The curve above show the potential energy profile experienced by an adatom.

ping of adatoms on top of islands have profound effects on the morphological evolution during film growth (see section 2.3).

Although surface diffusion is normally a thermally activated process there have been direct measurements of increased diffusivities when the surface is subjected to low energy ion bombardment [33,34]. Signs of increased rates of surface diffusion are also commonly observed in the film morphology of films deposited with low energy ion assistance (see e.g. [35]). Computer simulations of the effects of low energy bombardment of surfaces show that the processes leading to larger diffusivities are rather complicated and can take a number of different paths [34, 36-38].

When looking at diffusion on larger scales it is helpful to think in terms of chemical potentials. The chemical potential is an analogue of for example electric potential or gravitational potential. Particles, atoms and molecules, tend to diffuse to lower their chemical potential just as objects move to lower their gravitational potentials. The local chemical potential for adatoms on a surface is determined by the adatom density, the strain state of the surface, the curvature of the surface and the presence of adatom sinks on the surface [39]. The 
chemical potential can be written as

$$
\mu=(W-\Gamma K) \Omega .
$$

Where $W$ is the surface strain energy density, $\Gamma$ is the surface energy density, $K$ is the surface curvature and $\Omega$ is the atomic volume. $W$ is positive if the surface is in tension and negative if the surface is under compression while $K$ is positive for a convex surface and negative for a concave surface. Differences in the adatom density will also give rise to chemical potential differences. Adatoms will experience a driving force for diffusion to even out any gradients in the chemical potential by relieving strain, smoothening the surface and evening out adatom density gradients, whether the atoms diffuse is a matter of kinetics.

\subsection{The initial stages of film growth}

Thin films deposition is performed under far from ideal conditions. Even the best (and very expensive) substrates have rather large densities of surface defects such as vacancies and steps, reactive contaminants are present both in the source material and in the residual gas of the deposition chamber, all while the flux of depositing species is large. Adatoms are therefore bound to encounter sites on the substrate where they are trapped or other adatoms to which they can bind. All these events result in less mobile or immobile clusters of adatoms, nuclei, that form in the first stages of films growth.

\subsubsection{Nucleation}

Adatoms arriving on a perfectly flat surface in the very initial stages of film growth will diffuse randomly until they either encounter another adatom and form a dimer or desorb from the surface. The dimer can, in turn, either grow by the addition of another adatom or dissolve back into two separate adatoms. Larger clusters atoms similarly grow and shrink by attachment and detachment of atoms. However, detachment is unlikely due to the high supersaturation ${ }^{3}$ encountered in PVD. Clusters consisting of two or more atoms are often stable $[29,40]$, i.e. on average more likely to gain another atom than to loose one from detachment. The critical cluster size, $i^{*}$, is therefore often 1 . Different

\footnotetext{
${ }^{3}$ A surface is supersaturated when the number density of adatoms is larger than the equilibrium number density of adatoms would be at the same substrate temperature
} 


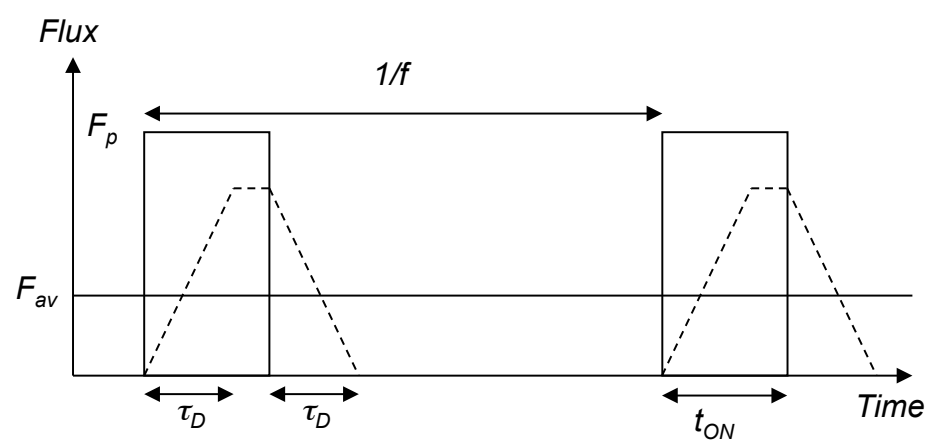

Figure 2.2: Idealized picture of pulsed deposition. The solid lines show the deposition flux in the pulse, $F_{p}$, and the time-averaged deposition flux, $F_{a v}$, while the dashed lines show the evolution of the adatom density with $\tau_{D}$ being the average adatom lifetime.

deposition temperatures and other factors such as surface symmetry can lead to critical cluster sizes larger than 1 [29].

The probability of dimer formation and thereby the nucleation density, $N$, depends on the likelihood of two adatoms encountering each other and rises if the number density of adatoms increases. In other words $N$ is proportional to the deposition flux, F. On the other hand the probability of adatoms incorporating into a larger cluster instead of forming a dimer increases if the adatoms can diffuse longer distances, that is if the diffusivity $(D)$ is large, resulting in a smaller $N$. An expression, or scaling relationship, describing this can be derived from atomistic nucleation theory,

$$
N=\left(\frac{F}{D}\right)^{\chi}
$$

where $\chi=\frac{i^{*}}{i^{*}+2}$ for two dimensional growth and $\chi=\frac{i}{i+2.5}$ for three dimensional growth which for a critical cluster size of $i^{*}=1$ leads to $\chi=\frac{1}{3}$ for two dimensional growth and $\chi=\frac{2}{7}$ for three dimensional growth [29].

It has been found theoretically [41] that equation (2.2.1) no longer holds when the flux is pulsed. Instead of having a simple dependence on $F$ and $D, N$ is instead dependent on the pulsing frequency, $f$, the material flux pulse width, $t_{O N}$, and the average adatom lifetime, $\tau_{D}$. When a flux pulse impinges on the substrate the adatom density will increase to saturate after a time $\tau_{D}$ when the same number of adatoms are lost to nucleation as are added by deposition. The adatom density will then be stable until the flux pulse ends after which the adatom density will decay until the surface is depleted of adatoms after 
a time $\tau_{D}$, see figure 2.2. If $f$ is low enough for the time between pulses to be larger than the adatom lifetime, $1 / f \gg \tau_{D}$, it is evident that the nucleation density will be proportional to the steady state adatom density reached during the pulse. The steady state adatom density depends on the material flux in the pulse, $F_{\text {pulse }}$. In fact the nucleation behavior is analogous to that for a continuos deposition flux with $N$ scaling with $F_{\text {pulse }}$ instead of with $F$

$$
N=\left(\frac{F_{\text {pulse }}}{D}\right)^{\chi}
$$

A high frequency, with $1 / f \ll \tau_{D}$, will never allow the adatom density to decay to zero between pulses. The adatom density will instead saturate at a steady state level proportional to the average deposition flux, $F_{a v}$. This corresponds to deposition with a continuous deposition flux described by equation (2.2.1).

When the adatoms lifetime is approximately the same as the time between pulses, $1 / f \approx \tau_{D}$, there is not enough time for the adatom density to decay to zero between pulses. On the other hand it will not saturate after only a few pulses. The adatom density will instead build up over $n$ (eq. (2.2.3)) pulses as when the next flux pulse reach the substrate while there is still an appreciable number of adatoms on the surface from the previous pulse [41]

$$
n=\frac{1}{6 F_{\text {pulse }} t_{O N}} .
$$

The island density will then saturate at

$$
N \sim\left(F_{\text {pulse }} t_{\text {ON }}\right)^{\frac{1}{2}}
$$

Note that the saturation island density is not dependent on $D$ in equation (2.2.4). It is also possible to modify the nucleation behavior of growing films by adding impurities to or creating defects on the surface to create extra nucleation sites, thus increasing the nucleation density over the kinetic limits. Durand et al. [42] found that the nucleation density of $\mathrm{Ni}$ and Mo films deposited on highly ordered pyrolitic graphite (HOPG) can be changed by treating the substrates with different doses (number of incident ions per unit area) of $100 \mathrm{eV} \mathrm{Ar}{ }^{+}$ions. The nucleation density of the deposited films was found to scale with the ion dose. A larger nucleation density compared to for thermal evaporation was found when films were deposited using $100 \mathrm{eV} \mathrm{Ni}^{+}$ions as the depositing species. Ions with these energies have enough energy to affect the first few atomic layers 
of the substrate leading to the creation of various kinds of near-surface defects on the substrate [43], the density of which is directly related to the ion dose. These defects act as traps for adatoms, nucleation centers, leading to the observed increases of the nucleation density. Similar effects have been observed by Kalff et al. [44] who observed a considerable increase in the island density for Pt deposited on $\mathrm{Pt}(111)$ by ion beam assisted deposition over the same amount of material deposited by thermal evaporation. They showed that the energetic particles in ion beam deposition creates considerable amounts of damage to the surface creating additional adatoms and vacancies in the substrate. These extra adatoms cause additional nucleation leading to the observed increase of the nucleation density by a factor 27 .

Exposure of the substrate to impurities, e.g. from the residual gas, can also cause extra nucleation centers leading to an increase of the nucleation density [29] although these effects can, to some extent, be mitigated by choosing appropriate deposition conditions, i.e. high deposition rates, to minimize the time the surface is exposed to the residual gas.

\subsubsection{Island growth and coarsening}

Several processes take place simultaneously as the nuclei grow and become grains. Atoms continuously attach to, either directly from the vapor or as diffusing adatoms, and detach from the grains with a positive net growth rate for most grains. To understand the processes taking place it is helpful to first consider what happens to a number of differently sized grains on a surface without any deposition taking place. Atoms will constantly detach from an attach to the grains with no net change in size for an isolated grain. Any given grain will therefore be surrounded by a two-dimensional cloud of adatoms at any given moment. Detachment of an atom from a grain is more probable the smaller the grain is as the binding energy for surface atoms depend on the grain curvature, which is inversely proportional to the grain size. The adatom density around small grains will therefore be higher than around large grains. If two grains of different size are situated near each other there will be a gradient in the adatom density $^{4}$ between the grains creating a driving force for diffusion from higher adatom density regions around the small grain to the lower adatom density regions around the large grain as shown in figure 2.3. This results in a net loss of

\footnotetext{
${ }^{4}$ or a concentration gradient or a difference in the chemical potential
} 


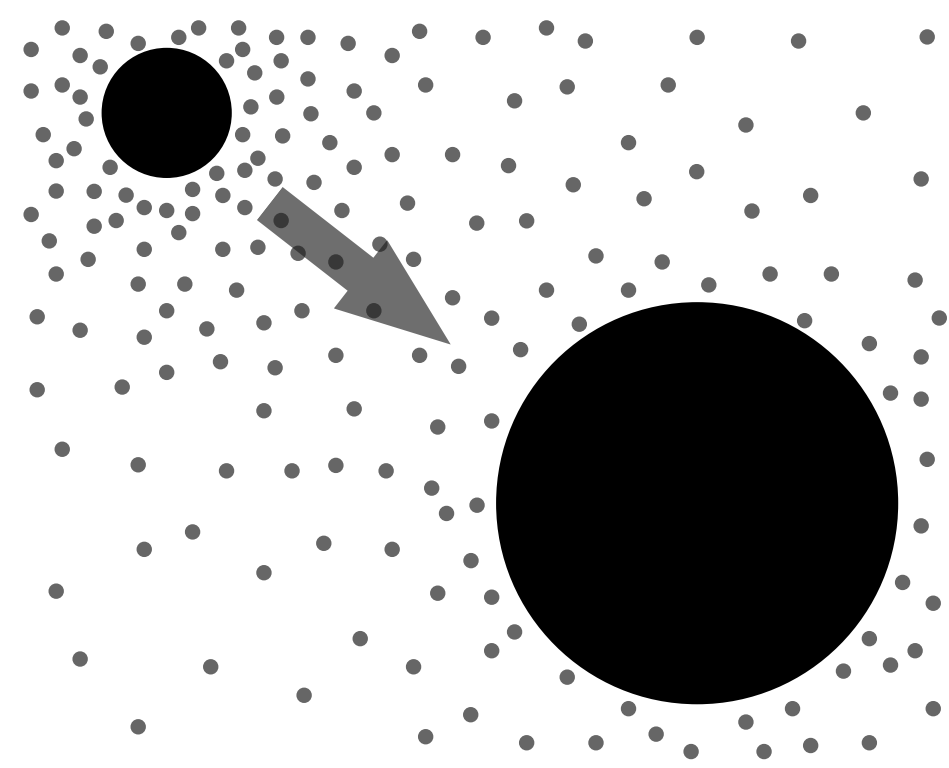

Figure 2.3: Schematic of grain coarsening through Ostwald ripening. The large black circles symbolize islands and the small grey circles symbolize adatoms. The arrow shows the direction of the net flux of adatoms from the small island to the large island do the gradient in adatom density.

atoms for the small grain and a net gain of atoms for the large grain that will accelerate as the size difference grows larger in a process known as Ostwald ripening [45-47].

The crystallographic orientation of the grains is more or less random at the early stages of growth unless the substrate acts as a crystallographic template. It should be noted that the surface locally can be periodic on amorphous substrates and act as a template in the very early stages of film growth [48]. The initial orientation of the grain might be energetically unfavorable with regard to the equilibrium structure of the grain. The grain will in that case be restructured as it grows larger unless the configuration is kinetically frozen. High energy surfaces will restructure unless there are kinetic restrictions in which case they can grow in a way that change the surface to a more favorable structure. The surface area of low energy surfaces generally increases while the surface area of neighboring surfaces decreases as high energy surfaces will grow themselves out of existence. $[49,50]$. 


\subsubsection{Coalescence and percolation}

The growing islands will eventually meet. As soon as two islands are close enough to interact they will begin restructuring to minimize the energy in the systems. Impinging islands will deform elastically, touch and form a grain boundary thereby trading surface energy for interface energy and strain energy [48]. Atoms will diffuse, mainly along the grain surface as bulk diffusion is several orders of magnitude slower, into the neck between the grains to minimize their chemical potential by moving from regions with a positive curvature to the neck which has a negative curvature. Surface diffusion continues to change the grain shape until the new grain reaches its equilibrium shape. Size differences between the coalescing grains will lead to growth of the large grain at the expense of the smaller due to the larger curvature of the smaller grain. One of the consequences of island coalescence is that the areal fraction of the surface covered by deposited material decreases. These newly released surfaces are often large enough to allow for nucleation of a new generation of islands, known as secondary nuclei.

Iijima et al. [51] investigated island coalescence of $\mathrm{Au}$ islands supported on $\mathrm{SiO}_{2}$ substrate using transmission electron microscopy. They found that small islands with a diameter of $1 \mathrm{~nm}$ coalesce like liquid droplets and that a new equiaxed island formed within $1 / 60 \mathrm{~s}$ while slightly larger particles ( 2-3 nm diameters) completed coalensce in $1 / 20 \mathrm{~s}$. Yet larger particles (diameter $>5 \mathrm{~nm}$ ) are crystalline and have a different coalescence behavior. A neck is formed between the clusters with a grain boundary in the middle if the grain are of different crystallographic orientations. The neck is slowly filled and the grain boundary might diffuse out through the smaller grain in the coalescing pair. The coalescence process for larger solid particles is much slower than for smaller liquidlike particles. Rotation of grains of different orientation was also observed to take place in the initial stages of coalescence of crystalline grains.

The time to complete a coalescence event between two solid half-spheres has been approximated by Nichols and Mullins $[52,53]$ to be

$$
\tau_{\text {coal }}=\frac{R^{4}}{B}
$$

assuming that the coalescence is driven by surface diffusion and that the surface energy and diffusion is isotropic. Here $B$ (equation (2.2.6)) is a coalescence parameter $[53,54]$ dependent on the surface diffusion coefficient $\left(D_{s}\right)$, the sur- 
face energy $(\gamma)$, the atomic volume $(\Omega)$ and the number of adatoms per unit area $\left(S_{0}\right)$

$$
B=\frac{D_{s} \gamma \Omega^{2} S_{0}}{k T} .
$$

The interplay between the coalescence time and the a few other timescales connected to film deposition has a large influence on when a growing film goes through key morphological transitions. Namely the elongation transition, when the average grain no longer has an equiaxed in-plane shape, the percolation transition, when the films of conductive materials first becomes conductive over macroscopic distances ${ }^{5}$, and the formation of a continuous film. At some point during the deposition the coalescence time will be larger than the time between island impingement events. A third island can then impinge on one of the coalescing islands before the coalescence has been completed resulting in a kinetically frozen elongated cluster of islands. Elongated clusters can also form when new material is added to coalescing islands at a rate that continuously increases the coalescence time faster than coalescence can proceed. It is possible to manipulate the coalescence processes to a larger extent in pulsed deposition processes where the amount of deposited material per pulse and the pulsing frequency, $F$, can be controlled independently. Every flux pulse will add a some material to the islands thus increasing the island radius $R$. Two coalescing islands subjected to a flux pulse will therefore see an increase in the coalescence time, $\delta \tau_{\text {coal }}$. If $\delta \tau_{\text {coal }}$ is larger than the time between pulses, $t=1 / F$, the completion of coalescence will be delayed to after the deposition of the next material pulse further delaying the completion of coalescence. After this point the elongated clusters of islands will be stable under subsequent deposition and join with other elongated clusters forming a percolated film consisting of a tortuous network of material separated by channels where the substrate surface has yet to be covered by material. Film growth proceeds with filling of these channels until all of the substrate is covered by a continuous film. An example of the structural evolution during pulsed deposition of $\mathrm{Ag}$ is shown in 2.4.

\subsection{Microstructure evolution during film growth}

After coalescence the film fully covers the substrate. The structural evolution of the film is now decided by the ability of atoms on the surface and atoms in the

\footnotetext{
${ }^{5}$ The name originates in that electrons percolate through the film
} 


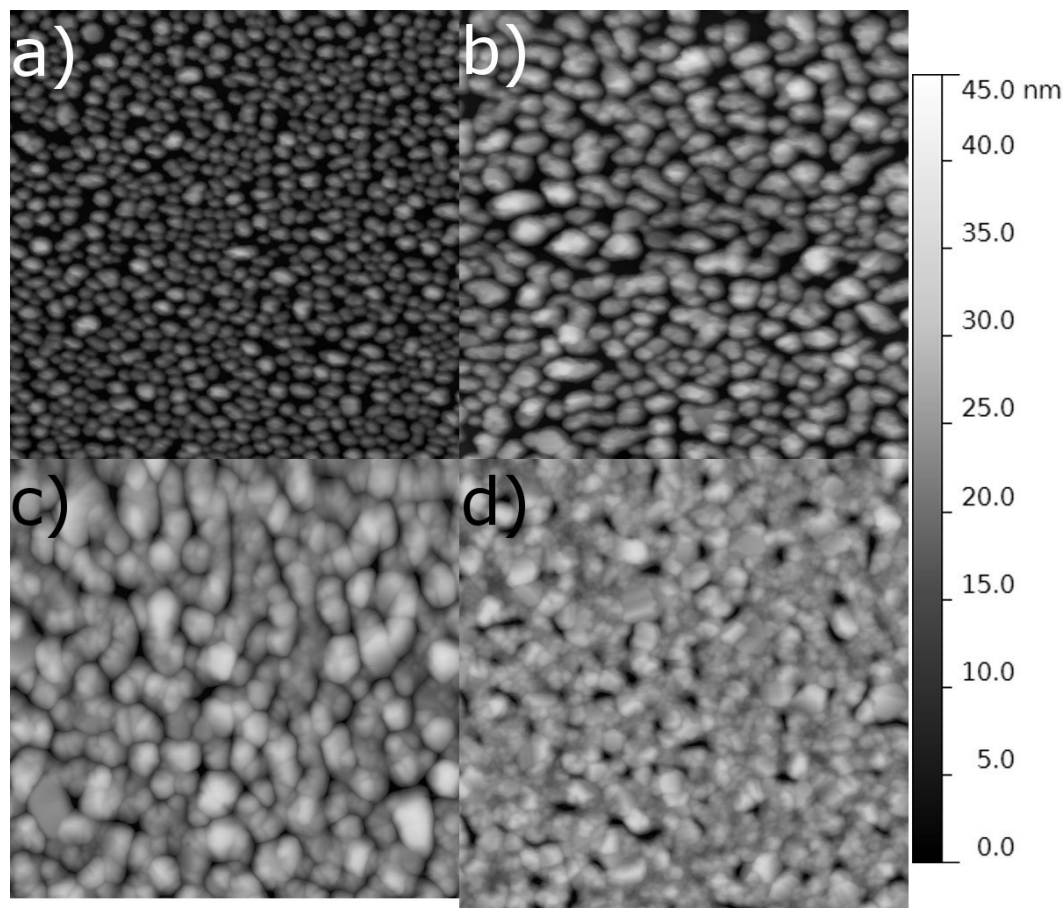

Figure 2.4: Ag deposited by pulsed deposition at a frequency of $50 \mathrm{~Hz}$ at thicknesses corresponding to different morphological transitions, (a) well separated equiaxed islands distinctive for when the coalescence is not hindered by deposition, (b) near the percolation transition, (c) hole filling and (d) near the formation of a continuous film. 
grains to move along the grain surface and between the grains. Even though this thesis deals with growth of polycrystalline thin films its instructive to have a brief look at how single crystalline films grow since the grains in polycrystalline films are single crystals. This section deals with how growth proceeds on the surface of a single crystal of the same material, known as homoepitaxial growth, how kinetics affects the surface morphology and how this and other factors affect the microstructural evolution of polycrystalline films.

\subsubsection{Kinetically limited epitaxial growth}

The growth mode and therefore the surface morphology during epitaxial growth is decided by the interplay between material transport between different atomic layers, the interlayer transport, and the nucleation of new islands. The surface of any single crystal, regardless if the crystal is macroscopic or a single grain in a polycrystalline film, have atomic steps separated by flat terraces. Film growth on single crystals proceeds in one of four principal growth modes, step flow growth, layer-by-layer growth, mound formation or self-affine growth (shown schematically in figure 2.5) depending on the deposition conditions. Step flow growth, figure 2.5 (a), occurs when diffusion is fast compared to deposition and the distance between surface steps is smaller than the average distance between nuclei. Instead of forming new nuclei on the terrace adatoms attach to the step edges resulting in lateral growth of the terraces. Although step flow is the most likely when interlayer diffusion is unlimited it is also, in principle, possible when interlayer diffusion restricted as it can proceed through adatom attachment to the ascending step only.

If the average distance between nuclei is smaller than the terrace width nucleation will take place on the terraces. Growth will proceed in a layer-by-layer fashion, figure 2.5, (b) as long as interlayer diffusion is fast enough to allow for atoms deposited on top of the islands to overcome the step edge barrier before they encounter other atoms and form a nuclei on top of the island. These atomically high islands will grow and coalesce to almost fully cover the underlying atomic layer before nucleation takes place on top of the islands and the cycle starts again. High substrate temperatures or low step edge barriers are required for layer-by-layer growth to not break down.

Mound formation, figure 2.5 (c), occurs when interlayer transport of adatoms is suppressed enough for adatoms to be trapped on top of islands and enable 
a)

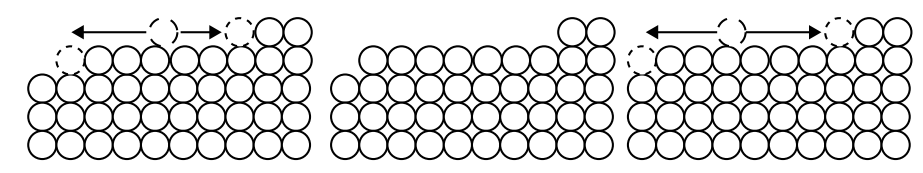

b)

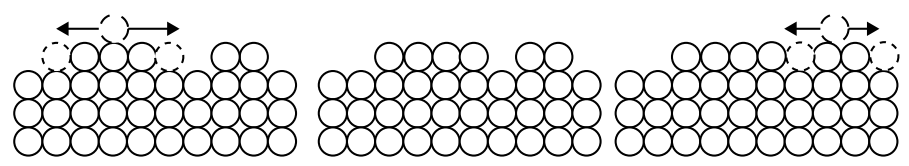

c)

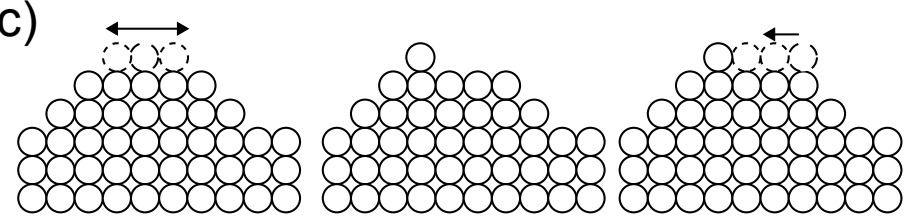

d)

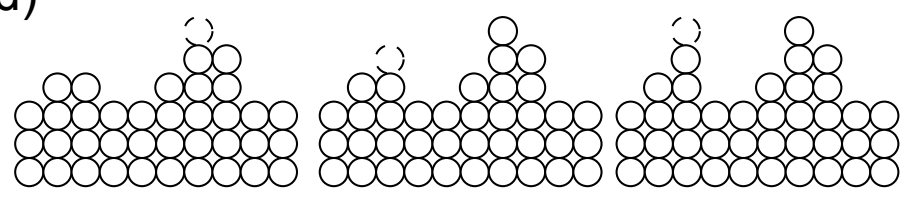

Figure 2.5: The growth modes during epitaxial growth: a) step-flow growth, b) layerby-layer growth c) mound formation and d) self-affine growth. The dashed circles adatoms (long dashes) and possible adsorption sites (short dashes). 


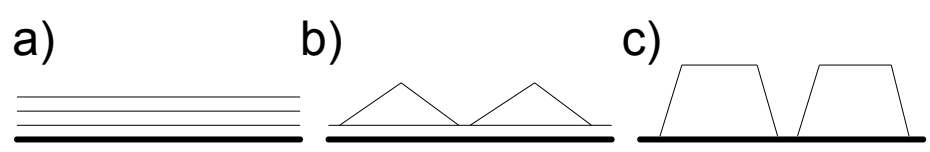

Figure 2.6: Schematic illustration of the thermodynamically defined growth modes in heteroepitaxial film growth. a) Island growth, b) Layer-by-layer plus island growth and c) layer-by-layer growth.

nucleation of a new atomic layer, either due to low deposition temperature or the presence of a high step-edge barrier. The constant nucleation of new layers on top of islands will result in considerable surface roughness after deposition of a few atomic layers of material. The surface roughness will keep building up for the duration of the deposition and can result in high levels of surface roughness for thicker films.

Intralayer diffusion is inhibited when the substrate temperature is (very) low resulting in a depositing atoms sticking more or less where they land. This growth mode is called self-affine or hit-and-stick growth and is pictured in figure 2.5 (c). Although self-affine growth results in quite some surface roughness on the atomic scale it is random and does not evolve a great deal with increasing film thickness.

The picture presented above is idealized and rather simplistic. The growth mode of a film is not only affected by temperature and step-edge barriers but also by other factors such as deposition rate and bombardment by energetic particles. It is for example possible to induce a layer-by-layer-like growth mode by using very high instantaneous deposition rates [55]. The high deposition rate leads to a high density of small islands which limits the amount of second layer nucleation due to island sizes smaller than the critical size needed for nucleation. Energetic bombardment increases inter- and intralayer mass transport in several ways [36-38] and can therefore also give rise to a layer-bylayer-like or step-flow-like growth, under conditions where it normally doesn't take place.

\subsubsection{Growth modes from a thermodynamic perspective}

Thermodynamical considerations play a large role in the growth mode of films on dissimilar substrates together with kinetics. The growth mode of heteroepitaxial film is decided by the relationship between the surface energy of the sub- 
strate, $\gamma_{s}$, and the film, $\gamma_{f}$, and the energy of the interface between the film and the substrate, $\gamma_{i}$ [1]. All systems seeks to minimize their free energy by maximizing the area of lowest energy surfaces whenever possible while minimizing the interface energy. If $\gamma_{f}+\gamma_{i}>\gamma_{s}$ island growth (also known as VolmerWeber growth, figure 2.6 a)) will take place to maximize the exposed area of the substrate thereby minimizing the surface energy. If instead $\gamma_{s}>\gamma_{f}+\gamma_{i}$ the film will completely wet the substrate and grow in a layer-by-layer fashion, also referred to as Frank-van der Merve growth, as shown in figure $2.6 \mathrm{c}$ ). A third growth mode (figure $2.6 \mathrm{c}$ )) which starts out as layer-by-layer growth followed by island formation, often called Stranski-Krastanov growth, is also commonly observed. This growth mode is the result of a complex interplay between surface and interface energy minimization and strain relief. Although all these growth modes were defined for heteroepitaxial growth they are also commonly used to describe the growth modes of polycrystalline films.

\subsubsection{Polycrystalline thin films}

The microstructural evolution of vapor deposited thin films during growth is highly dependent on the deposition conditions, both those that can be controlled directly and those that cannot. Some trends in the microstructural evolution of film deposited under controlled conditions became apparent already in the early years of thin film deposition. Material deposited at temperatures above or below certain temperature thresholds in comparison to their melting temperature display similar microstructures, see for example [1, 35, 48, 56-59] and references therein. This gave rise to the widely used structure zone diagrams, two examples of which are shown in figure 2.7, where the microstructure evolution is shown schematically as a function of the homologous temperature, or the substrate temperature in Kelvin normalized to the melting temperature of the deposited material $\left(T_{s} / T_{m}\right)$, and the energy of the depositing species. Films deposited at substrate temperatures far from their melting temperature $\left(T_{s} / T_{m}<0.2\right)$ usually consist of fibrous columnar grains with voided grain boundaries while films deposited at higher temperatures $\left(0.5<T_{s} / T_{m}<0.8\right)$ consist of large columnar grains with dense grain boundaries. At temperatures close to the melting point $\left(T_{s} / T_{m}>0.8\right)$ films consist of large eqiaxed grains forming due to recrystallization and segregation of of impurities to the surface and grain boundaries. These growth regimes are called zone I, II and III in or- 
a)

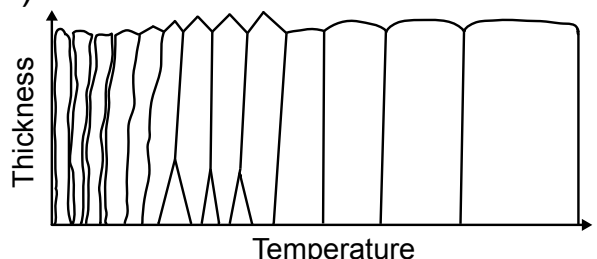

b)

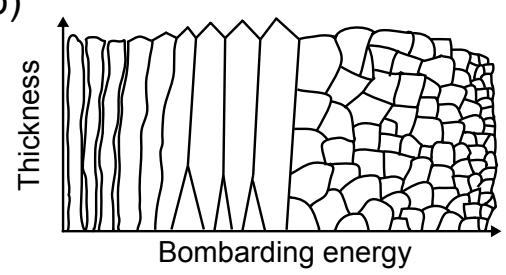

Figure 2.7: Examples of structure zone diagrams. a) The microstructural evolution as a function of homologous temperature $\left(T_{s} / T_{m}\right)$ and $b$ ) the microstructural evolution as a function of the energy of the impinging species $\left(E_{i}\right)$ at one specific homologous temperature. After [35, 59].

der of rising deposition temperature. The microstructure of films deposited by e.g. sputter deposition also have an additional dependence on energy transferred from energetic particles to he growing film giving rise to an additional zone between zone I and II called zone T. The temperature range where zone $\mathrm{T}$ occurs varies with the energy and flux of the bombarding particles. Some of the structure zone models where developed for very thick films $(\sim 100 \mu \mathrm{m})$ where another zone (III) with large equiaxed grains can be observed at high temperatures

The distinct zones are observed because of the difference in activation energy for different diffusion processes. At the low temperatures of zone I even surface diffusion with its rather low activation barrier is slow, thus deposited atoms stick more or less where they land leading to large nucleation densities and grains with a small lateral footprint. Film growth on top of the grains is selfaffine leading to a rapid build up of surface roughness causing shadowing. The low diffusivity and the shadowing lead grains with a large surface area and voided grain boundaries. Increasing the surface diffusivity, by higher deposition temperature and/or energetic bombardment of the growing film leads to gradual changes of the structure. The grains grow slightly larger, the grain surface smoother and the grain boundaries denser. Going from a low energy deposition flux to a high energy ${ }^{6}$ deposition flux at a constant growth temperature also induces microstructural changes as illustrated in figure $2.7 \mathrm{~b}$. Low energy bombardment only affects the first few atomic layers leading mainly to enhanced surface diffusion. Higher energy bombardment (some tens of $\mathrm{eV}$ depending on material) lead to defect creation in the first few atomic layers

\footnotetext{
${ }^{6} \mathrm{High}$ energies are here up to a few hundred $\mathrm{eV}$.
} 
of the film. These defects can act as nucleation sites and lead to nucleation of new grains, repeated nucleation, with a different orientation on top of the old grain. Yet larger bombarding energies lead to the creation of more defects and defect being created deeper in the growing film by collision cascades. The high defect density makes repeated nucleation more common resulting in eqiaxed nanocrystalline films $[35,60]$.

When the surface diffusivity is large enough for adatoms to cross the grain boundaries, competitive growth comes into play and the film structure evolution is characterized by zone $\mathrm{T}$ growth. The temperatures at which the zone $\mathrm{T}$ growth occurs are not high enough to give rise to any clear preferred crystallographic orientation during the nucleation and grain coarsening stages of the growth leading to an initial random orientation. Depositing atoms can therefore land on grains of any orientation and as a consequence of this on surfaces with different diffusivities. Adatoms on high mobility surfaces will diffuse larger distances before settling than adatoms on low mobility surfaces and will, if they are close to a grain boundary, have a larger likelihood of jumping to a neighboring grain. This results in a net flux of atoms from grains terminated by high mobility surfaces to grains terminated by low mobility surfaces and therefore a higher growth rate for these grains. These grains are also more prone to have a mound-like growth mode leading to a buildup of surface roughness causing shadowing and a yet higher difference in growth rate for different grains. The shadowing also leads to less deposition near the grain boundaries and the development porous grain boundaries. The grains with the lowest adatom mobility will overgrow the grains terminated by high mobility surfaces leading to films with a strong preferred crystallographic orientation and a lateral grain size and surface roughness that increase with films thickness.

Zone II growth takes place at temperatures when bulk diffusion becomes significant. Leading to grain boundaries being mobile throughout the growth process. Grain growth to minimize the grain boundary and surface areas therefore takes place not only during the initial growth stages but also during growth of a continuous film. This process, known as continuous or normal grain growth where all growing grains have approximately the same grain size, stops only when the grains have a strong preferred orientation or when the lateral grain size reaches 2 to 3 times the film thickness [35]. Grain growth can continue via 
discontinuous, or abnormal, growth when only a subset of all grains grow to very large grain sizes. The growing grains must have a considerable energetic advantage over the neighboring grains for discontinuous grain growth to occur. 


\section{Stresses in thin films}

Mechanical stresses in thin films can cause failure of the films through cracking or buckling that can lead to decohesion. Another problematic consequence of film stress is that the substrate is bent by the force from the film $[15,17,18]$. Stresses also affect the physical properties of films and can, for example, be used to tailor the band structure of semi-conducting films [18] and to modify the magnetic anisotropy in of films [19]. One of the most common causes of stresses in thin films is differences in thermal expansion between the film material and the substrate material if the film is deposited at elevated temperature or subjected to thermal cycling. The thermal stress written in differential form as [61]

$$
\frac{d \sigma_{f}}{d T}=\left(\alpha_{s}-\alpha_{f}\right)\left(\frac{E_{f}}{1-v_{f}}\right)
$$

where $\sigma_{f}$ is the film stress, $T$ is the temperature, $\alpha_{s}$ and $\alpha_{f}$ are the thermal expansion coefficients for the substrate and the film materials respectively, $E_{f}$ is the elastic modulus of the film material and $v_{f}$ is the Poisson ratio of the film material. Thermal stress is an example of extrinsic stress another, often larger, contribution to the total film stress is intrinsic stresses generated during the deposition. When the film wants to shrink but is constrained by the substrate the film stress is tensile and $\sigma$, by convention, is positive. When the film wants to expand but is constrained by the substrate $\sigma$ is negative.

Film stress is measured by two principal methods, X-ray diffraction [62] and curvature measurements pioneered by Stoney [63]. X-ray diffraction measures the crystallographic strain, $\epsilon$ in the material

$$
\epsilon=\frac{d-d_{0}}{d_{0}}
$$


a)
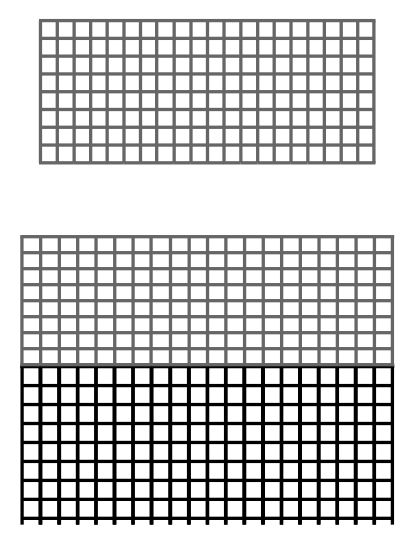

b)
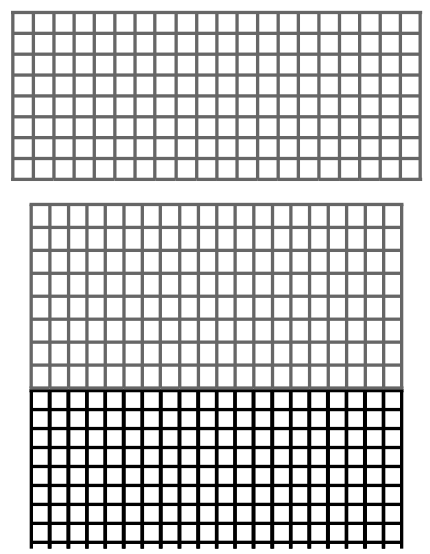

Figure 3.1: Cartoons of strained epitaxy where the film a) in a tensile strain state $\left(a_{0, \text { film }}<a_{0, \text { sub }}\right)$ and $\left.\mathrm{b}\right)$ is in a compressive strain state $\left(a_{0, \text { film }}>a_{0, \text { sub }}\right)$.

where $d$ is the measured lattice spacing and $d_{0}$ is the strain free lattice spacing of the material. The film stress, $\sigma$, is related to the strain through

$$
\sigma=E_{f} \epsilon
$$

where $E_{f}$ is the elastic modulus of the film material. Substrate curvature measurements provide a direct measure of what is called the stress-thickness product, $\sigma \times t$, from which the film stress can easily be deduced. The techniques for measuring film stress used in this work are described in more detail in 5.1.2 and 5.2 .

Another common source of film stress can be seen in epitaxial films where the film and the substrate doesn't have the same lattice spacing resulting in a lattice mismatch. If the atoms are in registry this lattice mismatch will give rise to a strain, $\epsilon$,

$$
\epsilon=\frac{a_{0, \text { sub }}-a_{0, f i l m}}{a_{0, f i l m}} .
$$

If the lattice spacing of the film $\left(a_{0, f i l m}\right)$ is smaller than the lattice spicing of he substrate $\left(a_{0, s u b}\right)$ the film will be in a tensile strain state as shown in figure 3.1 a). While if the lattice spacing of the film is larger than the lattice spacing of the of the substrate $\left(a_{0, s u b}\right)$ the film will be in a compressive strain state, figure 3.1 b). This strain will give rise to stress in the film according to equation (3.0.3). Strain energy will build up as the film grows thicker and will at some thickness become large enough so that it is more favorable to form misfit dislocations in 
the film-substrate interface and relieve the film strain.

\subsection{Surface stress}

Surface stress is one of the quantities describing the thermodynamics of surfaces, another being surface free energy. The surface stress, $f$, is defined as the reversible work per unit area needed to stretch a surface elastically while the surface energy, $\gamma$, is defined as the reversible work per unit area to create a surface, see e.g. $[64,65]$. Both quantities have the same unit, force per unit length, and are equivalent for liquids $[64,65]$. This is not the case for solids, where unlike liquids surface stresses solids can be both compressive and tensile. Surface stress can lead to reconstructions of crystal surfaces ${ }^{1}$ and the generation of considerable strain in freestanding films [64]. They are also as will be shown later (section 3.2.1) the cause of some intrinsic stresses in thin films.

The physical origin of surface stress can be explained by a thought experiment [65]: A surface is created when a crystal is cut. This results in a redistribution of charge density from the missing bonds above the surface and into the backbonds and in-between the surface atoms. This strengthens and shortens the backbonds and the equilibrium distance between the surface atoms. The resulting surface stress state is then tensile as the the surface atoms must be in registry with the bulk crystal. Adsorption of oxygen (or other electronegative species) on the surface will pull electrons out into the metal-oxygen bonds resulting in shorter bond lengths and a compressive surface stress.

\subsection{Intrinsic stresses}

Almost all thin films are subject to intrinsic stresses regardless if the films are amorphous, single crystals or polycrystalline and regardless of which technique was used for deposition. Polycrystalline films, the focus of this thesis, exhibits different and rather complicated stress evolutions with increasing film thickness depending on film material $[66,67]$ and process conditions such as temperature [68], deposition rate [66], energetic bombardment $[69,70]$ and contamination (i.e. background pressure during the deposition) [71]. For materials

\footnotetext{
${ }^{1}$ Atoms in the topmost atomic layers of reconstructed surfaces sit in positions that does not follow the packing sequence of the bulk crystal structure.
} 

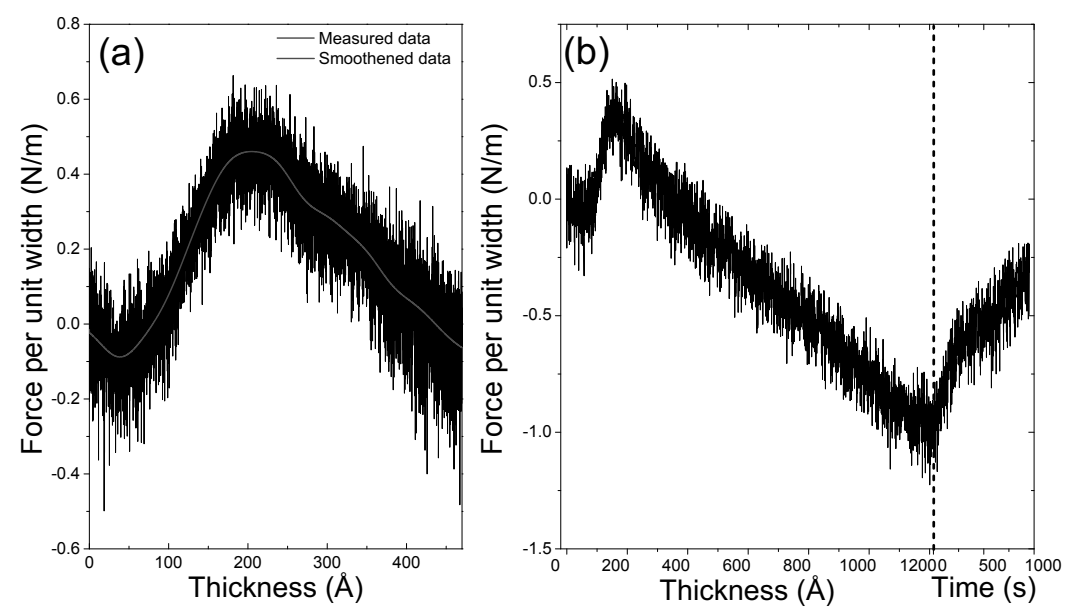

Figure 3.2: (a) The stress evolution during the first stages of growth of an Ag film on $\mathrm{SiO}_{2}$ at room temperature showing the compressive-tensile-compressive evolution and (b) the stress evolution of $\mathrm{Ag}$ deposited on $\mathrm{SiO}_{2}$ during and after deposition showing the stress relaxation typical for high adatom mobility conditions.

deposited under high mobility conditions with low levels of contamination the stress evolution is typically compressive-tensile-compressive with stress relaxations on deposition interruptions as shown in figure 3.2. The stress evolution for materials deposited for low mobility conditions is typically observed to be tensile or compressive-tensile without any stress relaxation on deposition interruptions as shown in figure 3.3 unless they are subjected to irradiation with energetic particles as is often the case in sputter deposition at low working gas pressures [70] or when a substrate bias is used [72]. The following sections will review the dominating mechanisms of stress generation during the different stages of the stress evolution.

Before moving on its good to take a moment to understand stress-thickness product (or force per unit width) vs. thickness plots, as shown in figure 3.2 and figure 3.3. These plots are acquired from in situ substrate curvature measurements during the deposition. An in depth description of curvature measurements can be found in chapter 5.2. The average stress $(\sigma)$ in the film up to a certain thickness can calculated from the stress-thickness product, $\sigma t_{f}$, using,

$$
\sigma=\frac{1}{t_{f}} \int_{0}^{t_{f}} \sigma(x) d x=\frac{\sigma t_{f}}{t_{f}}
$$

where $\sigma t_{f}$ is the measured stress-thickness product and $t_{f}$ is the film thickness. 


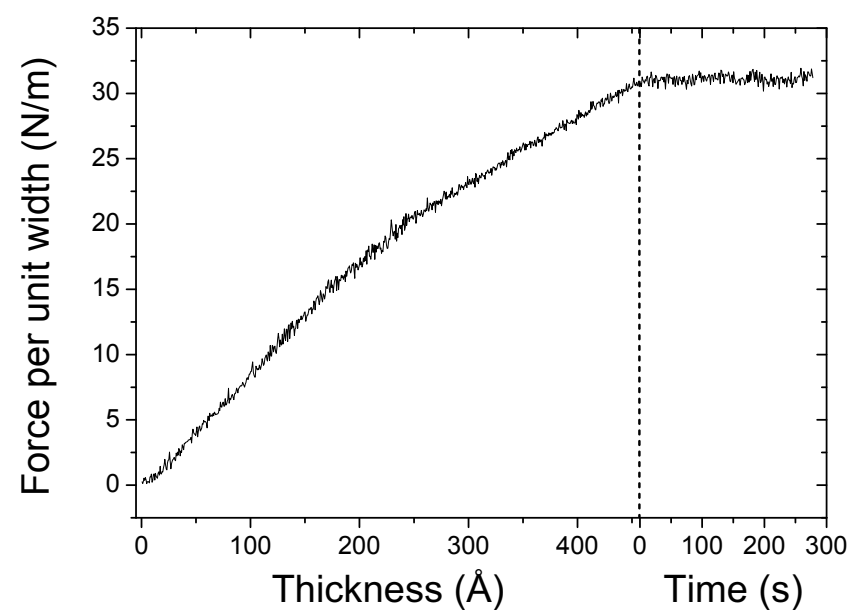

Figure 3.3: The stress evolution of $\mathrm{Mo}$ deposited on $\mathrm{SiO}_{2}$ at room temperature showing a tensile stress evolution without any stress relaxation on deposition interruptions typical for low atom mobility conditions.

The incremental stress, the stress in an infinitesimally thin added layer, is

$$
\sigma_{i n c}=\frac{d}{d t_{f}} \sigma t_{f},
$$

or the slope of the stress-thickness curve. Processes leading to changes to the stress in the film bulk are also reflected in the incremental stress making interpretation of the incremental stress difficult unless their contribution can be taken into account.

\subsubsection{Pre-coalescence stress}

Abermann et al. [66] were the first to observe the development of a compressive stress during the nucleation and island growth stages during growth of $\mathrm{Ag}$ on $\mathrm{MgF}_{2}$ and $\mathrm{SiO}_{2}$ by combining in situ stress measurements and transmission electron microscopy investigations. They connected the initial compressive stress to the contraction of the equilibrium lattice spacing by a surface stress induced Laplace pressure $\Delta P$, see e.g. [23, 64, 73-75],

$$
\Delta P=\frac{2 f}{r}
$$

where $\Delta P$ is the hydrostatic pressure exerted on a small particle with a radius $r$ by the surface stress $f$. In compressible materials the Laplace pressure results 
in a contraction of the of the equilibrium lattice parameter, $a$, according to

$$
a=a_{0}\left(1-\frac{\Delta P \kappa}{3}\right)
$$

where $a_{0}$ is the bulk lattice spacing and $\kappa$ is the compressibility of the material [74]. Mays et al. [74] showed that the lattice parameter of small $(<10 \mathrm{~nm}) \mathrm{Au}$ islands grown on amorphous carbon substrates increases with increasing island size according to eq. (3.2.3) and used this as a way to find the surface stress of $\mathrm{Au}$. This lattice parameter variation also is the key to understanding the origin of the initial compressive stress.

Small growing islands weakly bonded to the surface are initially mobile and can accommodate the continuously increasing lattice parameter by moving or changing their structure. At some island size, which depends on the strength of the bonding to the substrate, the number of bonds that need breaking will be too large for it to be energetically favorable for the islands to move or change shape. The smaller than bulk lattice parameter of the islands will be frozen in at this point and no longer increase with island size. Island growth will continue epitaxially on with the smaller than bulk lattice parameter resulting in a compressive film stress. To further complicate matters there is an interface stress, $g$, associated with the island-substrate interface which together with the surface stress will determine Laplace pressure and as a consequence the stress in the pre-coalescence stage [75]. The sum of the surface and interface stress must be positive for the Laplace pressure to result in a contraction of the equilibrium lattice parameter and a compressive stress in the pre-coalescence stage.

By modeling an island as a cylinder with a height, $t$, and diameter, $d$, Cammarata et al. [75] modeled the stress resulting from Laplace pressure as

$$
\sigma=(f+g)\left(\frac{1}{t}-\frac{1}{t_{0}}\right)+2 h\left(\frac{1}{d}-\frac{1}{d_{0}}\right)\left(1+2 \frac{S_{13}}{S_{11}+S_{12}}\right),
$$

where $f$ and $h$ are the surface stresses of the cylinder top and side, $g$ is the interface stress between the cylinder bottom and the substrate, $t$ is the cylinder height and $t_{0}$ is the height when the reduced lattice parameter is frozen in, $d$ is the cylinder diameter and and $d_{0}$ is the cylinder diameter when the reduced lattice parameter is frozen in and $S_{11}, S_{12}$ and $S_{13}$ are elastic compliaces.

Friesen et al. [25,76] found that partially reversible stress relaxations on growth interrupts occurs during the island growth stage. These relaxations and their reversibility cannot be explained by changes to the Laplace pressure induced 


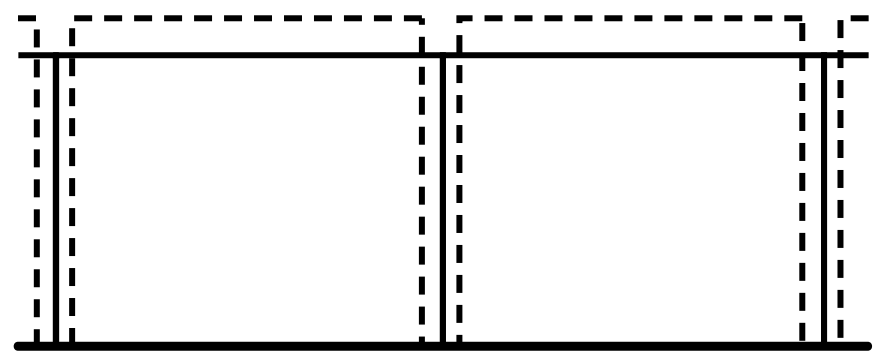

Figure 3.4: Hoffman's stress model builds on the energy grain when separated grains (dashed) snap together to form a continuous film with grain boundaries (full lines).

stress. Instead they reasoned that the presence of adatoms affects the surface stress. Changes in the adatom population, a decreasing population when the deposition flux is stopped and an increasing population when the deposition flux is resumed, result in changes in the surface stress. Theoretical investigations [77] have shown that adatoms, surface steps and islands results in changes in the surface stress of $\mathrm{Cu}(100)$ and $\mathrm{Cu}(111)$ surfaces with the $\mathrm{Cu}(100)$ surface being the most sensitive to changes in the feature density. Experimental investigations [78, 79] where the surface roughness have been monitored with monolayer accuracy while simultaneously monitoring the film stress during homoepitaxial growth show that the surface stress is correlated with the film roughness both during deposition and on deposition interruptions.

\subsubsection{Stress generation during island coalescence}

The tensile rise in the stress evolution was connected to island coalescence by Abermann et al. [66] by transmission electron microscopy imaging of films at thicknesses corresponding to the beginning, the middle and the end of the tensile stress rise. The island shape and size changes from small equiaxed islands at the beginning of the stress rise through larger elongated islands to an almost continuos film at the end of the stress rise. Hoffman and coworkers [80,81] modeled the generation of tensile stress in grain boundaries of continuous films by a considering that separated grains will experience a driving force to snap together and form a grain boundary to lower their surface energy as illustrated in figure 3.4. The model assumes an asymmetric interaction potential between the 


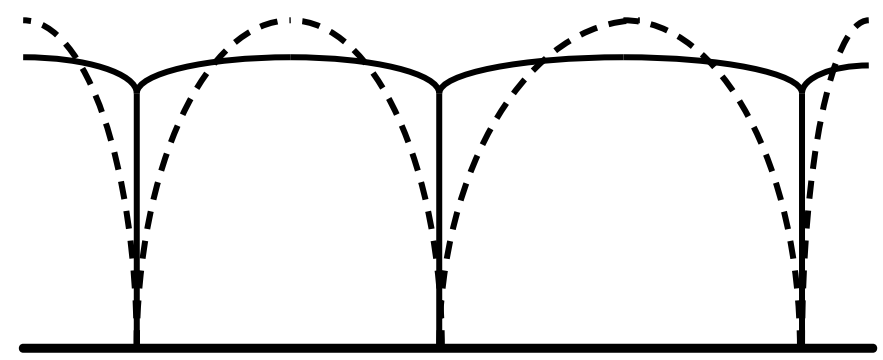

Figure 3.5: The geometry used in the stress model of Nix and Clemens [82]. The dashed lines show the grain geometry just before coalescence and the full lines the grain geometry after grain boundary zipping.

grains making up the grain boundary with atoms being randomly deposited into the grain boundary. The random deposition locally results in both tensile and compressive stresses along the boundary height. The net distortion of the grain from snapping together the the grain boundary, $\Delta$, results in a tensile stress due to the asymmetry of the potential. The magnitude of the tensile stress can be calculated as

$$
\sigma=\frac{E_{f}}{1-v} \frac{\Delta}{d}
$$

where $E_{f}$ is the elastic modulus, $v$ the Poisson ratio and $d$ is the diameter of the grain.

Nix and Clemens [82] suggested a model for stress generation during island coalescence based on the assumption that grain boundaries starts forming when isolated elliptical grains touch at the substrate surface. The grain boundary zips up by the grains deforming elastically trading surface energy for strain energy until a cusped cycloid surface is formed as shown in figure 3.5. By treating the top of the grain boundary as a crack they calculate that the zipping will stop when the energy required for extending the crack (i.e. shorten the grain boundary) equals the energy gained by extending the grain boundary. From this it is possible to calculate the average stress in the film as

$$
\langle\sigma\rangle=\left(\left(\frac{1+v}{1-v}\right) E_{f} \frac{2\left(2 \gamma_{s v}-\gamma_{g b}\right)}{d}\right)^{1 / 2}
$$

Although the grain boundary zipping model provide a more accurate picture of the coalescence process than Hoffman's model it severely overestimates the film stress during coalescence. 
a)

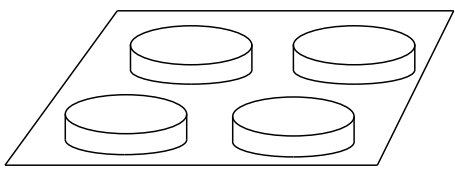

b)

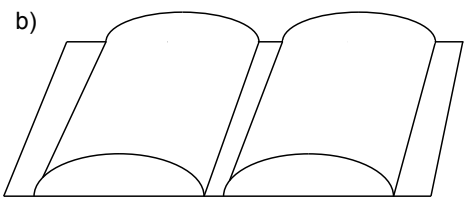

Figure 3.6: Two version of 2D geometries in the Freund and Chason model of tensile stress generation.

Freund and Chason [83] used a different approach to model the generation of tensile stresses during island coalescence. They based their analysis on theory for the elastic contact of spheres and estimated of the volume averaged film stress when a regular square array of half-spheres with the radius, $R$, coalesce into a homogeneous film of contacting square blocks,

$$
\langle\sigma\rangle=4 \frac{\gamma_{s v}-\frac{1}{2} \gamma_{g b}}{R}
$$

Using the same kind of analysis they also derived an expression for the average film stress during coalescence for other geometries or dimensionalities, namely of blocks (1D) as shown in figure 3.4, very long half-cylinders or cylindrical discs (both 2D) as shown in figure 3.6, the half-cylinder case being equivalent to the geometry considered by Nix and Clemens in figure 3.5, or half-spheres (3D),

$$
\frac{\langle\sigma\rangle^{(N)}}{E_{f}}=A_{N}\left(\frac{\gamma_{s v}-\frac{1}{2} \gamma_{g b}}{E R}\right)^{c_{N}},
$$

where the dimensionality of the model, $N=1,2$ or $3, c_{N}$ is numerical exponent, $c_{1}=\frac{1}{2}, c_{2}=\frac{2}{3}$ and $c_{3}=1$, and $A_{N}$ is a numerical factor, $A_{1}=0.82, A_{2}=0.44$ and $A_{3}=4$.

Equation (3.2.9) covers all the cases presented previously, the one-dimensional case is a geometry similar to that of Hoffman's model, Nix and Clemens analyzed the two-dimensional case of coalescence between long half-cylinders while the three-dimensional case covers the coalescence of a square array of half-spheres. The stresses estimated with this model are closer to matching experimental values than the Nix-Clemens model and have for a two-dimensional case also been shown to be in agreement with finite element modeling [84].

The creation of grain boundaries also leads to a change in the surface stress as free surface stress is exchanged for interface stress in the grain boundary [85]. This modifies the diameter dependent term of the Laplace stress induced 
compressive stress (equation 3.2.5) with the term

$$
\Delta \sigma_{d, i m p}=\left(\frac{h_{g b}-2 h}{d_{i m p}}\right)\left(1+2 \frac{S_{13}}{S_{11}+S_{12}}\right),
$$

where $h$ is the free surface stress, $h_{g b}$ is the interface stress of the grain boundary and $d_{i m p}$ is the grain diameter at when the grains impinge. The diameter dependent term of equation 3.2.5 then becomes,

$$
\sigma_{d, i m p}=\left(\frac{h_{g b}}{d_{i m p}}-2 \frac{h}{d_{0}}\right)\left(1+2 \frac{S_{13}}{S_{11}+S_{12}}\right) .
$$

The net stress contribution from surface and interface stresses when grain boundaries are formed will be tensile if the term $h_{g b}-2 h$ is negative.

\subsubsection{Stresses in continuous films}

After the tensile stress rise associated with coalescence, the film stress takes markedly different paths depending on the atomic mobility. For low atomic mobility the stress tend to be tensile while it for a high atomic mobility turns compressive again and reach a steady state magnitude that holds until the deposition is interrupted resulting in a relaxation of the compressive stress. This has been demonstrated for a large number of metals by deposition of the same material at different substrate temperatures ranging from cryogenic to hundreds of degrees Celsius [15, 18], with the low mobility behavior being observed for $T_{s} / T_{m}<0.2$ and high mobility behavior for $T_{s} / T_{m}>0.2$. The origins of stresses in continuous films are less well understood than for the earlier growth stages and is the subject for quite some debate in the literature.

\section{High mobility materials}

The origins of the post coalescence compressive stress in high mobility materials is an issue that is still the subject of much debate. The reason for this is the complicated dependence of the magnitude of the compressive stress on a number of process parameters as well as the microstructure of the film and its evolution. Interestingly deposition processes as dissimilar as thermal evaporation [15, 18, 86], sputter deposition [18, 87-90] and electrodeposition [91, 92] all result in similar dependencies of the compressive stress magnitude on process parameters common for the deposition processes. This points to that the 
compressive stress has its origin in film formation processes common for all deposition processes.

The sample temperature can rise considerably during deposition, especially in vacuum deposition processes, due to radiative heating from the deposition sources and the energy released when atoms condense on the growing film. If the film has a higher thermal expansion coefficient than the substrate, which in most of the investigated cases is the case as metal thin films (coefficients of thermal expansion $11 \times 10^{-6}-23 \times 10^{-6} \mathrm{~K}^{-1}$ for high mobility metals at $300 \mathrm{~K}$ [27]) are deposited on Si (coefficient of thermal expansion $2.6 \times 10^{-6} \mathrm{~K}^{-1}$ [27]) substrates, the heating give rise to a compressive film stress. If the deposition is interrupted the substrate cools down resulting in a relaxation of the thermal stress. The overall stress evolution due to thermal stresses therefore follows what has been observed for high mobility metals deposited at ambient temperature. Shull et al. [93] simultaneously measured the stress evolution and the substrate temperature evolution and showed that the steady state stress and the stress relaxation on deposition interruption persists when the thermal stress is subtracted form the stress evolution.

The magnitude of the steady state compressive stress varies with deposition rate, where high rates lead to a smaller stress magnitude [24, 25, 92,94] or even the stress becoming tensile $[91,95]$. As mentioned previously lower steady state compressive stresses are also seen for lower homologous temperatures. The deposition rate and temperature dependence indicate that kinetics play a large role in the generation of the compressive steady state stress. The stress relaxations on deposition interruption and their reversibility [93] indicate that they have a common origin with the compressive steady state stress. It has been argued that the steady state compressive stress is the result of local relaxation of the tensile grain boundary stress through adatom diffusion into the grain boundaries $[82,96]$. This cannot be the case as the incremental stress remains compressive until deposition is interrupted as he average film stress can become compressive. The average film stress would instead tend to zero if the steady state stress is the result of a relaxation process.

Abermann and Koch $[15,18,26,86,97,98]$ argue that the steady state compressive stress is inherited from the Laplace pressure induced stress in the precoalescence stage through epitaxial growth. If the grain diameter is significantly larger than the film thickness during coalescence it is possible that only 
the regions of the grains close to the grain boundaries are in tension while the grain centers still are in compression [85]. Grain growth is active at high mobility conditions and lead to the buildup of tensile stresses through elimination of grain boundaries [99]. Grain growth also results in a change in the surface stress as the grain diameter changes. A term

$$
\Delta \sigma_{d, \text { cont }}(d)=h_{g b}\left(\frac{1}{d}-\frac{1}{d_{i m p}}\right)\left(1+2 \frac{S_{13}}{S_{11}+S_{12}}\right),
$$

has to be added to equation 3.2.11 to get the total diameter dependent surface stress term

$$
\sigma_{d, \text { cont }}(d)=\left(\frac{h_{g b}}{d}-2 \frac{h}{d_{0}}\right)\left(1+2 \frac{S_{13}}{S_{11}+S_{12}}\right) .
$$

The total stress resulting from surface stresses in a continuous film can then be written as

$$
\sigma_{\text {cont }}=(f+g)\left(\frac{1}{t}-\frac{1}{t_{0}}\right)+\left(\frac{h_{g b}}{d}-2 \frac{h}{d_{0}}\right)\left(1+2 \frac{S_{13}}{S_{11}+S_{12}}\right) .
$$

Abermann and Koch argued that grain growth together with surface flattening $[18,26]$ is the origin of the stress relaxation observed on deposition interruption. However, grain growth is not a reversible process. Instead it is argued that the processes leading to stress relaxation on interruption and the return to the steady state compressive stress on deposition resumption indeed are irreversible but symmetric [100].

Another possible cause of the steady state stress is the modification of surface stress by surface defects such as adatoms in the same way as has been suggested for the stress relaxations seen in the pre-coalescence stage [25, 76, 79]. In a similar way Spaepen [23] has suggested that compressive stresses can be generated by surface steps modifying the surface stress. However, molecular dynamics simulations [77] have shown that the magnitude of the compressive stresses introduced by adatoms and surface is too small to explain the experimentally measured compressive stresses. Spaepen [23] also observed that approaching ledges on a surface can be compressive, pulled in towards their island, or tensile, pushed towards each other. When compressive ledges approach they have a larger than equilibrium spacing which occasionally might allow an extra atom to be incorporated in an interstitial position and overgrown resulting in a local smaller than equilibrium lattice spacing and compressive stress. This is likely not a very common process, but since the film stress depends on the biaxial 
modulus of the film material ( $\sim 100 \mathrm{GPa}$ ) the number of atoms needed to be incorporated in this way is of the order of 1 in 1000 to result compressive stresses of the order $100 \mathrm{MPa}$ which is close to the steady state stresses observed for high mobility materials [23].

The higher than equilibrium density of adatoms on a surface during deposition leads to an increase of the surface chemical potential, $\mu_{s}$, from the surface chemical potential when it is in equilibrium with the film, $\mu_{s}^{0}$ by a factor $\delta \mu_{s}$,

$$
\mu_{s}=\mu_{s}^{0}+\delta \mu_{s}
$$

The higher surface chemical potential will result in a driving force for diffusion to regions with lower chemical potentials. Chason et al. [24] noted that the chemical potential of a grain boundary,

$$
\mu_{g b}=\mu_{g b}^{0}-\sigma \Omega
$$

where $\mu_{g b}^{0}$ is the equilibrium chemical potential of the grain boundary, $\sigma$ is the stress normal to the grain boundary and $\Omega$ is the atomic volume, likely is smaller than the chemical potential of the surface during deposition. In that case the difference in chemical potential between the surface and the grain boundary,

$$
\Delta \mu=\mu_{s}-\mu_{g b}=\Delta \mu_{0}+\delta \mu_{s}+\sigma \Omega
$$

where $\Delta \mu_{0}=\mu_{s}^{0}-\mu_{g b}^{0}$ is the difference between the surface and grain boundary chemical potentials when there is no deposition, results in a driving force for diffusion into the grain boundaries of the film. According to Chason et al. [24] $\Delta \mu_{0}$ is small. When $\delta \mu$ is positive there is a driving force for adatom diffusion form the surface into the grain boundary.

By taking a simplified but still physically valid view of film growth where step flow growth occurs on top of the grains as shown in figure 3.7 [101] one can see that the grain boundary height will grow by one atomic layer when the step edges from both grains meet. The stress in each atomic layer can then be analyzed under the assumption that adatoms close to the triple junction between the grain boundary and the grain surfaces will experience a driving force for diffusion into the triple junction due to the chemical potential difference expressed in equation 3.2.17. Using the chemical potential difference as a starting point it is possible to calculate the rate of atoms diffusing into the triple junction $[102,103]$,

$$
\frac{\partial N_{i}}{\partial t}=2 C_{s} \frac{2 D}{a^{2}}\left(1-e^{-\frac{\Delta \mu}{k T}}\right) \simeq 2 C_{s} \frac{2 D}{a^{2}} \frac{\Delta \mu}{k T}
$$




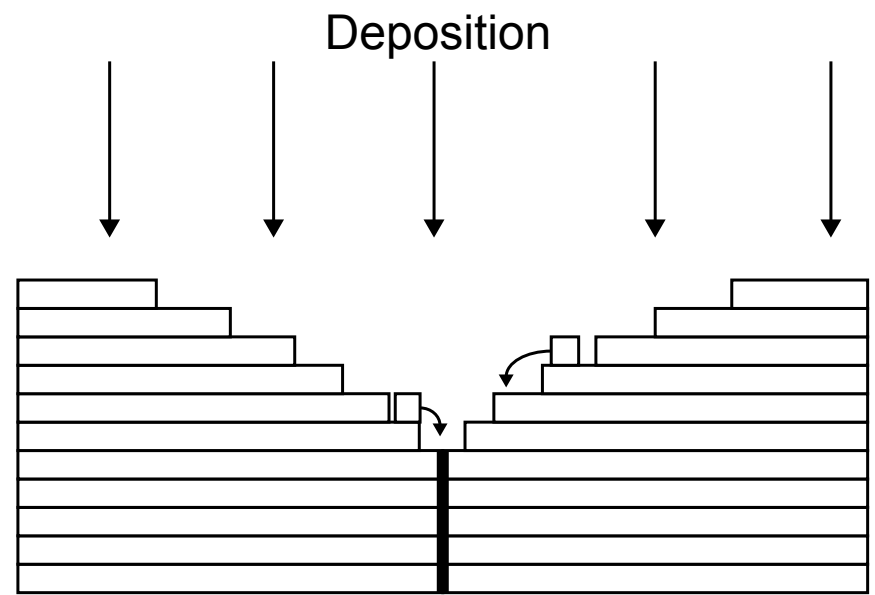

Figure 3.7: Schematic of step flow growth in the vicinity of a grain boundary, the thick black line. Atoms can be inserted into the top of the grain boundary generating compressive stress if kinetics allows otherwise the step edges on the opposite sides of the boundary will snap together generating tensile stress.

here the factor 2 is present as the adatoms can enter the grain boundary form the grains on both sides, $C_{S}$ is the fractional coverage of adatoms on the surface free to diffuse into the triple junction, $\mathrm{D}$ is an effective diffusivity for rate of adatoms hopping into the grain boundary from the surface and $a$ is the nominal atomic size. The factor $2 D / a^{2}$ is the transition rate of atoms from the surface to the grain boundary. Adatom diffusion into the triple junction will change the strain in the layer

$$
\Delta \epsilon_{i}=-\frac{N_{i} a}{L}
$$

where $L$ is the grain size.

The atom insertion model also takes into account that the stress generated in the triple junction can be tensile by using an approximation of the tensile stress generated when the triple junction snaps together to minimize the surface energy,

$$
\sigma_{T}=\alpha\left(\frac{\Delta \gamma}{L}\right)^{\frac{1}{2}}
$$

$\Delta \gamma$ is the difference between the surface and grain boundary energy and $\alpha$ is a constant dependent on the geometry and material properties.

It is possible to write a differential equation for the stress change in layer $i$ by 
combining the equations 3.2.17, 3.2.18 and 3.2.20:

$$
\frac{\partial \sigma_{i}}{\partial t}=-\frac{4 C_{s} M_{f}}{a k T} \frac{D}{L}\left(\sigma_{i} \Omega+\delta \mu_{s}\right)
$$

where $M_{f}=E_{f} / 1-v$ is the biaxial modulus of the film material. Equation 3.2.21 has a solution that can be written as [102,103]

$$
\sigma_{i}=\sigma_{C}+\left(\sigma_{T}-\sigma_{C}\right) e^{-\frac{t-t_{i}}{\tau}}
$$

where

$$
\begin{gathered}
\sigma_{C} \equiv-\frac{\delta \mu_{s}}{\Omega}, \\
\frac{1}{\tau} \equiv \beta \frac{D}{a L^{\prime}} \\
\beta \equiv \frac{4 C_{s} M_{f} \Omega}{k T} .
\end{gathered}
$$

Equation 3.2.22 only considers the stress change in layer $i$ from the time $\left(t=t_{i}\right)$ it is formed to the time when the triple junction of layer $i$ is buried under layer $i+1$ after a time $\Delta t_{i}$ (at $\left.t=t_{i}+\Delta t_{i}=t_{i+1}\right)$, or the monolayer formation time. The final stress in of layer $i$ is therefore

$$
\sigma_{i}=\sigma_{C}+\left(\sigma_{T}-\sigma_{T}\right) e^{-\frac{\Delta t_{i}}{\tau}}
$$

The time $\Delta t$ is related to the rate at which the grain boundary height changes. For a film in the late growth stages the grain boundary height changes at the same rate as the growth front, with the deposition rate $R$. The time to deposit a monolayer of material is then $\Delta t_{i}=a / R$. Substituting this into equation 3.2.26 gives the steady state stress

$$
\sigma_{i}=\sigma_{C}+\left(\sigma_{T}-\sigma_{C}\right) e^{-\beta \frac{D}{R L}}
$$

Equation 3.2.27 shows that the steady state stress depends on diffusivity, $D$, deposition rate, $R$, and grain size, $L$. A larger diffusivity is predicted to result in a higher compressive steady state stress magnitude while higher deposition rates or grain sizes are predicted to result in smaller steady stress magnitude.

The atom insertion model intrinsically provides an explanation for the stress relaxations seen on deposition interruption. When deposition is interrupted the adatom density on the surface will decrease rapidly lowering the chemical potential of the surface to its equilibrium value. The grain boundary on the other hand will have a chemical potential elevated above the equilibrium value 
due to atom insertion during the deposition. This will reverse the chemical potential difference resulting in a driving force for diffusion of atoms out of the grain boundary relieving the compressive stress induced by these atoms.

A number of investigations, both theoretical [104-106] and experimental [91, 92, 95, 107-109], have all provided partial evidence for the validity of the adatom insertion model. With the exception for the theoretical studies where adatom diffusion into grain boundaries is actually observed [104, 105] the experimental evidence is indirect. Like for the other suggested mechanisms for compressive stress generation direct experimental observation of adatom insertion into grain boundaries is very difficult if not impossible due to the small affected volumes and the dynamic processes resulting in the stress behavior. Sheldon $e t$ al. $[107,108]$ observed compressive stresses consistent with a adatom insertion into grain boundaries AlN films deposited at mobilities low enough for atom diffusion in grain boundaries to be restricted. Flötotto et al. [109] measured the stresses in $\mathrm{Ag}$ films deposited on $\mathrm{SiO}_{2}$ with or without a Ge nucleation layer. The Ge segregates to the surface of the growing Ag film limiting the surface diffusivity of $\mathrm{Ag}$ adatoms and resulting in a smaller grain size than for $\mathrm{Ag}$ deposited on $\mathrm{SiO}_{2}$ while leaving the grain boundary diffusivity unaffected. The steady state compressive stress and the stress relaxations were larger for $\mathrm{Ag}$ deposited on the Ge nucleation layer than for $\mathrm{Ag}$ deposited on $\mathrm{SiO}_{2}$ in accordance with the adatom insertion mechanism. Yang et al. [106] performed kinetic Monte Carlo simulations of film growth using surfactants reducing the adatom diffusivity and observed that this lead to a reduction of the compressive stress. The effect of deposition rate on the steady state stress magnitude in electrodeposited high mobility films have been investigated in several papers [91, 92, 95] all yielding results in line with the adatom insertion model. Bhandari et al. [95] used a templated growth approach where Ni films were grown on a patterned surface yielding two steps of island coalescence and continuous film growth first with a small grain size and then with a larger. The steady state compressive stress observed in the two continuous growth stages were consistent with the adatom insertion model with a larger stress for the smaller grain size. Shin $e t$ al. [92] used the possibility to etch back the film provided by electrodeposition and found that the steady state stress for etching was the same as that for deposition just tensile instead of compressive. They also showed that the stress evolution during several deposition-etching cycles was repeatable. Leib et al. [110] investigated the grain size dependence of the stress relaxation observed after 
depositions and found that the magnitude of the stress relaxation is linearly dependent on the grain boundary length per unit area in the sample which implies that the stress relaxation has it origin in the grain boundaries. Further investigations taking the kinetics of the relaxation into account through investigations of the temperature dependence of the relaxation process [111] found that rate of stress relief showed little or no temperature dependence indicating that the stress relaxation process is not diffusion driven. Investigations by $\mathrm{Yu}$ et al. [112] show that two processes are active during deposition interruptions a fast reversible relaxation and a slow irreversible relaxation. The slow irreversible process was found to be due to grain growth generating tensile stresses while the fast reversible process was suggested to be due to a change in surface morphology through surface self-diffusion.

Recently Gonzaléz-Gonzaléz et al. [113, 114] proposed a model for generation of compressive film stresses and stress relaxations based on a surface morphology they call an "inside bundling-outside grooving" morphology. It is based on the observation that groups of grains seem to bunch up in tight bundles that are separated by grooved grain boundaries upon thermal annealing of continuous films. The bunching up is accompanied by the grain rotation leading to a crystallographic in-plane alignment. They suggest that anisotropic interactions between grains lead bundling of some grains accompanied by a build-up of shear strains in the grains. This results in compressive stress building up in the grain boundary between the bundling grains. The stress relaxation was modeled by surface curvature, stress and surface slope driven diffusion on the grain surfaces and in the grain boundaries. When deposition is interrupted diffusional currents will act to minimize the surface curvature and surface slopes as well as the film stress resulting in a flattening of the grain and relaxation of the stress that has built up in the grain boundary.

\section{Low mobility materials}

In low mobility materials the film stress tends to be tensile with the tensile stress magnitude varying between materials $[67,115]$ and with substrate temperature $[68,80,81]$ unless the films are subjected to energetic bombardment $[70,116-$ 118 ] when the film stress can becomes compressive. Films of low mobility materials generally have a columnar microstructure falling in zone I or zone $\mathrm{T}$ of structure zone models (see figure 2.7) depending on the material and deposition 
conditions. Intracolumnar voids are usually quite common in zone $\mathrm{T}$ films due to kinetic limitations and shadowing [35]. Janssen et al. [119] showed that the decreasing tensile stress magnitude often observed with increasing film thickness [120] is a result of the tensile stress being generated in the grain boundaries of the film as the grain size increases with increasing film thickness. The magnitude of the tensile stresses was shown to be consistent with the Hoffman model, which is also the case for films deposited under low mobility conditions [16]. Voiding in the grain boundaries can grow quite severe in zone I and zone $\mathrm{T}$ films. If the grain boundary width is too large the grains will no longer be able to interact over the boundary resulting in a lower tensile film stress [121]. A mechanism for how the tensile stress is generated during growth was suggested by Sheldon et al. [122] . They reasoned that atomic steps meet and snap together in the grain boundaries generating continuously generating tensile stress in top of the grain boundary, see figure 3.7 .

The generation of compressive stresses have long been ascribed to the "atomic peening" mechanism suggested by D'Heurle [69], for example in sputter deposited low mobility metal films [70, 116-118]. According to the atomic peening mechanism energetic atoms and ions incident on the growing film cause shallow collision cascades that might cause extra atoms to get incorporated into the film [123]. Using appropriate deposition conditions Janssen et al. [124] deposited films with similar microstructures by sputter deposition with and without using a substrate bias to provide energetic bombardment of the growing film. They found that the stress evolutions in films followed the same curve but that the stress evolution of the film deposited under ion bombardment was shifted towards more compressive values. Using the $\sin ^{2} \psi$-method (see section 5.1.2) the they found that the lattice parameter of the compressive film was larger than what would be expected. This was interpreted in the light of a model where misfitting particles cause a lattice expansion which generate a triaxial stress field in the grains [125-127]. The shifted stress evolution and the $\sin ^{2} \psi$-results show that the mechanisms for tensile and compressive stress generation are independent of each other and additive. That is, it is possible to deposit films with zero net stress but high compressive stresses in the grains and highly tensile grain boundary regions.

Low energy bombardment of a growing film also drives surface diffusion and could therefore possibly lead to atom insertion into grain boundaries. The peen- 
ing induced stresses are for the most part larger and could mask the grain boundary contribution [128, 129]. Koutsokeras et al. [130] deconvoluted the different stress components in $\mathrm{ZrN}$ films deposited at different working pressure by measuring the total stress in the film by substrate curvature measurements and the stress in the grains by the $\sin ^{2} \psi$ method. They found that at a high working pressure, i.e. for low energies of the bombarding species, the grain boundary contribution was tensile while at a low working pressure the grain boundary contribution was compressive. In paper 1 we controlled the film density in Mo thin films using relatively low energy ion bombardment and found that under-dense films were in a tensile stress state while dense films were highly compressive. All films had a small lattice expansion that did not vary between the different samples pointing to that the film stress is generated by grain boundary densification in a similar way to what Chason $e t$ al. [24, 102, 103] suggested for high mobility materials. This was confirmed in paper 2 where we deposited dense Mo films with different grain sizes and found that the compressive stress magnitude was directly proportional to the grain boundary length per unit area.

The distinction between different stress generation mechanisms for high and low mobility materials is somewhat false. The question is what mechanism is dominating and for what deposition conditions. Point defect induced compressive stresses from atomic peening are unlikely to be large for film growth at high atom mobility (both surface and bulk) conditions as a majority of the defects will anneal out instead of being trapped in the lattice causing triaxial strain fields. Atom insertion into grain boundaries seem to be the dominating effect when it comes to compressive stress generation in the absence of point defect induced stresses and only requires a high enough atomic mobility on the film surface to facilitate insertion into the top of the grain boundary. A high mobility of grain boundary atoms is however required to activate out-diffusion from the grain boundaries leading to a stress relaxation. Changes in the adatom and step density on the surface can likely be ruled out as the dominating contributors to stress generation and relaxations but they can be the dominating sources of stress in where the other mechanisms are suppressed.

Impurity incorporation and its effects on the film stress has not been discussed here. Oxygen incorporation, either from intentionally introduced $\mathrm{O}_{2}$ or from residual $\mathrm{H}_{2} \mathrm{O}$, in growing films leads to grain refinement and impurity seg- 
regation in many materials [131] and should reduce the atomic mobility on the surface and in the grain boundaries affecting the stress state of continuous films as well as the stress relaxations. This has been observed for a number of materials $[115,132-134]$. 


\section{Deposition processes}

Thin films often are deposited by a number of physical vapor deposition (PVD) processes ${ }^{1}$. Most of these are performed in a vacuum, usually at background pressures between $\sim 10^{-12}-10^{-6}$ Torr (or $\sim 10^{-10}-10^{-4} \mathrm{~Pa}$ ) in order to minimize contamination of the growing film. Among the least complicated are various evaporation processes where resistive or electron beam heating is applied to the deposition material in order to make the material evaporate. The evaporated atoms are thermalized and have a kinetic energy of $0.025 \mathrm{eV}$. As mentioned in previous chapters this might be less than what is required to achieve desired film morphologies. The depositing species are more energetic, a few $\mathrm{eV}$ depending on the material, when generated by the plasma based sputtering process. In sputtering it is also simple to use a substrate bias to extract ions from the plasma to provide energetic bombardment of the growing film. Both evaporation and sputtering generate deposition fluxes predominantly consisting of atoms making them line-of-sight deposition methods where the directionality of the deposition flux cannot be controlled easily. A desire for larger levels of control of the energy and direction of the depositing species have driven the development of ionized PVD processes where the deposition flux is (partially) ionized. Examples of ionized PVD processes are pulsed laser deposition, arc evaporation and a variety of ionized sputtering processes. The common denominator for all these processes is that they utilize high density plasmas to ionize the depositing species either through applying high power densities to the materials source as in pulsed laser deposition, arc evaporation and high

\footnotetext{
${ }^{1}$ Chemical vapor deposition (CVD) processes where precursor gases react on the substrate surface to form a thin film are also common as are different kinds of plating where the film is deposited form a precursor molecules dissolved in a liquid.
} 
power impulse magnetron sputtering or by using secondary plasma discharges, for example RF-coils or microwave discharges, in conjunction with a sputtering source. For this thesis sputtering processes have been used, since they utilize plasmas some basic plasma physics be treated before sputter deposition.

\subsection{Basic plasma physics}

Plasma is called the forth state of matter (the others being solid, liquid and gas) and can be seen as gas consisting of neutral particles, ions and electrons that exhibit a collective behavior. There is an equal number of positively and negatively charged particles in a plasma making it quasi-neutral. A plasma can be produced by heating a gas to temperatures high enough for outer shell electrons to free themselves from the gas atoms creating free electrons and ions $[1,135]$. This form of a plasma is called a thermal or equilibrium plasma since the electrons, ions and neutral atoms all have the same temperature ${ }^{2}$. Thermal plasmas are impractical from a materials processing perspective as the temperatures needed to create the plasma are on the order of tens of thousands $\mathrm{K}$ which will damage of destroy the objects meant to be treated. In processing, such as thin film deposition, its therefore more common to use non-equilibrium plasmas where electrons are much more energetic than ions. These plasmas are usually sustained using powered electrodes to energize the electrons. The difference in ion and electron energies originates in the low ionized fraction of the gas, usually below $10 \%$, in these plasmas. Energetic ions are likely to collide with the thermal gas atoms loosing much of their kinetic energy in the process. The small number of ions, and therefore the small number of collisions, mean that the gas will not be heated to any large extent leaving the ion and gas temperature close to ambient temperature with the kinetic energy of the gas species being $0.025 \mathrm{eV}$. The electrons on the other hand are energetic with energies ranging from $1-10 \mathrm{eV}$ and sometimes more.

Because of their much lower mass electrons are more mobile than ions. For plasmas contained in a conducting vessel, such as a metallic vacuum chamber, this results in a net flux of electrons escaping the plasma volume to the chamber wall. The escaping electrons will result in a positive potential in the

\footnotetext{
${ }^{2}$ In plasma physics temperature is often used as a measure of the kinetic energy of particles. A kinetic energy of $1 \mathrm{eV}$ corresponds to a temperature of $11600 \mathrm{~K}$.
} 


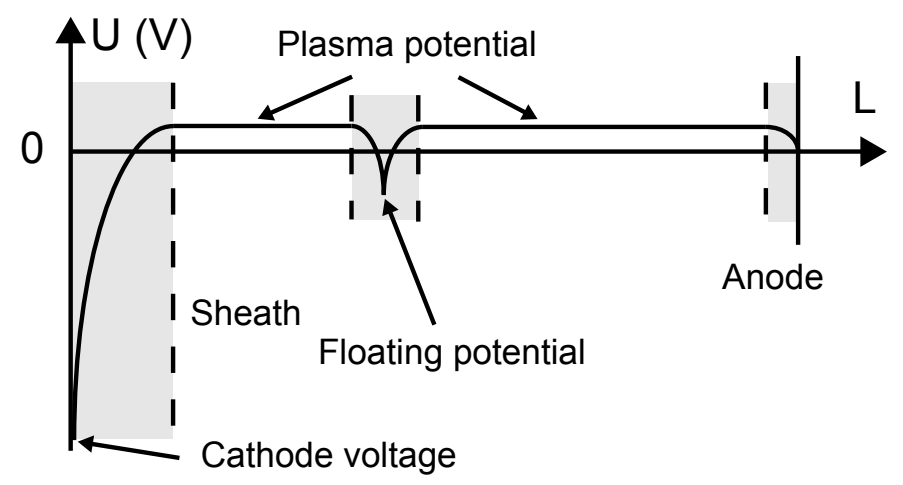

Figure 4.1: The potential profile in a plasma. The dashed lines mark the sheath edges.

plasma bulk making it more difficult for more electrons to escape the plasma. This potential, called the plasma potential, will increase until an equal number of electrons and ions escape the plasma maintaining the quasi-neutrality of the plasma. The plasma potential is usually a few volts above zero [136, 137], figure 4.1, resulting in an acceleration of the ions escaping the plasma towards the chamber walls to a kinetic energy of the same order. When an electrically floating object is inserted into the plasma it will be subjected to a net electron flux, again due to the electron mobility being larger than the ion mobility, leading to the buildup of negative charge on the object. This will continue until the electron and ion fluxes to the object reaches a balance and the potential of the object stabilizes at what is called the floating potential.

Thin regions called plasma sheaths where the full potential drop from the plasma potential to object potential takes place will develop around any object immersed in a plasma. Electrons generated in the sheets will be accelerated into the plasma by the electric fields across the sheaths. Electrons generated at the cathode in an electrically driven plasma are therefore accelerated to high energies (a cathode potential of a few hundred $\mathrm{V}$ is common). The high densities of gas atoms results in a high likelihood for collisions between electrons and gas atoms. Most of these collisions will be elastic with very little energy being transferred in the collision due to the large mass difference between atoms and electrons resulting in little more than changes in the electron trajectories due to scattering. Inelastic collisions between electrons and atoms might however result in direct ionization of atoms through the process

$$
e^{-}+A \rightarrow A^{+}+2 e^{-},
$$


known as electron impact ionization. Inelastic collisions also results in excitation of atoms

$$
e^{-}+A \rightarrow A^{*}+e^{-} .
$$

The excited species gives plasmas their characteristic glow when the excited electrons decay radiatively to lower energy states resulting in emission of light. Excited species can also take part in ionization by transferring their energy to another atom instead of emitting a photon

$$
A^{*}+B \rightarrow A+B^{+}
$$

in a process known as Penning ionization. Atoms can also be ionized in charge exchange collisions where an electron is transferred from an ion to an atom

$$
A^{+}+B \rightarrow A+B^{+} .
$$

The relative probabilities of these processes are dependent on the number density of the respective species, their energies and the energy required for ionization of an atom. The densities and energies of the species are in turn affected by gas pressure, gas composition and discharge conditions.

The plasma used in sputtering processes is usually generated by applying a negative voltage of a few hundred $\mathrm{V}$ to the target (cathode) in an inert gas, usually Ar, environment at a low pressure. Free electrons ${ }^{3}$ are then accelerated towards the anode, most often the chamber walls, by the electric field between the cathode and the anode. If the gas pressure is high enough the electrons will experience ionizing collisions with gas atoms generating more free electrons. This will lead to an avalanching number of ionizing collisions and the creation of a sustained plasma if the number of electrons produced by ionizing collisions is equal to or larger than the number of electrons lost to the anode.The ions will be accelerated towards the target by the electric field causing sputtering and secondary electron emission. Secondary electrons are emitted in an Auger-like process when an incoming ion is neutralized close to the surface an electron tunneling from the surface. The neutralization results in a release of energy that most often is emitted as a photon but that in some cases the energy is instead transferred to another electron providing it with enough energy to escape the surface be accelerated across the sheath and helping to sustain the plasma.

\footnotetext{
${ }^{3}$ There are always some free electrons in a gas, usually generated by ionizing collisions with for example cosmic rays.
} 


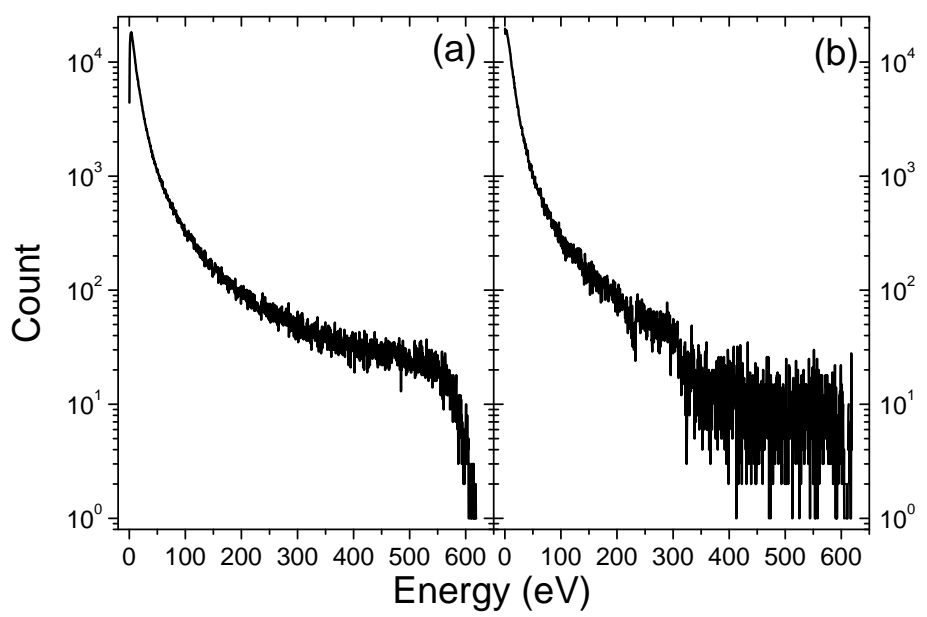

Figure 4.2: The energy distribution of Mo atoms sputtered by Ar with an energy of $774 \mathrm{eV} \mathrm{(a)}$ at the target and (b) after transport for $7.5 \mathrm{~cm}$ at a pressure of 1.25 mTorr as simulated by the TRIM code [138] and SIMTRA [139].

\subsection{Magnetron sputtering}

Sputtering is the ejection of atoms from a material source, or target, after the impact of an energetic atom or ion. These ions are often extracted from a plasma in front of the target. The ions will be neutralized just above the surface and collide with the target transferring some of its momentum to atoms in the target generating collisions cascades. Some of the momentum in the collision cascades will be directed towards the surface and can result in the ejection of an atom if the kinetic energy transferred to the atom is larger than the surface binding energy of the target material. Two advantages of sputtering compared to evaporation is that any material can be sputtered and that sputtering provides a hyperthermal deposition flux. Sputtered atoms initially have broad energy distribution with the most probable energy close to half the surface binding energy of the material [140], a few eV for most metals, with a long tail that can be several hundred $\mathrm{eV}$ as can be seen in figure 4.2. Sputtered atoms will be slowed down by collisions during the gas transport and can be thermalized if the working pressure or the distance to the substrate is high enough. The energetic gas atoms used for sputtering can, if the atomic mass of the target is high, be backscattered from the target. The energy of the backscattered species can be several hundred eV, see figure 4.3. 


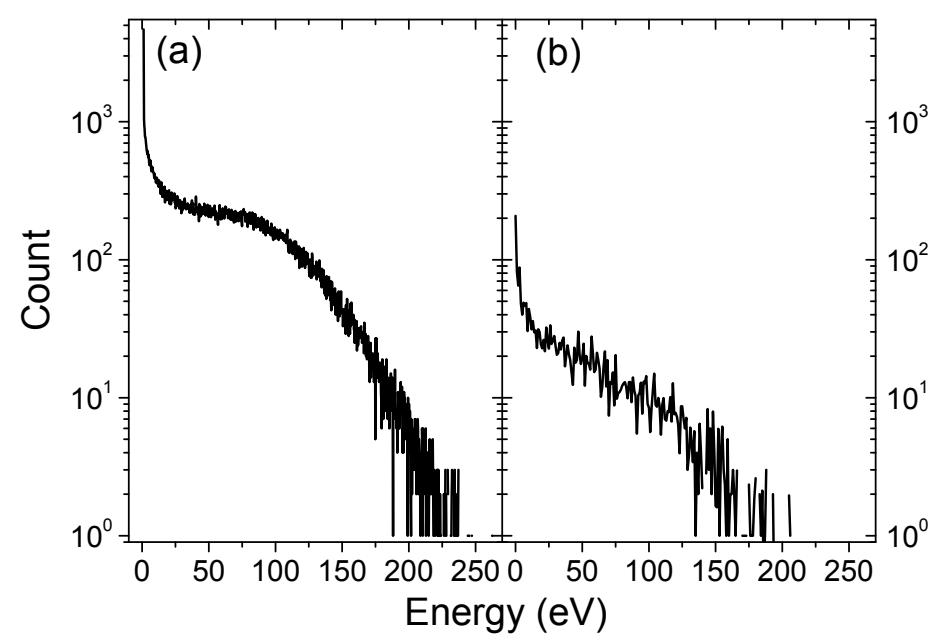

Figure 4.3: The energy distributions of Ar atoms with an incidence energy of $552 \mathrm{eV}$ backscattered from an Mo target (a) at the target and (b) at a position $19 \mathrm{~cm}$ from the target at a pressure of 1.25 mTorr as simulated by the TRIM code [138] and the OMEGA code [141].

In early sputter deposition systems pressures on the order of 100 mTorr and voltages of several $\mathrm{kV}$ were needed to provide enough ionization events to sustain the plasma [1]. At these pressures the mean free path for collision for a sputtered atom is below $1 \mathrm{~mm}$ on resulting in thermalization of the sputtered species well before they impinge on the substrate which is often undesirable from a film growth point of view. Desirable working pressures are usually 1-20 mTorr. A way of increasing the number of ionization events at low pressures is to increase the path travelled by electrons before they reach the chamber walls. This can be done by confining the electrons in a magnetic field. Electrons with a velocity, $v$, in an electric field, $E$, and a magnetic field, $B$, will experience a Lorentz force,

$$
\bar{F}=q(\bar{E}+\bar{v} \times \bar{B})
$$

Sputtering magnetrons make use of this by trapping electrons in a magnetic field trap consisting of two concentric magnets of opposite polarity that are placed behind the target. A doughnut shaped magnetic field trap is then formed in front of the target, figure 4.4. The electric and magnetic fields will be parallel close to the target surface forcing secondary electrons emitted in a direction that is not parallel to the electric and magnetic fields to move in a gyrating motion along the magnetic field lines effectively trapping the electrons within the 

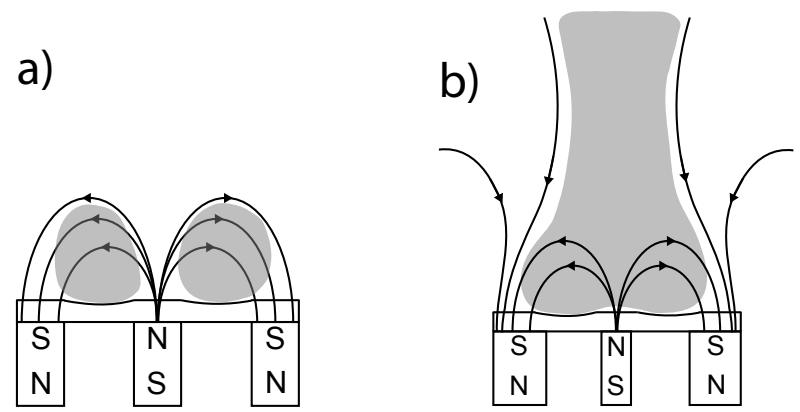

Figure 4.4: Two magnetron configurations: a) balanced magnetron and b) unbalanced magnetron. They grey regions show the regions the most intense plasma.

magnetic field trap. The magnetic field strength is chosen so that the electron gyration radius in on the order of millimeters while still not affecting the motion of ions to a large extent. Usage of a magnetron drastically increases the path travelled by electrons thus increasing the number ion ionizing collisions for each electron. The operating pressure for the discharges can then be reduced to below one mTorr, with common working pressures being 1-20 mTorr. If the field strength of the inner and the outer magnets is equal most electrons will be trapped confining the plasma close to the cathode as illustrated in figure 4.4 a). Some plasma in the vicinity of the substrate is usually desired to provide large ion fluxes to the substrate for energetic bombardment of the growing film. The magnetic trap can be made to leak electrons and thus extend the plasma towards the substrate by using different magnetic field strengths on the inner and outer magnets. If the inner magnet is stronger than the outer magnet the trap will leak electrons sideways. If instead the outer magnet is stronger electrons will leak forwards and extend the plasma towards the substrate as is shown in figure $4.4 \mathrm{~b}$ ) [142, 143].

Although energetic bombardment using working gas ions is an effective way to modify growing films it is sometimes desirable to have an ionized deposition flux. This partly alleviates the line of sight character of the neutral dominated deposition flux of magnetron sputtering to some extent allowing for deposition of uniform films on non-flat substrates as ionized species are steered by the electric fields in the plasma sheets to impinge at angles more close to the substrate normal [144, 145].

The dominating ionization mechanism in magnetron sputtering discharges is Penning ionization due to the low plasma density $\left(10^{16} \mathrm{~m}^{-3}\right)$ [135]. The low 


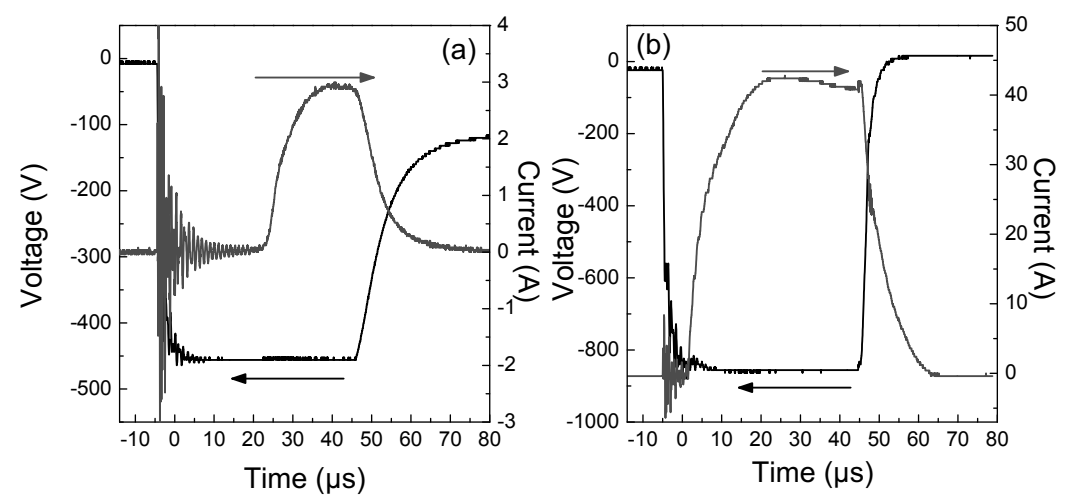

Figure 4.5: Exemples of HiPIMS pulses during sputtering of Ag at (a) low pulse power and (b) high pulse power.

probability of collision between an excited gas atom and a sputtered atom results in a low degree of ionization of the sputtered material. A more efficient way of ionizing the sputtered material is by electron impact ionization which is promoted by increasing the plasma density and/or the electron temperature. The desire to ionize the sputtered atoms has lead to the development of a number of modified magnetron sputtering methods where the magnetron discharge is complemented by an additional plasma source such as an RF-coil or a microwave cavity [146] used to enhance the ionization of the sputtered material.

\subsection{High Power Impulse Magnetron Sputtering}

Another way of realizing an ionized deposition flux is to apply a very high power to the target in a normal sputtering discharge to increase the plasma density. The high heat load in the target quickly makes continuous process impossible. If instead the power is applied in short pulses with a low duty cycle it is possible to keep the average power at the same level as for a continuos discharge while applying power several orders of magnitude higher in the pulses. Two examples of HiPIMS pulses can be seen in figure 4.5. In high power impulse magnetron sputtering (HiPIMS) discharges the pulse on-time is usually 10-500 $\mu$ s with a pulsing frequency between $10 \mathrm{~Hz}$ and $10 \mathrm{kHz}$ with peak powers up to tens of $\mathrm{kW} / \mathrm{cm}^{2}$ [146-149]. The high power densities result in plasma densities plasma densities up to $10^{19} \mathrm{~m}^{-3}[150,151]$ and ionized fractions of the sputtered material of up to $90 \%$ for some materials [152]. Both singly and dou- 


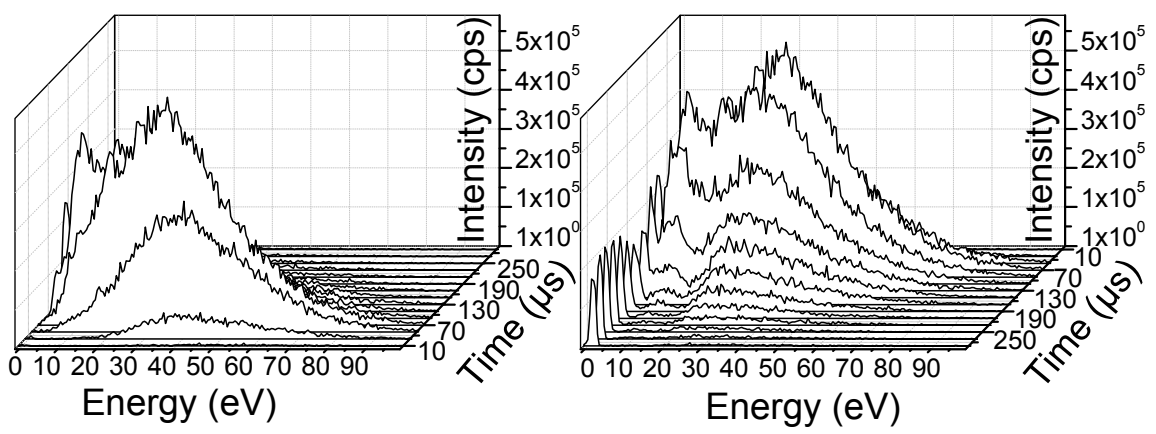

Figure 4.6: A time-resolved measurement of the ion energy distribution function of $\mathrm{Mo}^{+}$in a HiPIMS discharge at a working pressure of $1.25 \mathrm{mTorr}$.

bly charged metals ions are usually observed but metal ions with higher charge states can be generated for some discharge conditions [153].

The ionized sputtered species are more energetic than sputtered neutrals exhibiting a broad energy distribution with a tail extending out to $\sim 100 \mathrm{eV}$. The sputtered ion population consist of two subpopulations that can be resolved in time-resolved ion mass spectrometry measurements, figure 4.6. A large population of ions having a wide energy distribution centered around $\sim 40 \mathrm{eV}$ with a high energy tail arriving to the spectrometer approximately $30 \mu$ s after the pulse and a nearly thermalized population declining with time arriving after the energetic species. This translates to a pulsed deposition flux as have been shown by Mitschker and co-workers [154-156].

The highly ionized deposition flux also causes the main disadvantage of HiPIMS compared to ordinary magnetron sputtering. If the sputtered species are ionized close to the target only the most energetic ions will be able to escape the potential well of the plasma sheath, other ions will be attracted back to the target and take part in the sputtering process. The self-sputter yield of metals is usually lower than the sputter yield resulting in deposition rate losses of varying severity, losses of a few percent up to $70 \%$ compared to continuous magnetron sputtering have been recorded depending on target material and HiPIMS parameters [146-149, 157].

The prevalence of multiply charged energetic metal ions can result in bombardment induced growth defects affecting the physical properties of the film. These effects can be especially severe if a negative bias voltage is applied to the sub- 
strate as the multiply charged ions are accelerated to an energy corresponding to their charge time any potential drop they experience [158]. The effects of highly ionized and energetic deposition fluxes on growing films have been investigated for a number of material systems. Films deposited by HiPIMS generally have a dense microstructure and smooth surfaces even when deposited without intentional substrate heating $[60,159,160]$. This is connected to the intrinsic energetic bombardment in the process and could be the result of the mechanism for driving atom diffusion into the grain boundaries we suggest in paper 1. If the flux and energy of the bombarding species are large enough they might cause renucleation and a nano crystalline film morphology [60]. Energetic bombardment is also important for phase formation in metallic and ceramic films where high temperature phases such as $\alpha$-Ta [161], anatase and/or rutile $\mathrm{TiO}_{2}[162,163]$ and $\alpha-\mathrm{Al}_{2} \mathrm{O}_{3}[164,165]$ can be formed at comparatively low temperatures when the impinging ion energy and flux have been tuned by varying the pulse parameters of the HiPIMS discharge. 


\section{Thin film characterization}

The structural and mechanical properties of thin films are probed by a large variety of characterization methods. This chapter introduces the methods used for the thesis.

\subsection{X-ray diffractometry}

X-ray diffractometry (XRD) is one of the most useful characterization methods as it can provide a great deal of information about the film without requiring much sample preparation [166]. The method relies on interference between collimated $x$-rays reflected in the atomic planes of the sample. Constructive interference will occur when the Bragg criterion,

$$
2 d \sin (\theta)=n \lambda
$$

is fulfilled. Here $d$ is the spacing between the atomic planes in the crystal, $\lambda$ is the wavelength of the X-rays, $\theta$ the scattering angle and $n$ an integer. That is, constructive interference will occur when the path difference for X-rays reflected in parallel atomic planes is a whole number of wavelengths, figure 5.1. Measuring the reflected intensity from a sample as a function of the scattering angle gives rise to a peaks in the diffraction pattern corresponding to the lattice spacings of the atomic planes fulfilling the Bragg criterion at that scattering angle. XRD can be used to evaluate the orientation of the crystallites in a sample and the crystalline quality. It can also be used to determine the film thickness, crystallite sizes and in some cases the chemical composition of the sample.

XRD line scans are most often performed in two different geometries. The $\theta-2 \theta$-scan where the incidence angle $\theta$ and the scattering angle $2 \theta$ are scanned 


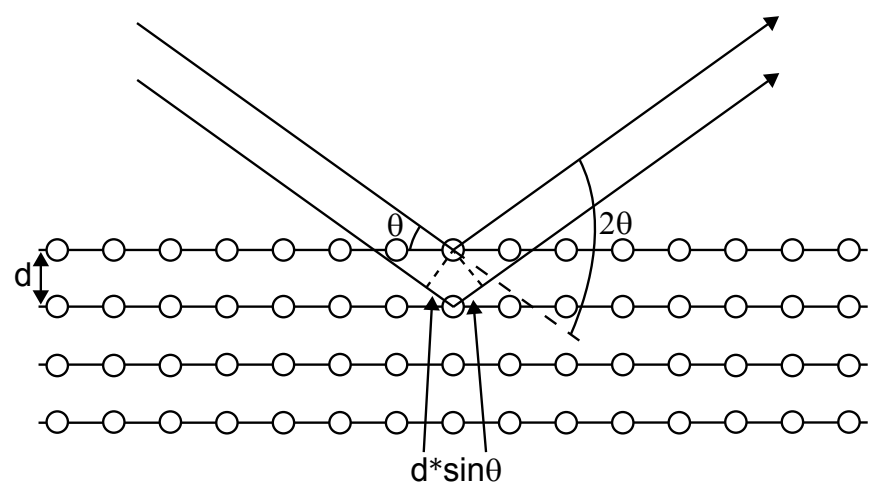

Figure 5.1: The geometry of Bragg diffraction. The path difference between two waves reflected of different atomic planes, $2 d \sin (\theta)$, need to be an whole number of wavelengths for constructive interference to occur.

synchronously. In this mode scattering only takes place in lattice planes parallel to the sample surface. By comparing the peak intensities from different diffraction peaks in $\theta-2 \theta$-scans it is possible to approximate the degree of preferred orientation in the sample. In the grazing incidence geometry the incidence angle is kept constant at a small angle (usually below $5^{\circ}$ ) while the scattering angle is varied. The small incidence angle results in more scattered intensity from the film. However, due to the geometry scattering takes place in lattice planes tilted at different angles with respect to the surface for all scattering angles. The results can therefore not be used to gauge the degree of preferred orientation and might miss peaks entirely if the film crystallites are highly aligned.

Changes in the lattice spacing will manifest as shifts of the diffraction peak compared to the unstrained peak position, if the lattice expands or contracts equally everywhere in the film, or peak broadening, if there is a distribution of lattice spacings. In-plane film stress, intrinsic or extrinsic, results in an outof-plane expansion or contraction of the lattice and thus shifts the diffraction peak position. The out-of-plane lattice expansion, or contraction, is related to the film stress according to,

$$
\frac{d}{d_{0}}=\left(1-\frac{v \times \sigma}{E}\right),
$$

where $d$ is the lattice parameter, $d_{0}$ is the stress free lattice parameter, $v$ is the Poisson ratio of the material, $\sigma$ is the film stress and $E$ is the elastic modulus of the material. 


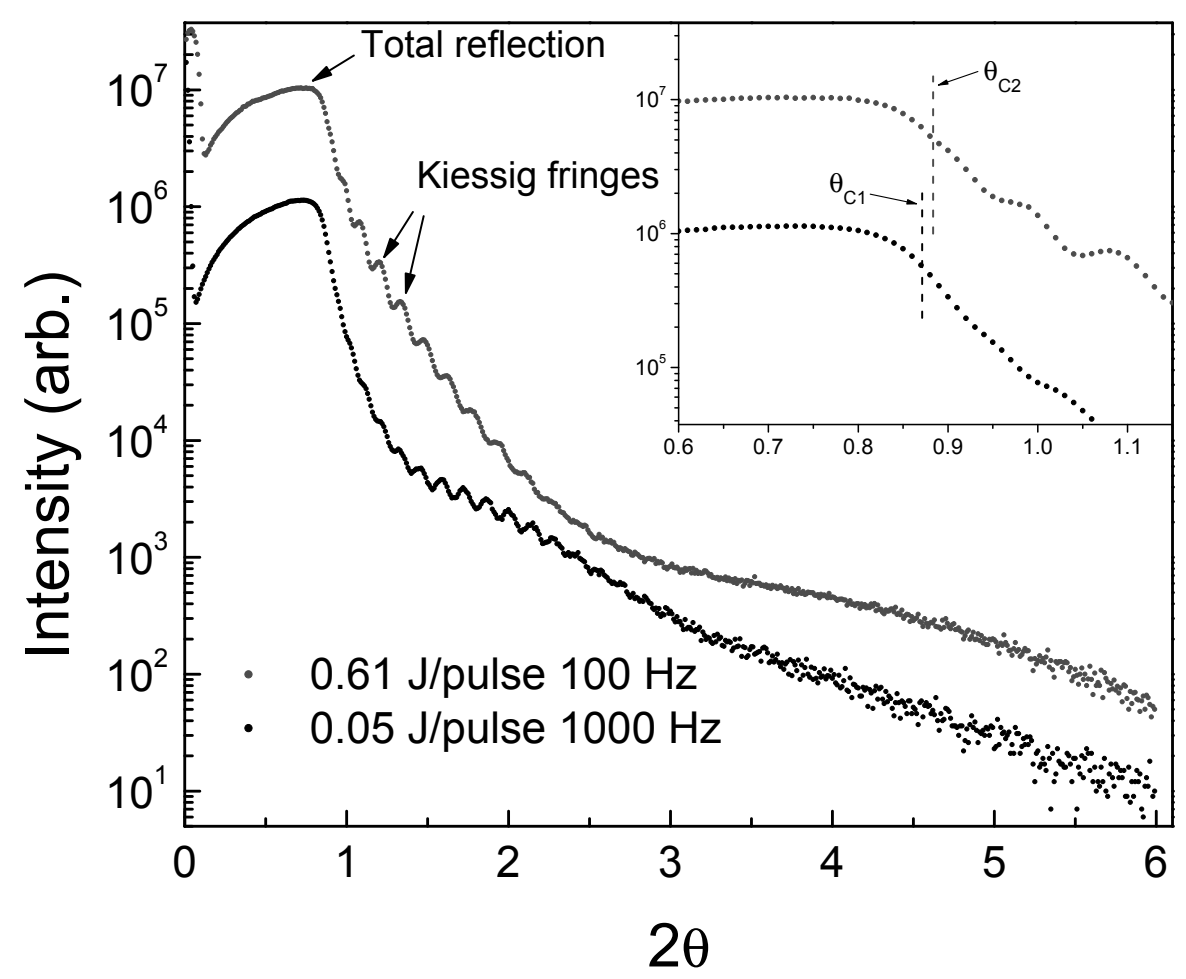

Figure 5.2: X-ray reflectivity measurements for two Mo samples deposited by HiPIMS using different pulse parameters. The separation of the Kiessig fringes show that the film thickness of the samples is approximately the same while the critical angles and curve shapes show that the roughness and densities differ between the samples.

\subsubsection{X-ray reflectometry}

X-ray are also reflected from interfaces in the material, for example the filmsubstrate interface and the film-air interface, and will for small enough angles interfere with $\mathrm{X}$-rays reflected from other interfaces in the sample if the path difference is a whole number of wavelengths. At small angles, $2 \theta \lesssim 1^{\circ}$ depending on the material, total external reflection occurs, see figure 5.2. The angle where $X$-rays can penetrate into the material is proportional to the electron density in the material which in turn is proportional to the mass density. Interference fringes, known as Kiessig fringes, can be seen at angles larger than the critical angle. The distance between the Kiessig fringes can be used to determine the film thickness. The distance between the Kiessig fringes is inversely propor- 


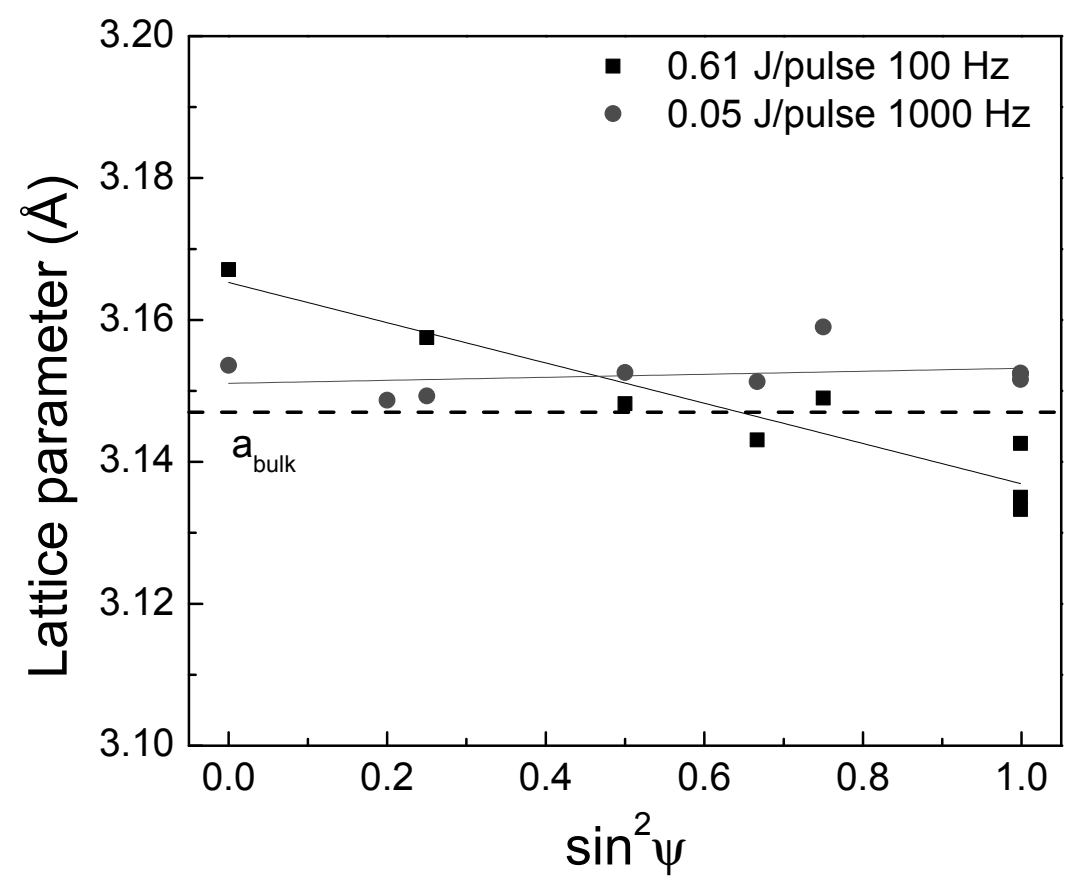

Figure 5.3: The results of $\sin ^{2} \psi$-measurements for Mo films deposited by HiPIMS with different pulse parameters. One film (squares) is in a compressive stress state while the other (circles) is nearly stress free. Note that the data for the nearly stress free film is larger than the stress free lattice parameter, $a_{b u l k}$, indicating a lattice expansion and the presence of defects in the film.

tional to the film thickness thereby limiting the maximum thickness that can be measured to what can be resolved by the X-ray optics. The dampening of the measured reflectivity is can be used to determine the surface and interface roughness of a film.

The thickness, roughness and density of films are usually determined by fitting the measured reflectivity curve to a model taking high order reflections, absorption, X-ray refractive indices of the layers and so on into account. XRR have been used extensively in this work both as a fast method for measuring the film thickness for deposition rate calibration purposes by also to determine the surface roughness and the film density. 


\subsubsection{The $\sin ^{2} \psi$-method}

Determination of film stresses from diffraction peak shifts is a method limited to equibiaxial in-plane stresses in defect free isotropic materials, in other cases peak shift analysis will be erroneous. A more robust method is the $\sin ^{2} \psi$ method where the lattice parameter for a certain diffraction peak is measured for different sample tilts. When in-plane compressive (tensile) stresses are present in the sample the lattice parameter for planes parallel to the surface will be expanded (contracted) compared to the equilibrium lattice parameter while the lattice parameter for planes perpendicular to the surface will be contracted (expanded). The average strain in the crystallites relates to the tilt angle, $\psi$, and the stress, $\sigma$, according to

$$
\frac{d_{\psi}-d_{0}}{d_{0}}=\frac{1+v}{E} \sin ^{2} \psi-2 \frac{v}{E} \sigma
$$

for biaxial film stresses. Here $d_{\psi}$ is the lattice parameter at tilt angle $\psi$ and $d_{0}$ is the stress free lattice parameter. Plotting the measured lattice parameter $d_{\psi}$ versus $\sin ^{2} \psi$ will according to equation 5.1.3 give a straight line where the slope of the line is related to the film stress and elastic properties, figure 5.3. When the $\sin ^{2} \psi$-method is used to determine stresses in elastically anisotropic materials equation 5.1 .3 need to be modified to take the anisotropy into account. This is done by introducing X-ray elastic constants, $\mathbf{S}_{1}$ and $\frac{1}{2} \mathbf{S}_{2}$, instead of the $-\frac{v}{E}$ and $\frac{1+v}{E}$ respectively. The $X$-ray elastic constants are tensor quantities that take the directionality of the elastic properties into account. The stress free direction, $\sin ^{2} \psi *$, in the crystal can be determined from the X-ray elastic constants according to

$$
\sin ^{2} \psi *=\sqrt{\frac{-2 \mathbf{S}_{1}}{\frac{1}{2} \mathbf{S}_{2}}} .
$$

The stress free lattice parameter, $d_{0}$, can then be determined from the $\sin ^{2} \psi$-plot. Film stress does not necessarily have to be biaxial. Growth induced point defects can give rise to a hydrostatic stress resulting in a triaxial lattice expansion and a triaxial stress state (see section 3.2.3). This is seen as a vertical shift of measured of the data $\sin ^{2} \psi$ to larger values [124]. The value $d_{0}$ determined from the $\sin ^{2} \psi$-measurements is therefore not necessarily the actual stress free lattice parameter but rather the stress free but defected lattice parameter [167, 168]. If the proper stress free lattice parameter is to be calculated a triaxial stress model must be used [125-127, 167]. Even though a biaxial stress model results in an 
Table 5.1: The lattice planes of Mo and their corresponding values for $\psi, \phi$ and $2 \theta$ in the (110) stereographic projection used for stress determination using the $\sin ^{2} \psi$ method. Note that the reflections measured at $\psi=88^{\circ}$ in reality are present at $\psi=90^{\circ}$ in the stereographic projection, $\psi=88^{\circ}$ has to be used due to instrumental limitations.

\begin{tabular}{cccc}
\hline Plane & $\psi\left({ }^{\circ}\right)$ & $\phi\left(^{\circ}\right)$ & $2 \theta\left(^{\circ}\right)$ \\
\hline \hline$(110)$ & 0 & - & 40.516 \\
$(310)$ & 26.57 & 0 & 101.410 \\
$(121)$ & 30 & 54.74 & 73.684 \\
$(020)$ & 45 & 0 & 58.609 \\
$(112)$ & 54.74 & 90 & 73.684 \\
$(011)$ & 60 & 54.74 & 40.516 \\
$(2 \overline{2} 2)$ & 88 & 54.74 & 115.964 \\
$(\overline{1} 12)$ & 88 & 54.74 & 73.684 \\
$(002)$ & 88 & 90 & 58.609 \\
\hline
\end{tabular}

incorrect determination of the stress free lattice parameter of the film is under triaxial stress both results in the same measured stress.

The $\sin ^{2} \psi$-method has been used for determining the stress in (110) oriented Mo films in this work. (110) oriented Mo has a small elastic anisotropy requiring modification of equation 5.1 .3 to

$$
\frac{d_{\psi, \phi}-d_{0}}{d_{0}}=\sigma\left(2 s_{12}+\frac{J}{2}+\left(\frac{s_{44}}{2}+\frac{J}{2} \sin ^{2} \phi\right)\right),
$$

where $J=s_{11}+s_{22}+s_{44} / 2$ is an anisotropy factor and $s_{i j}$ are components of the compliance tensor [169]. Because of the preferential orientation of the films it is impossible to do measurements where the same Bragg reflection is measured for a number of sample tilts to determine the lattice parameter. Instead the crystallite group method $[62,170]$ has been used. In the crystallite group method the sample is assumed to be a single crystal and the lattice parameter is determined by measuring the plane spacing of different crystal planes at their corresponding tilt angles, a method that works well for samples with a high degree of preferred orientation [127]. The stress is thereby measured in a subset of grains with the same orientation in polycrystalline materials and assumed to be the same in all grains due to grain interactions [127].

The crystallite group method has been used to determine the average film stresses and the stress free lattice parameters in Mo films with a (110) preferred orienta- 


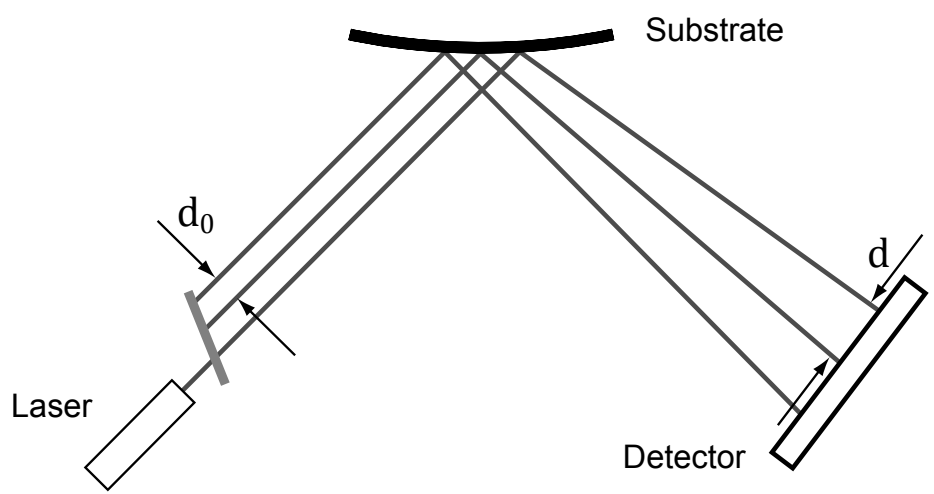

Figure 5.4: Schematic of a multi beam optical stress setup. A laser beam is passed through an etalon (or two) creating a parallel array of beams projected onto the sample. The distance between the reflected beams is recorded by a CCD-camera.

tion in paper 1 and 2. The measured lattice planes and their corresponding $\psi$, $\psi$ and $2 \theta$ angles in the (110) stereographic projection for bcc Mo are shown in table 5.1 with typical results shown in figure 5.3. The stress free lattice parameter was generally very slightly expanded compared to the lattice parameter of bulk Mo implying that the films were in a mainly biaxial stress state with a small triaxial stress component.

\subsection{Stress measurements by substrate curvature}

A stressed thin film wants to expand or contract but is constrained by the substrate, as a consequence the film exerts a force on the substrate causing it to bend. How much the substrate bends depends on the elastic properties of the substrate, the substrate thickness and the force per unit width that the film exerts on the substrate. The original equation relating the film force per unit width to the substrate curvature was derived by Stoney [63] and has then been developed further, see e.g. [171]. The Stoney equation is

$$
\frac{F}{w}=\frac{M_{s} t_{s}^{2} \kappa}{6},
$$

where $F / w$ is the film force per unit width, $M_{S}$ is the biaxial modulus of the substrate, $t_{s}$ is the thickness of the substrate and the substrate curvature is the 
inverse of the radius of curvature of the substrate, $\kappa=1 / R_{c}$. The Stoney equation is valid under a number of assumptions [172]:

- The film and substrate thicknesses are much smaller than their lateral dimensions.

- The film is much thinner than the substrate.

- The substrate material is homogeneous and isotropic and the film material is isotropic.

- There is no stress in the out-of-plane direction of the film.

- Linear elasticity applies.

- The strain and the curvature is small.

A common problem for films with large stresses (several GPa) deposited on thin substrates is that the substrate curvature is not small. The Stoney equation no longer holds as the substrate curvature has a non-linear dependence on the film force.

The film force per unit width is related to the film stress in the film by

$$
\frac{F}{w}=\int_{0}^{t_{f}} \sigma(z) d z=\sigma_{\text {avg }} t_{f}
$$

where $t_{f}$ is the film thickness, $\sigma(z)$ is the film stress at height $z$ and $\sigma_{\text {avg }}$ is the average stress in the film, if the stress is not constant over the film thickness [171]. As equation 5.2.1 shows the film stress can be determined without a priori knowledge of the elastic properties of the film material.

The curvature of a substrate can be measured in situ by a number of methods such as capacitance measurements [173] and optical techniques such as laser scanning [174], two beam methods [175] and the multi beam optical stress sensor (MOSS) [176]. MOSS setups have been used for in situ stress measurements in this work. The working principle of the MOSS setup, shown schematically in figure 5.4, is that an array (either a line or a two dimensional grid) of parallel laser beams with the spacing $d_{0}$ are reflected off the substrate and recorded on a CCD camera with a spacing $d$. A curved substrate will make the beams converge or diverge depending on whether the substrate has a positive or negative curvature. The curvature of the substrate can be calculated from

$$
\kappa=\frac{1}{R_{c}}=\frac{d-d_{0}}{d_{0}}\left(\frac{\cos \alpha}{2 L}\right),
$$




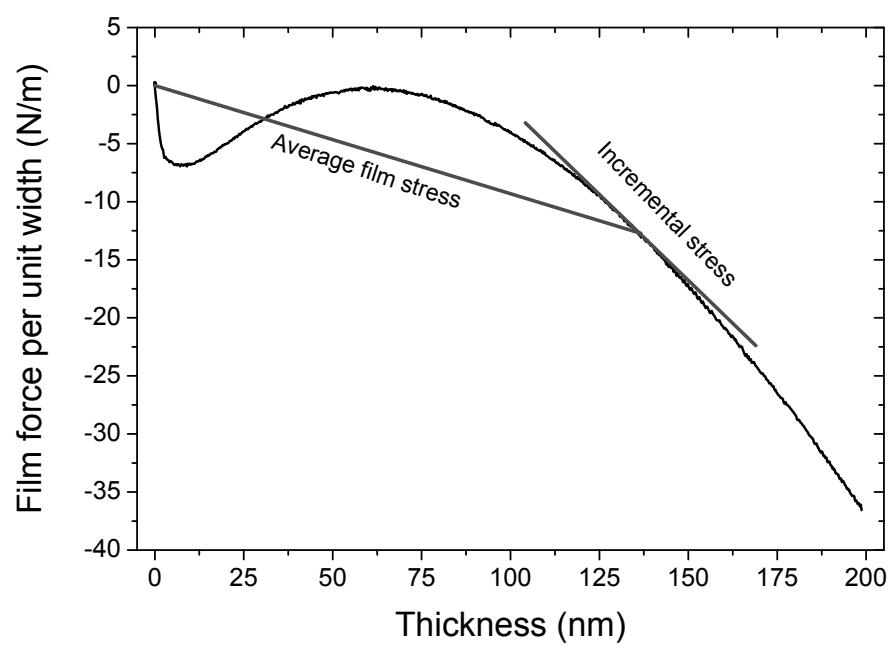

Figure 5.5: The evolution of the film force per unit width in a Mo layer deposited on a $\mathrm{Mo}_{1-x} \mathrm{Si}_{x}$ seed layer. The average film stress up to any thickness can be obtained by dividing the film force by the film thickness while the incremental stress can be determined by calculating the slope of the curve.

for a line of spots parallel to the laser beams and

$$
\kappa=\frac{d-d_{0}}{d_{0}}\left(\frac{1}{2 L \cos \alpha}\right),
$$

for a line of spots perpendicular to the laser beams. $L$ is the distance between the substrate and the CCD and $\alpha$ is the incidence angle of the laser beams. The measured curvature is then plugged into the Stoney equation (Eq. 5.2.1) to calculate the film force per unit width.

The MOss and the other curvature measurement techniques are easily adaptable for in situ measurements. The only requirements on the deposition chamber is that the substrate should be free to bend and that there is a free optical path between the laser, the substrate and the CCD. In situ measurements the generally performed without knowledge of the spacing of the beams incident on the substrate. Instead the initial spot spacing on the CCD is used as $d_{0}$ and all subsequent measurements are performed relative to this initial spacing. The curvature evolution is then recorded as a function of time. The thickness evolution of the film force per unit width (or stress-thickness product), figure 5.5, can then easily be obtained if the deposition rate is known. From such a plot the average film stress up to any point in the film can determined by dividing the stress thickness product by the film thickness. The instantaneous stress, that is 


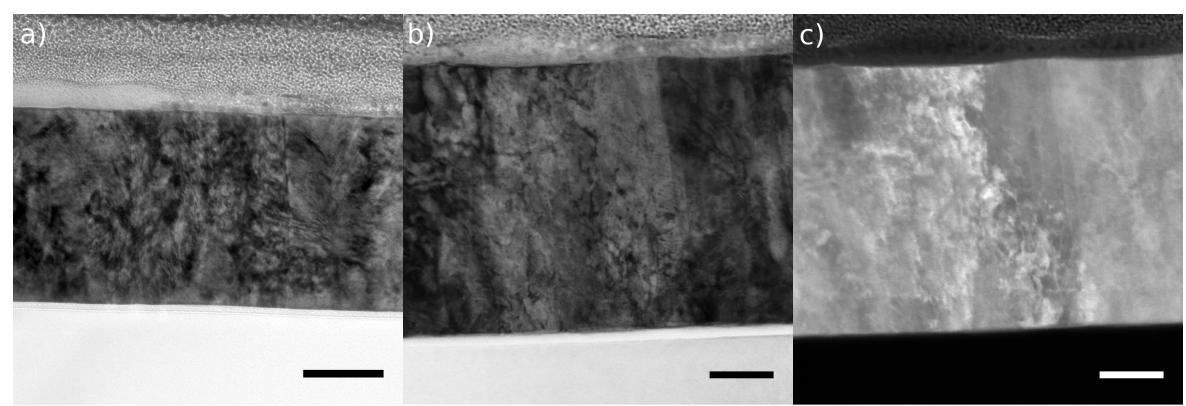

Figure 5.6: a) Bright field TEM image of an $\mathrm{Mo} / \mathrm{Mo}_{1-x} \mathrm{Si}_{x} / \mathrm{a}-\mathrm{Si}$ layer stack film deposited on Si. The scale bar is $100 \mathrm{~nm}$. b) BF-STEM image of the same sample, but not the same area as a). The a-Si layer is visible as a white band in the image. The scale bar is $50 \mathrm{~nm}$. c) HAADF-STEM image of the same area as b), the $\mathrm{Mo}_{1-x} \mathrm{Si}_{x}$ layer is visible as a slightly darker band in the bottom of the film due to the mass difference from Mo.

the stress in an infinitesimally thin layer, at any film thickness can be found by calculating the slope of the stress-thickness curve.

\subsection{Transmission electron microscopy}

Transmission electron microscopy (TEM) builds on that electrons accelerated to high energies (often between 100 and $300 \mathrm{keV}$ ) have short wavelengths ( a few picometers). Several orders of magnitude shorter than that of light increasing the resolving power of electron microscopes by several orders of magnitude compared to light microscopes. In transmission electron microscopy a parallel, coherent beam of electrons shaped by electromagnetic lenses is passed through a thin sample. The electron beam interacts with the sample material through scattering, absorption and diffraction and then focused onto a view screen or a CCD camera to form an image. Diffraction contrast is the result of Bragg diffraction in the crystal lattice and is affected both by the orientation of the sample as well as by local variations in the crystal lattice from e.g. defects. Regions that diffract much appear dark in bright field TEM. Regions of different thickness or with different atomic mass result in varying degrees of scattering and absorption with regions of high atomic mass or thickness appearing dark in the image [177]. The resulting image contrast is the combination of diffraction and mass-thickness contrast. The diffracted beams can be used to form a diffraction pattern making it possible to determine the crystal structure and orientation in 
regions of the sample. The short wavelength of the electrons provides a high enough resolution to resolve individual lattice planes and sometimes individual atoms in the crystal.

Thin samples requiring extensive sample preparation are needed for TEM. A sample thickness below $100 \mathrm{~nm}$ is sufficient but as thin samples as possible are desired. Sample preparation often requires a bit of trial and error before a good quality sample can be achieved. We found that focused ion beam milling produced samples with a more uniform thickness allowing for imaging of larger areas than traditional method of mechanical polishing and ion milling. Care needs to be taken during sample preparation as it is often quite destructive and can result in changes of the sample structure or induce artifacts in the sample.

\subsubsection{Scanning transmission electron microscopy}

The working principle of scanning transmission electron microscopy (STEM) is quite different from TEM instead of having a broad parallel beam incident on the sample the electron beam is focused to a point and rastered across the sample. Images are formed by recording the electron beam intensity at each point of the image with bright field (BF) and high angle annular dark field (HAADF) detectors. The BF detector record the transmitted beam intensity while the HAADF detectors detect electrons scattered at different angles. The contrast in HAADF images is dominated by mass-thickness contrast and is therefore ideal to probe for density changes in a sample.

\subsection{Atomic force microscopy}

Atomic force microscopy ARM is one of many scanning probe microscopy techniques and is used image the surface topography of samples. The working principle is that a sharp tip is rastered across the surface while the vertical position of the is monitored as it tracks the surface profile. The result is a height map of the surface as shown in figure 5.7. The tip is located at the end of a thin cantilever mounted on a piezoelectric scanner able to scan the tip laterally and vertically.

Atomic force microscopy has three main modes of operation, contact mode, tapping mode and non-contact mode. In contact mode the tip is put in contact 


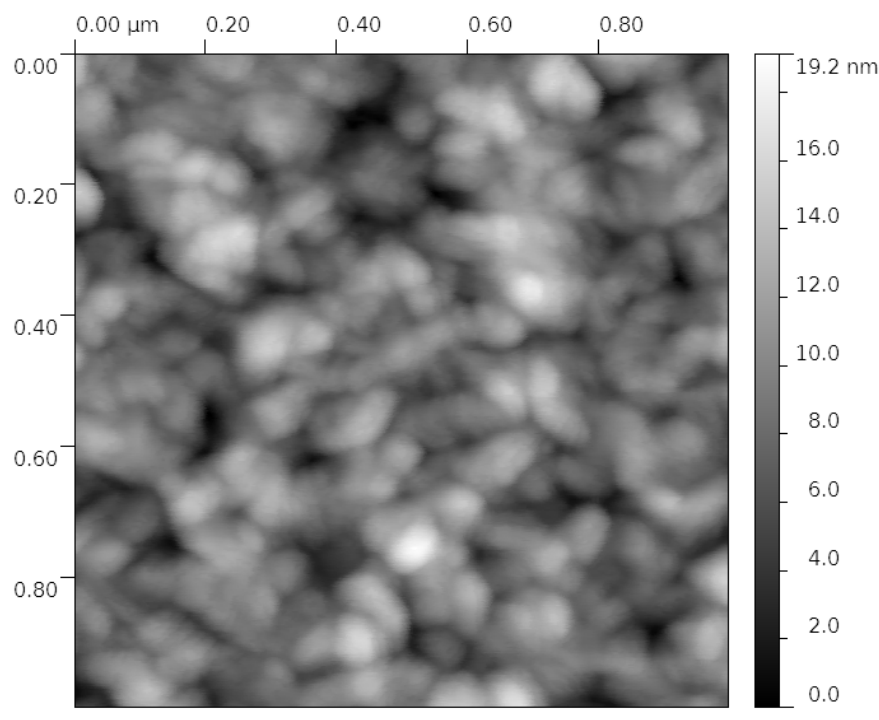

Figure 5.7: Atomic force microscopy image of the surface of a $150 \mathrm{~nm}$ thick Mo film.

with the surface and dragged across it while the deflection of the cantilever is monitored and kept constant. Contact mode AFM can result in damage of the tip and/or the surface resulting in erroneous measurements of the surface topography. Tapping mode AFM, also known as intermittent contact mode AFM, is gentler on the top and the sample than the contact mode. Here the cantilever is made to oscillate at or near its resonance frequency with a constant amplitude. Height information is gained using the oscillation amplitude as a regulation parameter. The tip is lowered towards the surface until the oscillation amplitude decreases due to the tip coming in contact with the surface. The height is then kept constant by the the regulation as the tip is scanned across the surface. Non-contact AFM also utilizes an oscillating cantilever and amplitude regulation. Here however the tip is oscillating close to but not touching the surface. The distance between the tip and the sample is small enough for the tip to interact with the sample through attractive Van der Waals-forces causing amplitude shifts when the cantilever height above the surface changes.

Surfaces exposed to atmosphere have a thin adsorbed layer of liquids. Contact mode and tapping mode AFM penetrates this layer allowing for higher resolution imaging than non-contact mode AFM under atmospheric conditions. The tip shape also affects imaging and can results in artifacts. This needs to be 


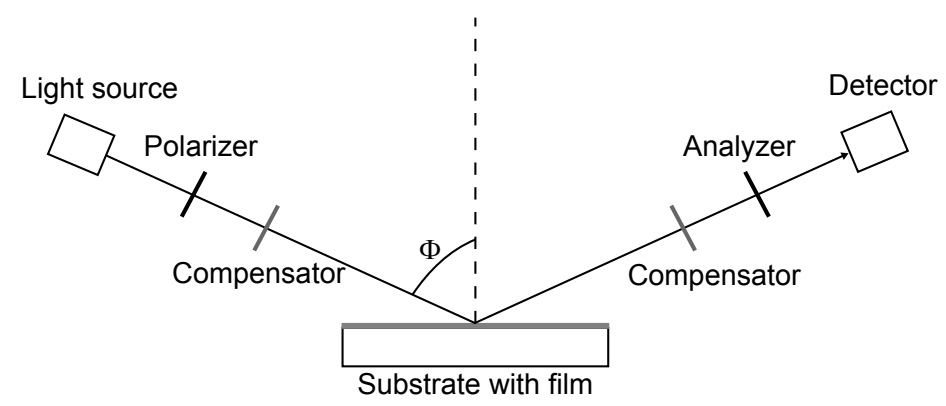

Figure 5.8: Schematic of an ellipsometry setup.

taken into account when interpreting AFM images. Some examples are if a feature with a radius smaller than tip radius is imaged resulting in an image of the tip rather than the feature. Tips can also have multiple peaks resulting in repetition of features.

Atomic force microscopy have been used for surface imaging and measurements of the in-plane grain size and surface roughness in Paper 1, 2 and 4.

\subsection{Spectroscopic ellipsometry}

Electromagnetic waves, such as light, incident on a surface interact with free and bound electrons in the material producing a response that is governed by the complex dielectric function $\epsilon(\omega)$ of the material, where $\omega$ is the angular frequency of the electromagnetic wave. Spectroscopic ellipsometry is used to determine the pseudo-dielectric function, $\langle\epsilon(\omega)\rangle$, which contains information of the film-substrate system and any interface effects. Through modeling of the film-substrate system it is then possible to find the optical properties and thickness of the film as well as the surface roughness and electrical properties $[178,179]$. Spectroscopic ellipsometry utilizes a wide band light source usually spanning a spectral region form near IR to UV light, although the exact spectral range varies between setups. Figure 5.8 shows a schematic of an ellipsometer. Light from the source is polarized linearly in a polarizer and passed through a compensator causing a phase shift between the components of the electromagnetic wave. It is then reflected in the sample where its polarization state changes one again, now to an elliptical polarization. After reflection the light is 
passed through another compensator and a fixed linear polarizer before reaching the detector. The measured quantity is called the ellipsometric ratio, $\rho$, and can be written as

$$
\rho=\tan (\Psi) e^{i \Delta}
$$

where $\tan (\Psi)$ is the amplitude ratio between the electric field components and $\Delta$ is the phase shift between the field components. The ellipsometric ratio can be used to find the pseudo-dielectric function of the film-substrate system. The complex dielectric function can usually not be used to directly calculate the optical constants of the film. Instead they are found using a mathematical model incorporating the known optical constants of the substrate and a dispersion relation modeling the optical response of the film. The calculated optical response of the model is then fitted to the measured data. Different dispersion relations model light-matter interactions with varying degrees of physical accuracy. In empirical dispersion relations only some of the parameters have a physical significance such as e.g. the refractive index and/or the film thickness. Classical dispersion relations are derived from classical electromagnetic theory and can take free and bound electrons in the material into account to model some optical and electrical properties of the film. Properties such as band gap and defect states can be modeled using quantum mechanical dispersion relations which take quantum mechanical effects into account in addition to classical effects. The choice of dispersion relation should be done taking both the degree of physical accuracy needed and convenience into account. In situ ellipsometry was performed to be able to measure the thickness dependence of the electrical properties of the Ag films in paper 3 and 4 in order to find the film thicknesses where the characteristic morphological transitions occur. 


\section{Plasma characterization}

There are a number of methods available to characterize plasma properties. From a film growth point of view the most interesting property is the energy and flux of different ionized and neutral species impinging on the film. This can be measured with a mass spectrometer equipped with an energy filter.

\subsection{Ion mass spectrometry}

Mass spectrometers designed for plasma analysis are usually differentially pumped as the particle transport in the spectrometer needs to be collision less. Species from the plasma are extracted into the spectrometer through a small $(<300 \mu \mathrm{m})$ orifice. Several electrodes are fitted just inside the orifice, the first is an electrode used to extract ions from the plasma and the second is an electrostatic lens used to focus the extracted ions into a beam. Spectrometers are usually also equipped with an ionizer using energetic electrons to ionize neutral particles. The ionizer is not used for ion mass spectrometry. The energy analyzer in the spectrometer used for this thesis is a Bessel box which consist of a cylinder with insulated end caps with small holes in the centers to let ions pass and piece blocking the direct path though the Bessel box. Voltages are applied to the cylinder and end caps to create an electric field that bends the path of ions traveling through the box. Ions with energies lower than the passing energy are retarded so that they cannot pass through the box while the trajectories of ions with energies higher than the pass energy are modified so that they cannot pass through the second end cap. The voltages of the cylinder, end caps and all electrodes after the energy filter are set against a centerline potential that can be swept in order to record the ion energy distribution function (IEDF). The 
ions are then passed through a quadruple mass filter before they are detected in a secondary electron multiplier detector [180]. Electrostatic lenses are fitted between all components to focus the ion beam for maximal transmission. The voltages on the front electrodes can be set to reject all ions making it to gate the spectrometer allowing for time-resolved measurements.

The transmission of ions through the spectrometer is complicated by the many parts in the system modifying the path travelled by ions. It is both energy and mass dependent making quantitative measurements difficult. The acceptance angle for species entering the spectrometer is highly dependent on the energy of the particles. The acceptance angle can be as large as $25^{\circ}$ for ion energies of $0.1 \mathrm{eV}$ and is below $1^{\circ}$ for ions with an energy of $100 \mathrm{eV}$ leading to a severe overestimation of the number of low energy species [181]. The electrostatic lenses also suffers from chromatic aberration, a change of focal length with ion energy, unless correct settings are used [181].

Although the spectrometers purports to measure the ion energy distribution functions for the measured species this is not exactly the case. The centerline potential of the spectrometer stops down the ion velocity component in the direction of the centerline of the spectrometer leaving any other velocity components intact. This results in the spectrometer actually measuring the ion velocity distribution function in the forward direction of the spectrometer in units of energy as the ion energy depends on the total ion velocity [182]. 


\section{Computational methods}

Many of the processes occurring during film growth are too fast and/or too localized to be possible to be observed experimentally. Instead computer simulations have to be used. For this thesis two types of simulations have been performed, gas transport simulations and growth simulations. In both cases stochastic Monte Carlo based simulation codes are used.

\subsection{Gas transport simulations}

The gas transport codes that have been used for this thesis, SIMTRA [139] and OMEGA [141], both work in a similar way. The simulations are performed on the same premises:

- The transported particles are assumed to be neutral.

- Collisions between particles are assumed to be binary and elastic.

- It is assumed that the transported particles do not interact with each other.

- The background gas is assumed to be in thermal equilibrium and to follow a Maxwellian energy distribution.

The simulations are performed on an atom by atom basis where atoms is sent into the simulated volume with initial energies and directions chosen at random from predefined starting energy and angular distribution functions. Using the initial conditions a cross section for collision between a transported atom and a gas atom is calculated, the cross section is then used to calculate the distance to a collision. The cross section is based on interaction potentials between the 
transported atom and Ar [139] or empirically measured collision parameters [141]. For each collision event the change in energy and direction of the transported atom is calculated. The new energy and direction is then used to calculate a new collision cross section and the processes is repeated until the particle reaches the bounding box of the simulation.

Since Monte Carlo simulations are stochastic simulations of large numbers of particles, of the order of $10^{6}-10^{7}$, are needed to achieve good statistics. The rather simple approach of the simulations still makes it possible to run the simulations on a normal PC in a reasonable time, some tens of minutes to a few hours depending on the number of simulated particles and the number of collisions.

\subsection{Film growth simulations}

Kinetic Monte Carlo (KMC) simulations of the initial stages of film growth was performed in paper 4. Just like the Monte Carlo simulations of gas transport the KMC simulations are stochastic. In KMC simulations there is a time step where an event out of an ensemble of events is randomly chosen to occur. For a film growth simulation this can be deposition of an atom or an atom diffusing one step on the surface. After each step the new configuration is evaluated according to a set of rules before a new step is initiated. The KMC code used in paper 4 is aimed at simulating three-dimensional island growth.

In the code deposition is random and takes place in well defined pulses. Deposited atoms are then allowed to diffuse randomly to nearest-neighbor positions on the square lattice at a rate determined by equation 2.1.2. If an adatom comes into contact with another adatom they irreversibly form an island (i.e. the critical nuclei size $i^{*}=1$ ). If an adatom comes into contact with an already existing island it is irreversibly incorporated into the island and moved to a position in the island that maintains a hemispherical island shape. This leads to a situation that resembles the three-dimensional island growth observed for e.g. $\mathrm{Ag}$ on $\mathrm{SiO}_{2}$. As islands grow they will come into contact and start coalescing. The time to complete a coalescence event is determined by equation 2.2.5 where the radius of the smaller island in the pair decides the coalescence time. The coalescence time is recalculated if any atoms are added to the coalescing islands before the coalescence event is finished. 
By continuously tracking the number of islands and the number of coalescing cluster as well as the nucleation, impingement and coalescence completion rates throughout the simulation it possible to see how different deposition parameters such as pulsing frequency and instantaneous deposition rate affect film growth. 
CHAPTER 7: COMPUTATIONAL METHODS 


\section{Summary of results}

\subsection{Intrinsic stresses in polycrystalline thin films}

The generation of compressive stresses in Mo films was investigated in paper 1 and 2. In paper 1 Mo films were deposited by HiPIMS at different peak pulse powers and two different pressures in order to control the energy and flux of the bombarding species. The depositions were performed without intentional substrate heating to minimize any changes to the film microstructure after deposition allowing for ex situ characterization of the films in their as deposited states. In order to gain an understanding on how the energies of the bombarding species changed with the discharge conditions ion mass spectrometry measurements and transport simulations using the TRIM [138] and SIMTRA [139] codes. The energy and flux of singly and doubly ionized Mo was found to be much larger for high peak pulse powers than for lower while the energy of depositing Mo atoms was about the same for all process conditions. Energetic Ar atoms backscattered from the target also contribute to the bombardment of the growing film.

The film stress, as measured by the crystallite group method, was low or slightly tensile for low peak powers and compressive for higher peak powers with the magnitude increasing with increasing peak power. The stress free lattice parameter was nearly constant and only slightly expanded compared to the stress free lattice parameter of bulk Mo for all film implying that the film stress mainly was biaxial for all samples. The film density was measured by $\mathrm{X}$-ray reflectivity and was found to the follow a similar pattern as the film stress. High peak target powers result in highly dense films while low peak target powers results in underdense films. The change in film density and stress with peak target power 
was accompanied by a an increase of the grain size making it difficult to deconvolute different stress generation mechanisms from each other. The mainly biaxial stress state of the films rules out lattice defects as the main cause of the compressive stress while the correlation between high compressive stresses and dense films imply that the stresses are generated by densification of the grain boundaries of the film.

The energies of the depositing species are large enough to create shallow collision cascades in the first few atomic layers of the growing film possibly generating self-interstitials in the crystal lattice. These interstitials are mobile at room temperature and should experience a driving force to diffuse towards the nearest underdense region of the film. For most of the film this is of course the surface but for interstitials generated near a grain boundary it might instead be the grain boundary. Energetic bombardment can also drive surface diffusion which also can lead to grain boundary densification by atom insertion.

In paper 2 we designed an experiment to unequivocally determine whether the biaxial compressive stresses observed in paper 1 have their origin in the grain boundaries of the film. The grain size was varied while keeping all other process parameters constant. $\mathrm{Mo}_{1-x} \mathrm{Si}_{x}$ films deposited on a-Si and thin Mo films were used as seed layers. Mo and $\mathrm{Mo}_{1-x} \mathrm{Si}_{x}$ deposited on a-Si crystallizes in the bcc-structure with lattice parameters close to that of Mo and grain sizes that vary over two orders of magnitude depending on the $\mathrm{Si}$ content in the films [183, 184]. Mo films were then deposited epitaxially on the seed layers under the deposition parameters similar to those of paper 1 known to lead to compressive stresses in films with a small grain size.

By performing in situ measurements of the film stress during deposition we found that the films reach a steady state compressive stress that is linearly dependent on the inverse grain size, which in turn is proportional to the grain boundary length per unit area. The epitaxial growth and identical deposition conditions in these experiments make it possible to rule out suggested mechanisms for stress generation such as Laplace pressure induced compressive stress or atom insertion at compressive ledges as the main mechanism of compressive stress generation. Instead it is shown that the compressive film stresses are generated in the grain boundaries. 


\subsection{Nucleation and growth of polycrystalline thin films}

In paper 3 we investigate the effects of a pulsed deposition flux and energetic bombardment on the early growth stages of Ag film growing as three dimensional islands on $\mathrm{SiO}_{2}$ by monitoring the thickness at which a continuous film is formed by in situ stress measurements and in situ spectroscopic ellipsometry. It was found that the thickness when the film becomes continuous decreases from $\sim 21 \mathrm{~nm}$ to $\sim 15 \mathrm{~nm}$ for a pulsing frequency range of $50-1000 \mathrm{~Hz}$ with identical power pulses while ion mass spectrometry and transport simulations showed that energetics of the deposition flux did not change when the pulsing frequency was varied. The effect of deposition rate on the coalescence completion thickness was investigated using a continuous magnetron sputtering process in the same interval of deposition rates as the pulsed process. No significant changes in the thickness at which a continuous film is formed was found in this deposition rate interval. The coalescence completion thickness was also found to decrease from $\sim 21 \mathrm{~nm}$ to $\sim 15 \mathrm{~nm}$ when the pulse power was increased from $20 \mathrm{~mJ}$ to $1200 \mathrm{~mJ}$ resulting in higher instantaneous deposition rates and larger fluxes of high energy $\mathrm{Ag}^{+}$ions.

The thickness where the film becomes continuous is for materials growing as three dimensional islands to a large part set by the island density. If the island density is high the film will become continuous at a lower thickness than if the island density is low. The island density is in turn determined by the nucleation and coalescence processes. Nucleation leads to island creation and completed coalescence events leads to island loss. We estimated the adatom life times for different surface coverages and the time needed to complete coalescence events for a range of island sizes and found that both are in the range where the pulsed deposition flux can interfere with nucleation and coalescence processes leading to higher nucleation densities and/or less completed coalescence events. Both of which can lead to a higher island density and a lower thickness at which the film becomes continuous a result that is in line with previous literature [185, 186]. The decrease in the thickness where a continuous film is formed with increasing pulse power was attributed to the higher instantaneous deposition rate in combination with energetic depositing ions leading to an increase in the nucleation density.

In paper 4 we performed an in depth investigation of the early growth stages of 
Ag growing as three dimensional islands on $\mathrm{SiO}_{2}$ by measuring the thickness at which a continuous film is formed as well as the thickness were the percolation transition takes place by in situ spectroscopic ellipsometry. Imaging by atomic force microscopy was used to corroborate the ellipsometry results with the film microstructure while kinetic Monte Carlo simulations were used to study the effects of the nucleation and coalescence processes on the film structure evolution in greater detail. Both the thickness where a continuous film is formed and the thickness at percolation was found to have the same power law scaling with an exponent of -0.18 with increasing frequency up to $400 \mathrm{~Hz}$ where a steady state thickness was reached. The ellipsometry results were found to be in good agreement with the AFM imaging. From the ellipsometry data it is possible to follow the surface areal coverage as a function of the amount of deposited material for thicknesses below the percolation transition. The areal coverage was found to be larger for a film deposited with a pulsing frequency of $1000 \mathrm{~Hz}$ than with a pulsing frequency of $50 \mathrm{~Hz}$. The areal coverage was then used to estimate the island density for the two pulsing frequencies assuming that the surface is covered by an homogeneous array of identical hemispherical islands. Good agreement between the measured areal coverage and the model was found for island constant island densities of $1 \times 10^{11}$ islands $/ \mathrm{cm}^{2}$ for 1000 $\mathrm{Hz}$ and $4 \times 10^{10}$ islands $/ \mathrm{cm}^{2}$ for $50 \mathrm{~Hz}$ for nominal thicknesses between $\sim 5 \mathrm{ML}$ and $\sim 20 \mathrm{ML}$.

Kinetic Monte Carlo simulations showed that the nucleation rate is not affected by the changing pulse frequencies in the investigated frequency interval. A pronounced decrease of the island density with an increasing nominal film thickness was observed for low pulsing frequencies while the island density was constant for high pulse frequencies. It was found that the decrease in the island density was caused by the completion of island coalescence between the pulses for low frequencies while island growth by addition of atoms at higher frequencies impedes coalescence.

\subsection{Energetic bombarding species in HiPIMS discharges}

In paper 5 we performed an investigation of the generation of high energy $\mathrm{Ar}^{+}$ ions in HiPIMS discharges by ion mass spectroscopy. The width of the high energy tail of the ion distribution functions for $\mathrm{Ar}^{+}$ions was found to increase 
with target mass during sputtering from $\mathrm{Cr}$, Mo and $\mathrm{W}$ targets. The results are in agreement with transport simulations performed on Ar atoms backscattered from the target during sputtering as well as previous literature on dc magnetron sputtering [187-190]. We suggest that the high plasma density in HiPIMS discharges might lead an increase of the degree of ionization of these high energy ions which in combination with a substrate bias might have detrimental effects on growing films. The results can also been used to explain part of the high energy tail observed for light gas ion such as $\mathrm{O}^{+}$and $\mathrm{N}^{+}$observed during reactive sputtering [163, 191-193]. 
CHAPTER 8: SUMMARY OF RESUltS 


\section{Contributions to the field}

The main focus of the research performed in this thesis has been to gain a better understanding on how the initial stages of thin film growth are affected by a pulsed deposition flux and to get a better understanding of the mechanisms resulting in compressive stresses in materials with a low atomic mobility.

In the investigations of stress generation in films deposited under low mobility conditions I have shown that:

- Compressive stresses can be generated by grain boundary densification under deposition conditions that allow for adatom diffusion while the temperature is kept low enough for bulk and grain boundary diffusion to be very small. This provides direct experimental evidence for the adatom insertion model of compressive stress generation.

- Large biaxial compressive stresses can be generated during low temperature film growth with an energetic deposition flux without any appreciable triaxial stress component.

These findings should contribute to determining what mechanisms are dominating the generation of compressive films stresses and for what deposition conditions different stress generation mechanisms are active. Of more practical concern is that I show that the smooth dense films often observed for deposition processes such as HiPIMS and cathodic arc evaporation might be in a highly compressive stress state if the grain size is small. I also show that it is possible to tune intrinsic stresses in non-recrystallizing polycrystalline films by tuning the grain size and the degree of grain boundary densification. 
For film growing in a three dimensional fashion under high mobility conditions I have demonstrated that:

- The pulsed deposition flux in HiPIMS can be used to manipulate time dependent processes during the initial stages of film growth.

- The film thickness at percolation and when a continuous film is formed is set by interaction between the pulsed deposition flux and coalescing islands with island coalescence being disrupted for high pulsing frequencies.

- Increases of the instantaneous deposition rate and/or the energy of the depositing species leads to a lower thickness for the formation of a continuous film due to higher nucleation densities.

A pulsed deposition flux thereby provide a number of additional "knobs" to turn during the deposition process to achieve desired film morphologies allowing for deposition of films with tailor made microstructures and properties.

I have also demonstrated that a considerable flux of energetic ionized $\mathrm{Ar}^{+}$ions originating as Ar atoms backscattered from the target is present during sputtering of high atomic mass targets. The high energies of these ions can result in damage in and implantation of Ar into the growing, especially if a substrate bias is used to further accelerate the ions. This also has implications for reactive sputter deposition where backscattering might explain part of the high energy tail observed for $\mathrm{N}^{+}$or $\mathrm{O}^{+}$ions. 


\section{Future outlook}

Future work taking this thesis as a starting point can take many different directions. I would like to take the opportunity to point out some specific research directions I find particularly interesting.

Possible research directions for stress generation studies are:

- In paper 1 we suggested several mechanisms that could lead to incorporation of atoms into grain boundaries. Molecular dynamics simulations of deposition of energetic species should be able show what routes that actually lead to atom incorporation into the grain boundaries.

- Using high-resolution TEM techniques it is possible to image strain fields in crystals. This could be used to image the strain fields in the grains of e.g. a Mo film and to identify if certain types of grain boundaries are more susceptible to atom incorporation than others.

- In the TEM investigations of the Mo films in paper 2 we observed image contrast indicative of high defect densities in the films although the small expansion of the stress free lattice parameter from the $\sin ^{2} \psi$-measurements indicated low levels of defect incorporation. Investigations of the defect density, defect type and generation mechanisms would be interesting.

- We have shown that it is possible to incorporate atoms into the grain boundaries of Mo films. Experiments on polycrystalline films on other metals and metal nitrides or oxides would be able to show if this is a generally applicable mechanism and, as different material have different thresholds for defect creation, how defect incorporation affects the film stress. 
Possible research directions for nucleation studies are:

- Surface plasmons can be excited on Ag nano particles. Control of the size and separation of the particles is needed to be able to tune the plasmon resonance energy.

- We have demonstrated how the time domain of the deposition flux interacts with the coalescence of three dimensional islands on a surface. The same principles should be possible to apply for two dimensional islands on a surface.

- Certain crystal surfaces have preferential directions for surface diffusion and could be used together with a pulsed deposition to fabricate nanostructure with controlled sizes and e.g. anisotropic optical properties. 


\section{References}

[1] M. Ohring. Materials Science of Thin Films. Academic Press, San Diego, CA, 2nd edition (2002).

[2] P. Mayrhofer, C. Mitterer, L. Hultman, and H. Clemens. Prog. Mater. Sci. 51 (2006) 1032.

[3] M. Meyers, A. Mishra, and D. Benson. Prog. Mater. Sci. 51 (2006) 427.

[4] T. Zhu and J. Li. Prog. Mater. Sci. 55 (2010) 710.

[5] K. Kleovoulou and P. C. Kelires. Phys. Rev. B 88 (2013) 245202.

[6] S. Veprek. J. Vac. Sci. Technol. A 31 (2013) 050822.

[7] K. A. Willets and R. P. Van Duyne. Annu. Rev. Phys. Chem. 58 (2007) 267.

[8] S. Hayashi and T. Okamoto. J. Phys. D. Appl. Phys. 45 (2012) 433001.

[9] M. S. Tame, K. R. McEnery, S. K. Özdemir, J. Lee, S. A. Maier, and M. S. Kim. Nat. Phys. 9 (2013) 329.

[10] A. P. Alivisatos. Science 271 (1996) 933.

[11] P. Moriarity. Reports Prog. Phys. 64 (2001) 297.

[12] D. G. Cahill, P. V. Braun, G. Chen, D. R. Clarke, S. Fan, K. E. Goodson, P. Keblinski, W. P. King, G. D. Mahan, A. Majumdar, H. J. Maris, S. R. Phillpot, E. Pop, and L. Shi. Appl. Phys. Rev. 1 (2014) 011305.

[13] H. Windischmann. J. Appl. Phys. 62 (1987) 1800.

[14] J. A. Thornton. Thin Solid Films 171 (1989) 5.

[15] R. Koch. J. Phys. Condens. Matter 6 (1994) 9519. 
[16] J. A. Floro, E. Chason, R. C. Cammarata, and D. J. Srolovitz. MRS Bull. 27 (2002) 19.

[17] G. C. A. M. Janssen. Thin Solid Films 515 (2007) 6654.

[18] R. Koch. Surf. Coatings Technol. 204 (2010) 1973.

[19] D. Sander. Reports Prog. Phys. 62 (1999) 809.

[20] D. Sander. J. Phys. Condens. Matter 16 (2004) R603.

[21] D. Sander, Z. Tian, and J. Kirschner. J. Physics. Condens. matter 21 (2009) 134015.

[22] V. Consonni, N. Baier, O. Robach, C. Cayron, F. Donatini, and G. Feuillet. Phys. Rev. B 89 (2014) 035310.

[23] F. Spaepen. Acta Mater. 48 (2000) 31.

[24] E. Chason, B. Sheldon, L. Freund, J. Floro, and S. Hearne. Phys. Rev. Lett. 88 (2002) 156103.

[25] C. Friesen, S. C. Seel, and C. V. Thompson. J. Appl. Phys. 95 (2004) 1011.

[26] R. Koch, D. Hu, and A. Das. Phys. Rev. Lett. 94 (2005) 146101.

[27] W. M. Haynes, ed. CRC Handbook of Chemistry and Physics. CRC Press/Taylor and Francis, Boca Raton, FL., 94th edition (2014).

[28] H. Watanabe, N. Yamada, and M. Okaji. Int. J. Thermophys. 25 (2004) 221.

[29] T. Michely and J. Krug. Islands, Mounds and Atoms: Patterns and Processes in Crystal Growth far from Equilibrium. Springer-Verlag, Berlin Heidelberg (2003).

[30] H. Brune. Surf. Sci. Rep. 31 (1998) 125.

[31] G. Ehrlich and F. G. Hudda. J. Chem. Phys. 44 (1966) 1039.

[32] R. L. Schwoebel and E. J. Shipsey. J. Appl. Phys. 37 (1966) 3682.

[33] R. Ditchfield and E. G. Seebauer. Phys. Rev. Lett. 82 (1999) 1185.

[34] R. Ditchfield and E. G. Seebauer. Phys. Rev. B 63 (2001) 125317.

[35] I. Petrov, P. B. Barna, L. Hultman, and J. E. Greene. J. Vac. Sci. Technol. A 21 (2003) S117. 
[36] D. Adamovic, E. P. Münger, V. Chirita, L. Hultman, and J. E. Greene. Appl. Phys. Lett. 86 (2005) 211915.

[37] D. Adamovic, V. Chirita, E. P. Münger, L. Hultman, and J. E. Greene. Thin Solid Films 515 (2006) 2235.

[38] D. Adamović, V. Chirita, E. P. Münger, L. Hultman, and J. E. Greene. Phys. Rev. B 76 (2007) 115418.

[39] C. H. Wu. J. Mech. Phys. Solids 44 (1996) 2059.

[40] Z. Zhang and M. G. Lagally. Science (80-. ). 276 (1997) 377.

[41] P. Jensen and B. Niemeyer. Surf. Sci. 384 (1997) L823.

[42] H.-A. Durand, K. Sekine, K. Etoh, K. Ito, and I. Kataoka. Surf. Coatings Technol. 125 (2000) 111.

[43] H.-A. Durand, K. Sekine, K. Etoh, K. Ito, and I. Kataoka. Thin Solid Films 336 (1998) 42.

[44] M. Kalff, M. Breeman, M. Morgenstern, T. Michely, and G. Comsa. Appl. Phys. Lett. 70 (1997) 182.

[45] W. Ostwald. Zeitschrift für Phys. Chemie 37 (1901) 385.

[46] P. W. Voorhees. J. Stat. Phys. 38 (1985) 231.

[47] C. Ratsch and J. A. Venables. J. Vac. Sci. Technol. A 21 (2003) S96.

[48] C. V. Thompson. Annu. Rev. Mater. Sci. 30 (2000) 159.

[49] K. S. Sree Harsha. Principles of Physical Vapor Deposition of Thin Films. Elsevier Ltd., Oxford, 1st edition (2006).

[50] C. V. Thompson and R. Carel. Mater. Sci. Eng. B 32 (1995) 211.

[51] S. Iijima and P. M. Ajayan. J. Appl. Phys. 70 (1991) 5138.

[52] F. A. Nichols and W. W. Mullins. J. Appl. Phys. 36 (1965) 1826.

[53] F. A. Nichols. J. Appl. Phys. 37 (1966) 2805.

[54] G. Jeffers, M. A. Dubson, and P. M. Duxbury. J. Appl. Phys. 75 (1994) 5016.

[55] G. Koster, G. J. H. M. Rijnders, D. H. A. Blank, and H. Rogalla. Appl. Phys. Lett. 74 (1999) 3729. 
[56] B. A. Movchan and A. V. Demchishin. Phys. Met. Metallogr. 28 (1969) 653.

[57] J. A. Thornton. J. Vac. Sci. Technol. 11 (1974) 666.

[58] J. A. Thornton. J. Vac. Sci. Technol. A 4 (1986) 3059.

[59] A. Anders. Thin Solid Films 518 (2010) 4087.

[60] J. Alami, K. Sarakinos, F. Uslu, and M. Wuttig. J. Phys. D. Appl. Phys. 42 (2009) 7.

[61] M. F. Doerner and W. D. Nix. Crit. Rev. Solid State Mater. Sci. 14 (1988) 225.

[62] U. Welzel, J. Ligot, P. Lamparter, A. C. Vermeulen, and E. J. Mittemeijer. J. Appl. Crystallogr. 38 (2005) 1.

[63] G. G. Stoney. Proc. R. Soc. London. Ser. A 82 (1909) 172.

[64] R. C. Cammarata. Prog. Surf. Sci. 46 (1994) 1.

[65] H. Ibach. Surf. Sci. Rep. 29 (1997) 195.

[66] R. Abermann, R. Kramer, and J. Maser. Thin Solid Films 52 (1978) 215.

[67] E. Klokholm and B. S. Berry. J. Electrochem. Soc. 115 (1968) 823.

[68] E. Klokholm. J. Vac. Sci. Technol. 6 (1969) 138.

[69] F. M. D'Heurle. Metall. Mater. Trans. B 1 (1970) 725.

[70] D. W. Hoffman and J. A. Thornton. Thin Solid Films 45 (1977) 387.

[71] R. Abermann and R. Koch. Thin Solid Films 142 (1986) 65.

[72] A. G. Blachman. Metall. Trans. 2 (1971) 699.

[73] J. Vermaak, C. Mays, and D. Kuhlmann-Wilsdorf. Surf. Sci. 12 (1968) 128.

[74] C. W. Mays, J. S. Vermaak, and D. Kuhlmann-Wilsdorf. Surf. Sci. 12 (1968) 134.

[75] R. C. Cammarata, T. M. Trimble, and D. J. Srolovitz. J. Mater. Res. 15 (2000) 2468.

[76] C. Friesen and C. V. Thompson. Phys. Rev. Lett. 89 (2002) 126103.

[77] C.-W. Pao, D. Srolovitz, and C. V. Thompson. Phys. Rev. B 74 (2006) 155437. 
[78] D. Sander, S. Ouazi, V. Stepanyuk, D. Bazhanov, and J. Kirschner. Surf. Sci. 512 (2002) 281.

[79] C. Friesen and C. V. Thompson. Phys. Rev. Lett. 93 (2004) 056104.

[80] F. A. Doljack and R. W. Hoffman. Thin Solid Films 12 (1972) 71.

[81] R. Hoffman. Thin Solid Films 34 (1976) 185.

[82] W. D. Nix and B. M. Clemens. J. Mater. Res. 14 (1999) 3467.

[83] L. B. Freund and E. Chason. J. Appl. Phys. 89 (2001) 4866.

[84] S. C. Seel and C. V. Thompson. J. Appl. Phys. 93 (2003) 9038.

[85] R. C. Cammarata, K. Sieradzki, and F. Spaepen. J. Appl. Phys. 87 (2000) 1227.

[86] R. Abermann and R. Koch. Thin Solid Films 29 (1985) 71.

[87] M. A. Phillips, V. Ramaswamy, B. M. Clemens, and W. D. Nix. J. Mater. Res. 15 (2000) 2540.

[88] M. Pletea, W. Brückner, H. Wendrock, and R. Kaltofen. J. Appl. Phys. 97 (2005) 054908.

[89] M. Pletea, R. Koch, H. Wendrock, R. Kaltofen, and O. G. Schmidt. J. Phys. Condens. Matter 225008 (2009) 8.

[90] G. Abadias, A. Fillon, J. J. Colin, A. Michel, and C. Jaouen. Vacuum 100 (2014) 36.

[91] S. J. Hearne and J. A. Floro. J. Appl. Phys. 97 (2005) 014901.

[92] J. W. Shin and E. Chason. Phys. Rev. Lett. 103 (2009) 056102.

[93] A. L. Shull and F. Spaepen. J. Appl. Phys. 80 (1996) 6243.

[94] A. L. Del Vecchio and F. Spaepen. J. Appl. Phys. 101 (2007) 063518.

[95] A. Bhandari, B. W. Sheldon, and S. J. Hearne. J. Appl. Phys. 101 (2007) 033528.

[96] S. C. Seel, C. V. Thompson, S. J. Hearne, and J. A. Floro. J. Appl. Phys. 88 (2000) 7079. 
[97] R. Abermann, R. Koch, and R. Kramer. Thin Solid Films 58 (1979) 365.

[98] R. Abermann. Vacuum 41 (1990) 1279.

[99] P. Chaudhari. J. Vac. Sci. Technol. 9 (1972) 520.

[100] R. Koch, D. Hu, and A. Das. Phys. Rev. Lett. 95 (2005) 229602.

[101] M. Rost. Phys. Rev. Lett. 99 (2007) 1.

[102] E. Chason, J. W. Shin, S. J. Hearne, and L. B. Freund. J. Appl. Phys. 111 (2012) 083520.

[103] E. Chason. Thin Solid Films 526 (2012) 1.

[104] C.-W. Pao, S. M. Foiles, E. B. Webb, D. J. Srolovitz, and J. A. Floro. Phys. Rev. Lett. 99 (2007) 036102.

[105] C.-W. Pao, S. M. Foiles, E. B. Webb, D. J. Srolovitz, and J. A. Floro. Phys. Rev. B 79 (2009) 224113.

[106] Y. Yang, H. Huang, S. K. Xiang, and E. Chason. Appl. Phys. Lett. 96 (2010) 211903.

[107] B. W. Sheldon, A. Ditkowski, R. Beresford, E. Chason, and J. Rankin. J. Appl. Phys. 94 (2003) 948.

[108] B. W. Sheldon, A. Rajamani, A. Bhandari, E. Chason, S. K. Hong, and R. Beresford. J. Appl. Phys. 98 (2005) 043509.

[109] D. Flötotto, Z. M. Wang, L. P. H. Jeurgens, E. Bischoff, and E. J. Mittemeijer. J. Appl. Phys. 112 (2012) 043503.

[110] J. Leib, R. Mönig, and C. V. Thompson. Phys. Rev. Lett. 102 (2009) 256101.

[111] J. Leib and C. V. Thompson. Phys. Rev. B 82 (2010) 121402(R).

[112] H. Z. Yu, J. S. Leib, S. T. Boles, and C. V. Thompson. J. Appl. Phys. 115 (2014) 043521.

[113] A. González-González, G. M. Alonzo-Medina, A. I. Oliva, C. Polop, J. L. Sacedón, and E. Vasco. Phys. Rev. B 84 (2011) 155450.

[114] A. González-González, C. Polop, and E. Vasco. Phys. Rev. Lett. 110 (2013) 056101. 
[115] G. Thurner and R. Abermann. Thin Solid Films 192 (1990) 277.

[116] J. A. Thornton and D. W. Hoffman. J. Vac. Sci. Technol. 14 (1977) 164.

[117] D. W. Hoffman and J. A. Thornton. Thin Solid Films 40 (1977) 355.

[118] D. W. Hoffman and J. A. Thornton. J. Vac. Sci. Technol. 20 (1982) 355.

[119] G. C. A. M. Janssen, A. J. Dammers, V. G. M. Sivel, and W. R. Wang. Appl. Phys. Lett. 83 (2003) 3287.

[120] A. Misra, H. Kung, T. E. Mitchell, and M. Nastasi. J. Mater. Res. 15 (2000) 756.

[121] S. Y. Grachev, F. D. Tichelaar, and G. C. A. M. Janssen. J. Appl. Phys. 97 (2005) 073508.

[122] B. W. Sheldon, K. H. A. Lau, and A. Rajamani. J. Appl. Phys. 90 (2001) 5097.

[123] F. M. D'Heurle and J. M. E. Harper. Thin Solid Films 171 (1989) 81.

[124] G. C. A. M. Janssen and J.-D. Kamminga. Appl. Phys. Lett. 85 (2004) 3086.

[125] J.-D. Kamminga, T. H. de Keijser, R. Delhez, and E. J. Mittemeijer. Thin Solid Films 317 (1998) 169.

[126] J.-D. Kamminga, T. H. de Keijser, R. Delhez, and E. J. Mittemeijer. J. Appl. Phys. 88 (2000) 6332.

[127] G. Abadias. J. Appl. Phys. 95 (2004) 2414.

[128] R. Daniel, K. J. Martinschitz, J. Keckes, and C. Mitterer. Acta Mater. 58 (2010) 2621.

[129] R. Daniel, D. Holec, M. Bartosik, J. Keckes, and C. Mitterer. Acta Mater. 59 (2011) 6631.

[130] L. E. Koutsokeras and G. Abadias. J. Appl. Phys. 111 (2012) 093509.

[131] P. B. Barna and M. Adamik. Thin Solid Films 317 (1998) 27.

[132] H. Martinz and R. Abermann. Thin Solid Films 89 (1982) 133.

[133] R. Abermann and H. Martinz. Thin Solid Films 111 (1984) 303. 
[134] R. Abermann. Thin Solid Films 186 (1989) 233.

[135] S. M. Rossnagel. In J. L. Vossen and W. Kern, eds., Thin Film Process. II, chapter II-1. Academic Press, inc., San Diego, CA, 1 st. edition (1991), pp. 11-79.

[136] J. T. Gudmundsson, J. Alami, and U. Helmersson. Appl. Phys. Lett. 78 (2001) 3427.

[137] V. Stranak, S. Drache, M. Cada, Z. Hubicka, M. Tichy, and R. Hippler. Contrib. to Plasma Phys. 51 (2011) 237.

[138] J. F. Ziegler, J. P. Biersack, and U. Littmark. The Stopping and Range of Ions in Solids. Pergamon, New York (1985).

[139] K. Van Aeken, S. Mahieu, and D. Depla. J. Phys. D. Appl. Phys. 41 (2008) 205307.

[140] M. Thompson. Phys. Rep. 69 (1981) 335.

[141] D. Lundin, C. Vitelaru, L. D. Poucques, N. Brenning, and T. Minea. J. Phys. D. Appl. Phys. 46 (2013) 175201.

[142] B. Window and N. Savvides. J. Vac. Sci. Technol. A 4 (1986) 453.

[143] B. Window and N. Savvides. J. Vac. Sci. Technol. A 4 (1986) 196.

[144] J. Alami, P. O. A. Persson, D. Music, J. T. Gudmundsson, J. Böhlmark, and U. Helmersson. J. Vac. Sci. Technol. A 23 (2005) 278.

[145] G. Greczynski, J. Jensen, and L. Hultman. Thin Solid Films 519 (2011) 6354.

[146] U. Helmersson, M. Lattemann, J. Böhlmark, A. P. Ehiasarian, and J. T. Gudmundsson. Thin Solid Films 513 (2006) 1.

[147] K. Sarakinos, J. Alami, and S. Konstantinidis. Surf. Coatings Technol. 204 (2010) 1661.

[148] D. Lundin and K. Sarakinos. J. Mater. Res. 27 (2012) 780.

[149] J. T. Gudmundsson, N. Brenning, D. Lundin, and U. Helmersson. J. Vac. Sci. Technol. A 30 (2012) 030801.

[150] J. Böhlmark, J. Gudmundsson, J. Alami, M. Latteman, and U. Helmersson. IEEE Trans. Plasma Sci. 33 (2005) 346. 
REFERENCES

[151] J. T. Gudmundsson, P. Sigurjonsson, P. Larsson, D. Lundin, and U. Helmersson. J. Appl. Phys. 105 (2009) 123302.

[152] J. Böhlmark, J. Alami, C. Christou, A. P. Ehiasarian, and U. Helmersson. J. Vac. Sci. Technol. A 23 (2005) 18.

[153] J. Andersson, A. P. Ehiasarian, and A. Anders. Appl. Phys. Lett. 93 (2008) 071504.

[154] F. Mitschker, M. Prenzel, J. Benedikt, and A. von Keudell. J. Phys. D. Appl. Phys. 45 (2012) 402001.

[155] F. Mitschker, M. Prenzel, J. Benedikt, C. Maszl, and A. von Keudell. J. Phys. D. Appl. Phys. 46 (2013) 155204.

[156] F. Mitschker, M. Prenzel, J. Benedikt, C. Maszl, and A. von Keudell. J. Phys. D. Appl. Phys. 46 (2013) 495201.

[157] N. Brenning, C. Huo, D. Lundin, M. A. Raadu, C. Vitelaru, G. D. Stancu, T. Minea, and U. Helmersson. Plasma Sources Sci. Technol. 21 (2012) 025005.

[158] G. Greczynski, J. Lu, M. Johansson, J. Jensen, I. Petrov, J. Greene, and L. Hultman. Surf. Coatings Technol. 206 (2012) 4202.

[159] M. Samuelsson, D. Lundin, J. Jensen, M. A. Raadu, J. T. Gudmundsson, and U. Helmersson. Surf. Coatings Technol. 205 (2010) 591.

[160] M. Lattemann, U. Helmersson, and J. E. Greene. Thin Solid Films 518 (2010) 5978.

[161] J. Alami, P. Eklund, J. M. Andersson, M. Lattemann, E. Wallin, J. Böhlmark, P. Persson, and U. Helmersson. Thin Solid Films 515 (2007) 3434.

[162] J. Alami, K. Sarakinos, F. Uslu, C. Klever, J. Dukwen, and M. Wuttig. J. Phys. D. Appl. Phys. 42 (2009) 115204.

[163] M. Aiempanakit, U. Helmersson, A. Aijaz, P. Larsson, R. Magnusson, J. Jensen, and T. Kubart. Surf. Coatings Technol. 205 (2011) 4828.

[164] E. Wallin, T. I. Selinder, M. Elfwing, and U. Helmersson. EPL (Europhysics Lett. 82 (2008) 36002. 
[165] T. Selinder, E. Coronel, E. Wallin, and U. Helmersson. Int. J. Refract. Met. Hard Mater. 27 (2009) 507.

[166] M. Birkholz. Thin Film Analysis by X-ray Scattering. Wiley-VCH Verlag $\mathrm{GmbH} \& \mathrm{Co} . \mathrm{KGaA}$, Weinheim (2006).

[167] A. Debelle, G. Abadias, A. Michel, and C. Jaouen. Appl. Phys. Lett. 84 (2004) 5034 .

[168] A. Debelle, G. Abadias, A. Michel, C. Jaouen, and V. Pelosin. J. Vac. Sci. Technol. A 25 (2007) 1438.

[169] B. M. Clemens and J. A. Bain. MRS Bull. (1992) 46.

[170] V. Hauk, W. K. Krug, R. W. M. Oudelhoven, and L. Pintschovius. Zeitschrift für Met. 79 (1988) 159.

[171] G. C. A. M. Janssen, M. Abdalla, F. Vankeulen, B. Pujada, and B. Vanvenrooy. Thin Solid Films 517 (2009) 1858.

[172] L. B. Freund, J. A. Floro, and E. Chason. Appl. Phys. Lett. 74 (1999) 1987.

[173] R. Koch, H. Leonhard, G. Thurner, and R. Abermann. Rev. Sci. Instrum. 61 (1990) 3859.

[174] P. A. Flinn, D. S. Gardner, and W. D. Nix. IEEE Trans. Electron Devices 34 (1987) 689.

[175] G. J. Leusink, T. G. M. Oosterlaken, G. C. A. M. Janssen, and S. Radelaar. Rev. Sci. Instrum. 63 (1992) 3143.

[176] E. Chason and B. W. Sheldon. Surf. Eng. 19 (2003) 387.

[177] D. B. Williams and C. B. Carter. Transmission Electron Microscopy. Springer, New York, 2nd edition (2009).

[178] I. P. Herman. Optical Diagnostics for Thin Film Processing. Academic Press, Inc., San Diego, CA (1996).

[179] H. Fujiwara. Spectroscopic Ellipsometry. John Wiley \& Sons, Ltd, Chichester, UK (2007).

[180] J. Benedikt, A. Hecimovic, D. Ellerweg, and A. von Keudell. J. Phys. D. Appl. Phys. 45 (2012) 403001. 
[181] E. A. G. Hamers, W. G. J. H. M. van Sark, J. Bezemer, W. J. Goedheer, and W. F. van der Weg. Int. J. Mass Spectrom. Ion Process. 173 (1998) 91.

[182] K. Ellmer, R. Wendt, and K. Wiesemann. Int. J. Mass Spectrom. 223-224 (2003) 679.

[183] A. Fillon, G. Abadias, A. Michel, C. Jaouen, and P. Villechaise. Phys. Rev. Lett. 104 (2010) 096101.

[184] A. Fillon, C. Jaouen, A. Michel, G. Abadias, C. Tromas, L. Belliard, B. Perrin, and P. Djemia. Phys. Rev. B 88 (2013) 174104.

[185] J. M. Warrender and M. J. Aziz. Appl. Phys. A 79 (2004) 713.

[186] J. M. Warrender and M. J. Aziz. Phys. Rev. B 76 (2007) 045414.

[187] M. Mišina, L. R. Shaginyan, M. Maček, and P. Panjan. Surf. Coatings Technol. 142-144 (2001) 348.

[188] H. Matsui, H. Toyoda, and H. Sugai. J. Vac. Sci. Technol. A 23 (2005) 671.

[189] Y. Takagi, Y. Sakashita, H. Toyoda, and H. Sugai. Vacuum 80 (2006) 581.

[190] T. Welzel, S. Naumov, and K. Ellmer. J. Appl. Phys. 109 (2011) 073303.

[191] M. Aiempanakit, A. Aijaz, D. Lundin, U. Helmersson, and T. Kubart. J. Appl. Phys. 113 (2013) 133302.

[192] G. Greczynski and L. Hultman. Vacuum 84 (2010) 1159.

[193] G. Greczynski, J. Lu, J. Jensen, S. Bolz, W. Kölker, C. Schiffers, O. Lemmer, J. Greene, and L. Hultman. Surf. Coatings Technol. . 
REFERENCES 


\section{Papers}

The articles associated with this thesis have been removed for copyright reasons. For more details about these see:

http://urn.kb.se/resolve?urn=urn:nbn:se:liu:diva-105791 